\author{
UNIVERSIDADE DE SÃO PAULO \\ ESCOLA DE ENFERMAGEM DE RIBEIRÃO PRETO
}

WANDERLEI ABADIO DE OLIVEIRA

Relações entre bullying na adolescência e interações familiares: do singular ao plural 


\title{
Relações entre bullying na adolescência e interações familiares: do singular ao plural
}

\begin{abstract}
Tese apresentada para obtenção do título de Doutor em Ciências, no âmbito do Convênio Acadêmico Internacional para Co-orientação de tese de doutorado celebrado pela Escola de Enfermagem de Ribeirão Preto da Universidade de São Paulo e pela Università Cattolica del Sacro Cuore (Milão/Itália). Programa de PósGraduação Enfermagem em Saúde Pública.
\end{abstract}

Área de concentração: Assistência à Criança e ao Adolescente

Orientadoras:

Profa. Dra. Marta Angélica Iossi Silva

Profa. Dra. Simona Carla Silvia Caravita 
Autorizo a reprodução e divulgação total ou parcial deste trabalho, por qualquer meio convencional ou eletrônico, para fins de estudo e pesquisa, desde que citada a fonte.

Oliveira, Wanderlei Abadio de

Relações entre bullying na adolescência e interações familiares: do singular ao plural. Ribeirão Preto, 2017.

159 p. : il. ; $30 \mathrm{~cm}$

Tese de Doutorado, apresentada à Escola de Enfermagem de Ribeirão Preto/USP. Área de concentração: Enfermagem Saúde Pública.

Orientador: Marta Angélica Iossi Silva

Coorientador: Simona Carla Silvia Caravita

1. Saúde Escolar. 2. Violência. 3.Saúde do Adolescente. 4. Bullying. 


\section{FOLHA DE APROVAÇÃo}

OLIVEIRA, Wanderlei Abadio de.

Relações entre bullying na adolescência e interações familiares: do singular ao plural

Tese apresentada para obtenção do título de Doutor em Ciências, no âmbito do Convênio Acadêmico Internacional para Coorientação de tese de doutorado celebrado pela Escola de Enfermagem de Ribeirão Preto da Universidade de São Paulo e pela Università Cattolica del Sacro Cuore.

Aprovado em:

Banca Examinadora

Prof. Dr. Instituição:

Julgamento: Assinatura:

Prof. Dr. Instituição:

Julgamento: Assinatura:

Prof. Dr. Instituição:

Julgamento: Assinatura:

Prof. Dr. Instituição:

Julgamento: Assinatura:

Prof. Dr. Instituição:

Julgamento: Assinatura: 
Aos que têm medo da(s) adolescência(s) e dos adolescentes.

Aos adolescentes que, muitas vezes, são interpretados como "difíceis" ou "em crise: façamos mais laços afetivos, políticos e tolerantes com esse momento do desenvolvimento humano.

Aos adolescentes que participaram desse estudo de forma generosa e colaborativa. Com carinho, aos meus sobrinhos que vivenciam a "adolescência cronológica" e adolecem de forma singular nesse momento da conclusão dessa tese. 
Pesquisa financiada:

Fundação de Amparo à Pesquisa do Estado de São Paulo (FAPESP).

Processo 2014/13062-7.

Coordenação de Aperfeiçoamento de Pessoal de Nível Superior (CAPES).

Programa de Demanda social (DS) e PDSE/Bex 7029/14-4 - estágio sanduíche (2015). 


\section{AGRADECIMENTOS ${ }^{1}$}

Trazer uma saudade muito esquisita escondida no coração.

Ver que está tão diferente, e que já sabe tantas novidades... Agradecer tanta coisa que a gente não pode acreditar que esteja acontecendo.

Pra falar a verdade, sentir-se quite com a vida. Manoel de Barros (2010, p. 58-65)

Primeriamente agradeço a Deus, uma necessidade e o melhor parceiro para a minha megalomania, como sentenciava o saudoso Ariano Suassuna. Descobrir que não me falta nada nesse ponto da caminhada, dar um suspiro bom de alívio e ver-me pago de tudo é reflexo de minha fé, sem a qual não haveria sentido para a existência.

Em segundo lugar, agradeço aos adolescentes que participaram dessa pesquisa, revelando processos de vida e existir que, nem sempre, são fáceis. Da mesma forma, agradeço aos graduandos Jéssica Luiza, Ana Carolina e Arthur Afonso que me auxiliaram e aliviaram o denso processo de coleta de dados. Assim como ao Jorge, parceiro intelectual, amigo e leitor crítico.

Ao lembrar da casa da minha infância, meus pais (Walter e Roseli), meus irmãos (Solange e Fábio), sobrinhos (Aline, Alana, Alan, Brenda e Breno) e cunhado (Alexandre): agradeço por serem suficientemente bons, afetuosos e por me aguentarem. Gratidão!

Ao mesmo tempo, como é bom ter deixado a pequena terra em que nasci. Ter fugido para cidades maiores e poder conhecer outras vidas. Nesse sentido, talvez eu ainda não saiba amar direito, mas sempre existem poesias e poetas que nos ajudam. Como o Leonardo, a quem agradeço a cumplicidade, a parceria, a alegria, o afeto e os momentos compartilhados que são bálsamos para a caminhada.

Ao contemplar minha trajetória na pós-graduação, também, lembro-me das amizades nela construídas ou consolidadas (Claudio, Iara, Neire, Marisa, Carla, Andrea, Marina, Marcelo, Diene, Julliane e Flávia) e dos demais colegas com os quais as trocas de experiência foram intensas: obrigado!

Nesse sentido, ainda, minha gratidão ao Grupo PROASE que me acolheu em 2009 e enriqueceu minha formação ao longo dos últimos anos. Da mesma forma que reconheço a importância dos professores da EERP, com os quais compartilhei diferentes momentos

\footnotetext{
${ }^{1}$ Baseado e com fragmentos do poema "Olhos parados" (BARROS, 2010, p. 58-63).
} 
e são peças elementares no processo, na condução e para conclusão dessa tese. Estendendo a Shirley meu muito obrigado pela assistência e disponibilidade.

Como é bom saber que a gente tem amigos de fato! Isso me faz recordar que alguns estão longe em termos geográficos, mas perto do coração. Especialmente, agradeço aqueles que contribuem ou contribuíram com minha formação, com minha existência: Walter, Sofia, Eliane, Aragão, Cida, Ester, Guido, Daniel, Fernando, Jaqueline e Vânia.

Essas lembranças fomentam em mim uma vontade de escrever para todos. Especialmente para uma que compõe a banca examinadora desse trabalho: a Profa. Dra. Rosimár Querino. Dileta parceira intelectual e amiga. Agradecer não expressa minha gratidão, apreço e consideração por seus muitos modos de ser professora/amiga/mulher/mãe.

Agradeço, também, aos demais professores que compõem a banca, que leram, tornaram-se interlocutores do meu trabalho e contribuem em sua avaliação. É importante descobrir, no mundo que nos envolve, alguma voz que tenha acento parecido, que contribua com nosso processo formativo de forma crítica e reflexiva.

E nessa arte composta por lembranças e agradecimentos, como não lembrar dos diferentes lugares pelos quais andei e das coisas que vi nos anos de doutorado. Lembrar das viagens, dos mentores e amigos que ficaram longe me oportuniza agradecer a Profa. Dra. Simona Caravita pela acolhida, o carinho e a sensibilidade com que me recebeu em Milão/Itália para o estágio sanduíche. Ela ofereceu grandes contribuições para esse trabalho que merecem ser reconhecidas. Gratidão!

Declaro, ainda, que eu gosto desse momento de conclusão, dessa emoção tão cheia de riquezas intímas e que só são possíveis por ação da minha orientadora, Profa. Dra. Marta Angélica. Obrigado pela acolhida, pelas muitas conversas e orientações, por transformar o meu processo de vida, por me fazer um candidato a doutor e uma pessoa melhor, por oferecer robustez a esse produto que apresento, por sua sensibilidade e amizade. Agradecimento que se estende à sua família: Ricardo e Pamêla.

Por fim, é muito bom ter vindo de tão longe, mas estar agora caminhando e chegar ao fim só é possível graças ao financiamento que recebi ao longo dos anos de doutorado. Assim, agradeço: à Coordenação de Aperfeiçoamento de Pessoal de Nível Superior (CAPES) pelo auxílio financeiro nos primeiros anos do doutorado, bem como no estágio sanduíche em 2015; e à Fundação de Amparo à Pesquisa do Estado de São Paulo (FAPESP) pelo auxílio com bolsa de doutorado direto no país (Processo 2014/13062-7). 
Ó passar-se invisível pela alma da alameda de casas espaçosas Imaginando a feição ideal dentro de cada uma!

Ir recebendo um pouco de poesia no peito Sem lembranças do mundo, sem começo... Chegar ao fim sem saber que passou Tranquilo como as casas, Cheio de aroma como os jardins, Desaparecer. Não contar nada a ninguém.

Não tentar um poema. Nem olhar o nome na placa. Esquecer. Invisível, deixar apenas que a emoção perdure

Fique na nossa vida fresca e incompreensível Um mistério suave alisando para sempre o coração.

Singular, tão singular...

Manoel de Barros (2010, p. 42-43) 


\section{RESUMO}

OLIVEIRA, W.A. Relações entre bullying na adolescência e interações familiares: do singular ao plural. 157f. Tese (Doutorado) - Escola de Enfermagem de Ribeirão Preto, Universidade de São Paulo, Ribeirão Preto, Brasil, 2017.

Os objetos de investigação desse estudo foram o bullying escolar e as interações familiares. 0 bullying é um tipo de violência considerado problema de saúde pública e as interações familiares são caracterizadas pelas práticas parentais, comportamentos e sentimentos. Objetivou-se analisar e compreender a relação entre a qualidade das interações familiares de adolescentes e o envolvimento em situações de bullying escolar, a partir da perspectiva dos estudantes. Participaram do estudo 2.354 (meninas $=50,7 \%$; idade média $\mathrm{M}=14,5$ anos, $\mathrm{DP}=2,0$ anos) estudantes do ensino fundamental e médio, de 11 escolas públicas de Uberaba/MG. A abordagem da triangulação metodológica foi adotada e se conjugou na coleta de dados o uso de duas escalas (bullying e interações familiares), além da técnica de entrevistas semiestruturadas. Os procedimentos de análise dos dados incluíram: análise estatística descritiva; análise de variância e regressão logística para avaliar o poder preditivo ou protetivo de variáveis familiares em relação ao bullying escolar. As entrevistas foram analisadas por meio da análise de conteúdo, em sua modalidade temática, no software Atlas.TI. Desse processo emergiram três categorias temáticas: 1) Inter-relações e influências familiares no que ocorre na escola; 2) Família como espaço para o desenvolvimento ético e moral; 3) Sinergias e enfrentamento de base familiar e escolar. 0 referencial teórico-metodológico adotado foi a Teoria Bioecológica do Desenvolvimento de Urie Bronfenbrenner. 0 estudo identificou uma prevalência de $10,3 \%$ de estudantes agressores, $10,1 \%$ de vítimas e 5,4\% de vítimas-agressoras na amostra. Na análise combinada dos dados, verificou-se que os estudantes não-envolvidos em situações de bullying possuíam melhores interações familiares, sugerindo um padrão inverso de interações familiares para estudantes identificados como agressores, vítimas e vítimas-agressoras. A análise de variância revelou essa constatação ao identificar diferenças significativas entre os grupos de estudantes (não-envolvidos, agressores, vítimas e vítimas-agressoras) no que se refere à qualidade das interações familiares. Efeitos do monitoramento e o estabelecimento de regras no contexto familiar foi um aspecto protetivo identificado, e se observou que envolvimento, comunicação e clima conjugal positivos e apego às figuras parentais são dimensões a serem exploradas para definir estratégias de proteção e enfrentamento do bullying. Aspectos negativos das interações familiares foram associadas a maior possibilidade de bullying ou vitimização entre os estudantes. Confirmou-se que a qualidade das interações familiares exerce influência no envolvimento dos adolescentes em situações de bullying escolar enquanto agressores, vítimas ou vítimas-agressoras. Os dados encontrados foram congruentes com estudos que revelaram serem as famílias de agressores e vítimas menos funcionais do que as famílias de estudantes sem envolvimento com bullying. A triangulação metodológica foi relevante para captar os sentidos e os significados atribuídos pelos adolescentes às diferentes interações familiares na construção de práticas de bullying e vitimização. As influências temporais e potenciais das experiências familiares incluíram desde situações que protegem àquelas que são potencialmente perigosas para que os estudantes pratiquem ou sofram bullying na escola. Implicações para a área da saúde foram exploradas a partir dos aspectos empíricos explorados no estudo. 


\begin{abstract}
OLIVEIRA, W.A. Relationship between bullying during adolescence and family interactions: from the individual to the collective. 157f. Thesis (Doctoral) - Ribeirão Preto College of Nursing, University of São Paulo, Ribeirão Preto, Brazil, 2017.
\end{abstract}

This study's research objects were school bullying and family interactions. Bullying is a type of violence considered to be a public health problem and family interactions are characterized by parental practices, behaviors and feelings. The objective was to analyze and understand the relationship between the quality of adolescents' family interactions and their involvement in school bullying from their own students' perspective. A total of 2,354 primary and middle school students (girls $=50.7 \%$; average age $=14.5$ years old, $\mathrm{SD}=2.0$ years) from 11 public schools from Uberaba, MG, Brazil participated in the study. Methodological triangulation was adopted and data were collected using two scales (bullying and family interactions), in addition to semi-structured interviews. Data analysis procedures included: descriptive statistical analysis; ANOVA to check for differences and similarities among the means obtained by the groups involved in bullying in regard to nine dimensions of quality of family interaction; and logistic regression to assess the predictive or protective power of family variables in regard to school bullying. Interviews were analyzed using content thematic analysis through Atlas.TI. From this process emerged three thematic categories: 1) Inter-relationships and the influence of families on what happen at the school; 2) Family as a space for ethical and moral development; 3) Synergies and family and school-based coping. The theoreticalmethodological framework adopted was the Bronfenbrenner's bio-ecological development theory. The results reveal a prevalence of $10.3 \%$ of bullies, $10.1 \%$ of victims, and $5.4 \%$ of victims-bullies in the sample. The combined data analysis verified that students not involved with bullying enjoyed better family interactions, suggesting there is an inverse pattern of family interactions for those identified as bullies, victims or victimbullies. Variance analysis confirmed this, as it identified significant differences among groups (students not involved with bullying, bullies, victims, and victim-bullies) in regard to the quality of family interactions. Effects from monitoring and the establishment of rules in the family context constituted a protective factor, while positive involvement, communication and marital climate and attachment to parental figures are dimensions to be explored and verified in regard to issues concerning protective factors and coping. The negative aspects of family interactions were associated with a higher likelihood of bullying or victimization among students. The quality of family interactions plays a role in the involvement of adolescents with school bullying, whether as bullies, victims or victim-bullies. These findings are in agreement with those from studies reporting that the families of bullies and victims are less functional than the families of students not involved with bullying. The triangulation of data was important to capturing the meanings adolescents assign to the different family interactions in the development of bullying and victimization. The temporal and potential influence of family experiences include situations from those of a protective nature to those with the potential to lead students to practice or suffer bullying at school. Implications for the health field were explored based on the empirical aspects explored in this study.

Descriptors: School Health. Violence. Adolescent Health. 


\section{RESUMEN}

OLIVEIRA, W.A. Relaciones entre acoso en la adolescencia e interacciones familiares: del singular al plural. 157f. Tesis (Doctorado) - Escuela de Enfermería de Ribeirão Preto, Universidad de São Paulo, Ribeirão Preto, Brasil, 2017.

Los objetos de investigación de este estudio fueron el acoso e las interacciones familiares. El acoso es un tipo de violencia considerado como un problema de salud pública y las interacciones familiares son caracterizadas por prácticas parentales, comportamientos y sentimientos. Se objetivó analizar y comprender la relación entre la calidad de las interacciones familiares de adolescentes y la participación en situaciones de acoso escolar, a partir de la perspectiva de los estudiantes. Participaron del estudio 2.354 (muchachas $=50,7 \%$; edad media $\mathrm{M}=14,5$ años, $\mathrm{DE}=2,0$ años) estudiantes de la enseñanza fundamental y media, de 11 escuelas públicas de Uberaba, MG. Se adoptó el abordaje de la triangulación metodológica y se conyugó en la recolección de datos el uso de dos escalas (acoso e interacciones familiares), además de la técnica de entrevistas semiestructuradas. Los procedimientos de análisis de los datos incluyeron: análisis estadístico descriptivo; ANOVA y regresión logística. Las entrevistas fueron analizadas por medio del análisis de contenido, en su modalidad temática, con el software Atlas.TI. De ese proceso surgieron tres categorías temáticas: 1) Interrelaciones e influencias familiares relacionado con lo que ocurre en la escuela; 2) La familia como espacio para el desarrollo ético y moral; 3) Sinergias y enfrentamiento de base familiar y escolar. El referencial teórico-metodológico adoptado fue la Teoría Bioecológica del Desarrollo de Bronfenbrenner. El estudio identificó una prevalencia de 10,3\% de estudiantes agresores, $10,1 \%$ de víctimas y 5,4\% de víctimas-agresoras, en la muestra. En el análisis combinado de los datos, se verificó que los estudiantes no-participantes en situaciones de acoso poseían mejores interacciones familiares, sugiriendo un patrón inverso de interacciones familiares para estudiantes identificados como agresores, víctimas e víctimas-agresoras. El análisis de variancia reveló esa constatación al identificar diferencias significativas entre los grupos de estudiantes (no-participantes, agresores, víctimas e víctimasagresoras) en lo que se refiere a la calidad de las interacciones familiares. Los efectos de la monitorización y el establecimiento de reglas en el contexto familiar fue un aspecto protector identificado, y se observó que la positiva participación, comunicación, el clima conyugal y el apego a las figuras parentales son dimensiones que deben ser exploradas cuando se evalúa el peso de cuestiones de protección y enfrentamiento del acoso. Los aspectos negativos de las interacciones familiares fueron asociados a una mayor posibilidad de acoso o victimización entre los estudiantes. Se confirmó que la calidad de las interacciones familiares ejerce influencia en la participación de los adolescentes en situaciones de acoso escolar como agresores, víctimas o víctimas-agresoras. Los datos encontrados fueron congruentes con estudios que revelaron que las familias de agresores y víctimas eran menos funcionales que las familias de estudiantes sin participación en acoso. La triangulación metodológica fue relevante para captar los sentidos y los significados atribuidos por los adolescentes a las diferentes interacciones familiares en la construcción de prácticas de acoso y victimización. Las influencias temporales y potenciales de las experiencias familiares incluyeron desde situaciones que protegen hasta las que son potencialmente peligrosas para que los estudiantes practiquen o sufran acoso en la escuela. Las implicaciones para el área de la salud fueron exploradas. 


\section{RIASSUNTO}

OLIVEIRA, W.A. Relazioni tra il bullismo nell'adolescenza e le interazioni familiari: dal singolare al plurale. 157f. Tesi (Dottorato) - Scuola di Infermieri di Ribeirão Preto, Università di San Paolo, Ribeirão Preto, Brasile, 2017.

Gli oggetti di questo studio sono stati il bullismo a scuola e le interazioni familiari. Il bullismo è un tipo di violenza considerato un problema di sanità pubblica e le interazioni familiari sono caratterizzate dalle pratiche genitoriali, i comportamenti e i sentimenti. L'obiettivo è stato quello di analizzare e capire la relazione tra la qualità delle interazioni familiari degli adolescenti e il coinvolgimento in situazioni di bullismo dal punto di vista degli studenti. Hanno partecipato allo studio 2.354 studenti (ragazze $=50$, il 7\%; età media $\mathrm{M}=14,5$ anni, $\mathrm{DP}=2,0$ anni) della scuole medie e superiori di 11 scuole pubbliche di Uberaba/MG. Ė stato adottato l'approccio della triangolazione metodologica e due scale (bullismo e interazioni familiari) sono state usate per la raccolta dati, oltre alla tecnica di interviste semi strutturate. Le procedure di analisi dati comprenderono: analisi statistica descrittiva; ANOVA e la regressione logistica. Le interviste sono state analizzate attraverso l'analisi del contenuto, nella sua modalità tematica, nell'Atlas.TI. Da questo processo sono emerse tre categorie tematiche: 1) Inter-relazioni e influenze familiari in ciò che succede a scuola; 2) La famiglia come lo spazio dello sviluppo etico e morale; 3) Sinergie e approccio di base familiare e scolastica. Il sistema di riferimento teoricometodologico adottato è stata la Teoria Bioecologica dello Sviluppo. Lo studio ha identificato una prevalenza del 10,3\% di studenti aggressori, il 10,1\% di vittime e il 5,4\% di vittime-aggressori nel campione. Nell'analisi combinata dei dati, è stato verificato che gli studenti non coinvolti in situazioni di bullismo avevano delle interazioni familiari migliori, il che suggerisce uno standard inverso di interazioni familiari per gli studenti identificati come aggressori, vittime e vittime-aggressori. L'analisi della varianza ha dimostrato questa constatazione, all'identificare delle differenze significative tra i gruppi di studenti (non coinvolti, aggressori, vittime e vittime-aggressori) riguardo alla qualità delle interazioni familiari. Gli effetti del monitoraggio e delle regole stabilite nel contesto familiare sono stati un aspetto protettivo identificato. Inoltre è stato osservato che il coinvolgimento, la comunicazione e l'ambiente coniugale positivi, oltre all'attaccamento alle figure genitoriali sono dimensioni da esplorare nel soppesare le questione della protezione e dell'approccio al bullismo. Gli aspetti negativi delle interazioni familiari sono stati associati a una maggiore possibilità di bullismo oppure di vittimizzazione tra gli studenti. Si è confermato che la qualità delle interazioni familiari esercita un'influenza sul coinvolgimento degli adolescenti in situazioni di bullismo a scuola nei ruoli di aggressori, vittime o vittime-aggressori. I dati trovati sono stati congruenti con gli studi che hanno rivelato che le famiglie degli aggressori e delle vittime sono meno funzionali rispetto alle famiglie degli studenti che non sono coinvolti con il bullismo. La triangolazione metodologica è stata rilevante per catturare i sensi e i significati attribuiti dagli adolescenti alle diverse interazione familiari nella costruzione di pratiche di bullismo e vittimizzazione. Le influenze temporali e potenziali delle esperienze familiari comprenderono dalle situazioni di protezione a quelle potenzialmente pericolose perché gli studenti pratichino o soffrano il bullismo a scuola. Delle implicazioni per l'area della sanità sono state esplorate a partire da aspetti empirici esplorati nello studio.

Parole chiave: Salute nella Scuola. Violenza. Salute degli Adolescenti. 


\section{LISTA DE FIGURAS}

Figura 1 - Modelo bioecológico do desenvolvimento para a criança e o adolescente........35

Figura 2 - Modelo bioecológico para a interface bullying e família..........................................36

Figura 3 - Fluxograma dos procedimentos de pesquisa ..........................................................48

Figura 4 - Dispersão das categorias temáticas de acordo com tipo de envolvimento em situações de bullying e ocorrência de citação selecionada por sexo ........................................81

Figura 5 - Modelo bioecológico para a interface bullying e família no estudo................... 100 


\section{LISTA DE TABELAS}

Tabela 1 - Resultados da análise fatorial exploratória dos itens da Escala de Agressão e Vitimização entre Pares (EVAP). 50

Tabela 2 - Resultados da análise fatorial exploratória dos itens da Escala de Qualidade de Interação Familiar (EQIF)

Tabela 3 - Caracterização dos estudantes do Ensino Fundamental e Ensino Médio de escolas públicas participantes da etapa quantitativa do estudo (total e por sexo) ............59 Tabela 4 - Caracterização dos estudantes do Ensino Fundamental e Ensino Médio de escolas públicas participantes da etapa qualitativa do estudo (geral e por sexo) 61 Tabela 5 - Distribuição dos participantes $(\mathrm{N}=2.354)$ segundo o tipo de envolvimento em situações de bullying (geral e por sexo)

Tabela 6 - Caracterização do grupo de participantes $(\mathrm{N}=2.354)$ segundo o tipo de envolvimento em situações de bullying e por sexo

Tabela 7 - ANOVA de acordo com o tipo de envolvimento em situações de bullying e em relação à qualidade da interação familiar geral.

Tabela 8 - ANOVA de acordo com o tipo de envolvimento em situações de bullying e em relação à qualidade da interação familiar com a figura paterna

Tabela 9 - ANOVA de acordo com o tipo de envolvimento em situações de bullying e em relação à qualidade da interação familiar com a figura materna. 68 Tabela 10 - ANOVA de acordo com o tipo de envolvimento em situações de bullying e em relação à qualidade da interação familiar com outra pessoa

Tabela 11 - ANOVA de acordo com o tipo de envolvimento em situações de bullying e em relação à qualidade da interação familiar geral, sexo masculino.

Tabela 12 - ANOVA de acordo com o tipo de envolvimento em situações de bullying e em relação à qualidade da interação familiar geral, sexo feminino 70 Tabela 13 - ANOVA de acordo com o tipo de envolvimento em situações de bullying e em relação à qualidade da interação familiar com a figura paterna, sexo masculino . . .71 Tabela 14 - ANOVA de acordo com o tipo de envolvimento em situações de bullying e em relação à qualidade da interação familiar com a figura paterna, sexo feminino...................72 Tabela 15 - ANOVA de acordo com o tipo de envolvimento em situações de bullying e em relação à qualidade da interação familiar com a figura materna, sexo masculino. .73 Tabela 16 - ANOVA de acordo com o tipo de envolvimento em situações de bullying e em relação à qualidade da interação familiar com a figura materna, sexo feminino .73 Tabela 17 - ANOVA de acordo com o tipo de envolvimento em situações de bullying e em relação à qualidade da interação familiar com outra pessoa, sexo masculino ......................74 Tabela 18 - ANOVA de acordo com o tipo de envolvimento em situações de bullying e em relação à qualidade da interação familiar com outra pessoa, sexo feminino 75 Tabela 19 - Fatores da qualidade de interação familiar associados ao envolvimento ou não envolvimento de estudantes em situações de bullying. 


\section{LISTA DE ABREVIATURAS E SIGLAS}

$\begin{array}{ll}\text { EERP } & \text { Escola de Enfermagem de Riberião Preto } \\ \text { EQUIF } & \text { Escala de Qualidade na Interação Familiar } \\ \text { ESF } & \text { Estratégia Saúde da Família } \\ \text { EVAP } & \text { Escala de Vitimização e Agressão entre Pares } \\ \text { Fac } & \text { Frequência absoluta acumulada } \\ \text { Fra } & \text { Frequência relativa absoluta } \\ \text { KMO } & \text { Kaiser-Meyer-Olkin } \\ \text { MG } & \text { Minas Gerais } \\ \text { PeNSE } & \text { Pesquisa Nacional de Saúde do Escolar } \\ \text { PPCT } & \text { Processo-Pessoa-Contexto-Tempo } \\ \text { PPS } & \text { Probability Proportional to Size } \\ \text { PPT } & \text { Probabilidade Proporcional ao Tamanho } \\ \text { RS } & \text { Rio Grande do Sul } \\ \text { SE } & \text { Sergipe } \\ \text { SEE } & \text { Secretaria Estadual de Educação } \\ \text { SPSS } & \text { Statistical Package for Social Sciences } \\ \text { TCLE } & \text { Termos de Consentimento Livre e Esclarecido } \\ \text { USP } & \text { Universidade de São Paulo }\end{array}$




\section{LISTA DE SÍMBOLOS}

Alfa de Cronbach 


\section{APRESENTAÇÃO}

Esse estudo aborda encontros significativos para a produção da vida e da maneira como nos tornamos humanos, como somos e nos relacionamos. Na abordagem dos encontros é analisado como as pessoas se relacionam, como cuidam umas das outras, como se amam, como se afetam e como vivem. Trata-se de uma proposta amadurecida ao longo do tempo e reflexo de anos dedicados à pesquisa sobre políticas públicas, participação popular, saúde coletiva, empoderamento social, cuidado integral e famílias que culminaram, em 2012, com a construção de um projeto direcionado para a questão do bullying escolar e sua interface com as interações familiares.

Assim, o foco da presente tese são os encontros entre estudantes e estudantes, encontros entre adolescentes e seus pais ou cuidadores, objetivando levar à análise a perspectiva dos adolescentes sobre como as práticas de bullying escolar podem ser construídas a partir de elementos das interações familiares. Nesse sentido, uma revisão de literatura integrativa mapeou o estado da arte e verificou que aspectos qualitativos do contexto familiar, características sociodemográficas e experiências negativas em casa eram variáveis associadas com o envolvimento de escolares em situações de bullying e vitimização. Os pais e cuidadodores, também, são importantes na maneira como abordam a questão como ilustrado pela sensível mémoria do já adulto, psicanalista e educador

Rubem Alves ao desabafar sobre situações de bullying sofridas na infância: "Uma pessoa querida me disse que tenho raiva das mulheres. Fico a pensar se essa raiva não tem raízes na minha mãe, que só me ensinava a não reagir, que desejava que eu fosse fraco e não enfrentasse a luta" (ALVES, 2011, p. 172).

Os resultados dos diferentes momentos dessa revisão de literatura já foram publicados em artigos e capítulos de livro (OLIVEIRA et al., 2017; OLIVEIRA et al., 2016b; OLIVEIRA et al., 2015a; OLIVEIRA et al., 2013) e se identificou uma produção científica variada e extensa sobre o tema, com muitos artigos publicados em revistas internacionais e resultados de pesquisas desenvolvidas na América do Norte e na Europa. Até 2014, apenas dois artigos brasileiros estavam divulgados e abordavam a interface entre as variáveis bullying e família. Assim sendo, observando essa escassez de estudos nacionais sobre a temática, mas reconhecendo que internacionalmente diferentes pesquisas já confirmaram alguns dos pressupostos e hipóteses dessa pesquisa: porque empreendê-la? 
Primeiramente, por se tratar de uma abordagem inédita (triangulação metodológica) e, em segundo lugar, por se considerar o bullying um fenômeno associado às questões contextuais. Assim sendo, resultados de diferentes realidades auxiliam na compreensão macro do fenômeno. Ao mesmo tempo, há um consenso de que os dados de uma determinada localidade não podem ser generalizados por se considerar os diferentes modelos educacionais e os aspectos transculturais.

Noutra perspectiva, esse detalhe, também, conduz à reflexão sobre os processos de pesquisa e como eles são densos em sua capilaridade (pesquisador, subjetividade(s), local de coleta de dados, universidade, programas de pós-graduação). Nesse sentido, recorre-se à pesquisa e estudo de Pablo Picasso sobre a (uma) obra original de Diego Velásquez intitulada, atualmente, "Las Meninas" (1656). A obra de Vesquez é considerada a representação magistral de condições históricas e sociais, e Picasso em sua pesquisa e releituras, esqueceu-se de Velasquez e compôs "do seu jeito" 58 versões "das meninas". Concluída a coleção, o celebre pintor sentenciou que as suas “Las Meninas" (1957) seriam cópias detestáveis, mas ainda assim seriam as "suas meninas" (NASCIMENTO, 2000). Analogamente, nessa pesquisa, apresenta-se um modo particular de olhar para o bullying escolar e sua interface com a qualidade da interação familiar de 2.354 adolescentes brasileiros ("nossos adolescentes"; "nosso estudo"). 0 texto está estruturado da seguinte forma:

- Introdução: seção em que são informadas as motivações, as questões norteadoras e o que foi pesquisado; são explorados aspectos conceituais do bullying e família, conexões possíveis entre essas variáveis e elementos do referencial teórico adotado.

- Objetivos, hipóteses e pressupostos, e Método: seções que demonstram as intenções propostas, as possibilidades de resultados a serem obtidos mediante aplicação do percurso metodológico assumido e detalhado.

- Resultados: seção de apresentação dos dados obtidos e sintetizados pelo autor, considerando objetivos, hipóteses e pressupostos do estudo.

- Discussão: seção que abriga comentários e posicionamentos sobre o significado dos resultados encontrados na pesquisa, em comparação com estudos anteriores; incluindo, ainda, implicações e pontos fortes da investigação e suas limitações.

- Considerações finais: seção em que há uma síntese das ideias predominantes no trabalho e considerações decorrentes da análise dos resultados; também são expostas recomendações gerais acerca de novos estudos e práticas interventivas. 


\section{SUMÁRIO}

1 INTRODUÇÃ

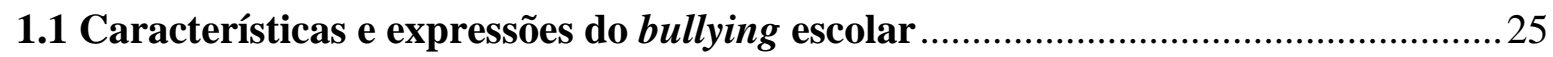

1.2 Um contexto imediato de desenvolvimento: $\mathbf{a}(\mathbf{s})$ família(s) ....................................2

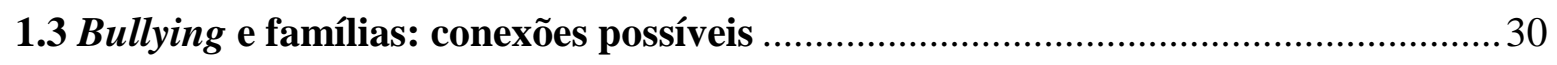

1.4 Um conjunto de bonecas russas: o paradigma biolecológico.................................... 33

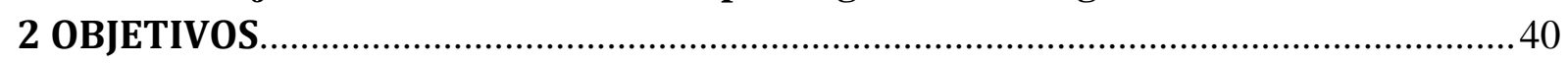

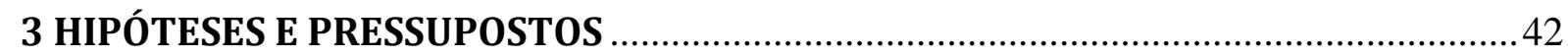

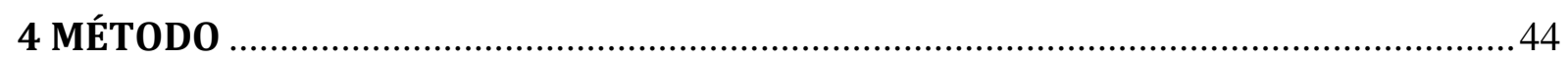

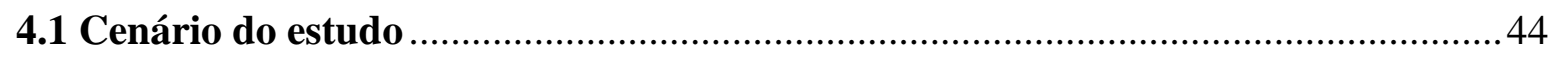

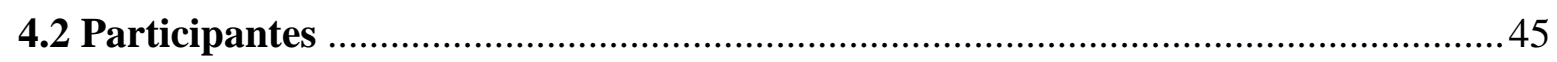

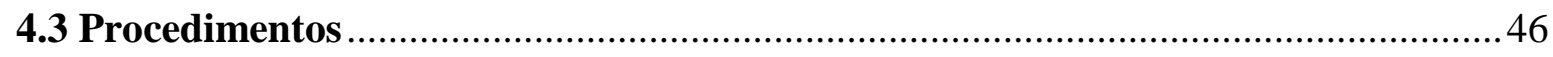

4.4 Instrumentos e técnica de pesquisa ........................................................................ 49

4.4.1 Escala de Agressão e Vitimização entre Pares (EVAP) ............................................. 49

4.4.2 Escala de Qualidade de Interação Familiar (EQIF) ..............................................50

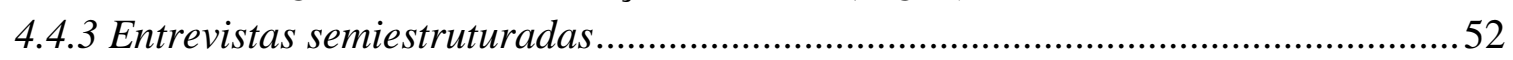

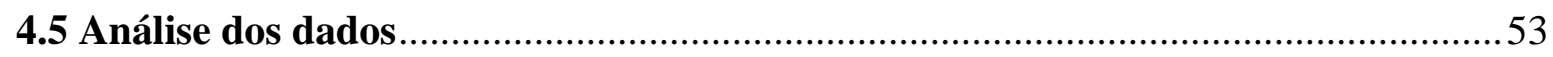

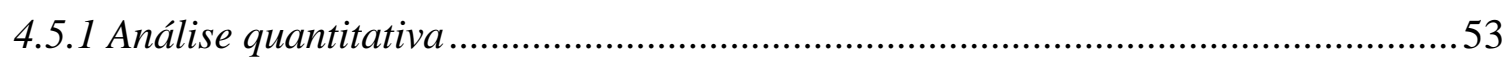

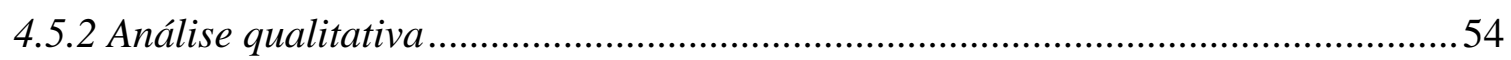

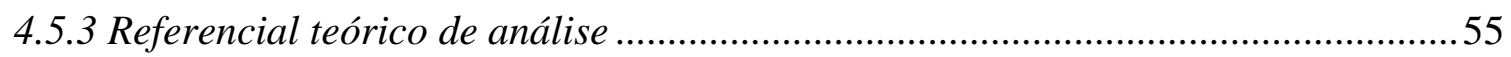

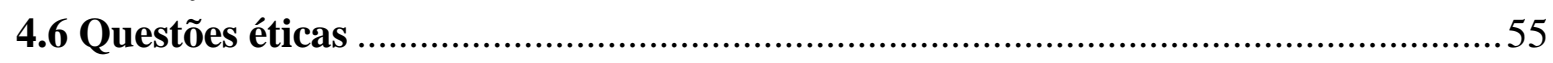

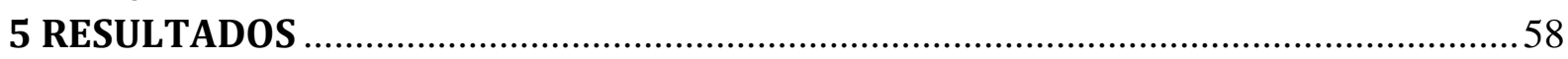

5.1 Caracterização dos participantes na etapa quantitativa...........................................58

5.2 Caracterização dos participantes na etapa qualitativa ........................................60

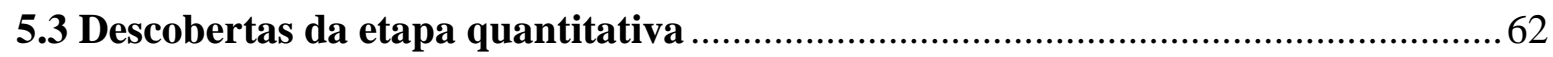

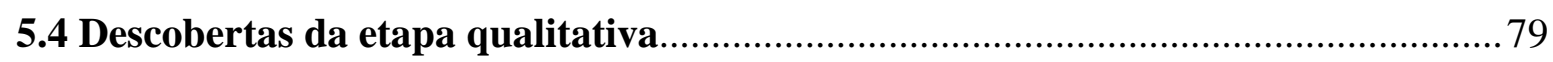

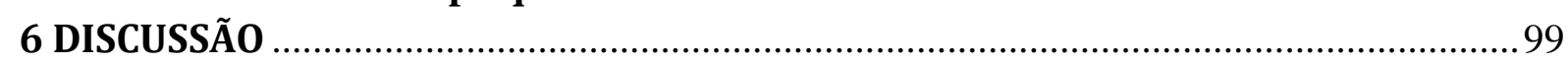

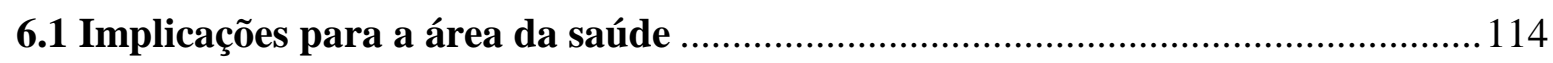

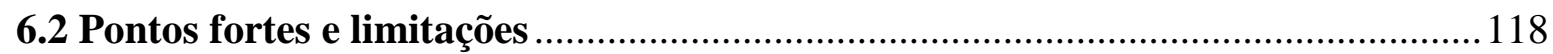

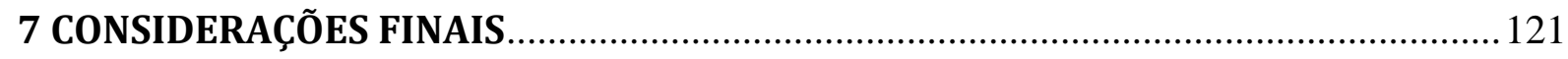

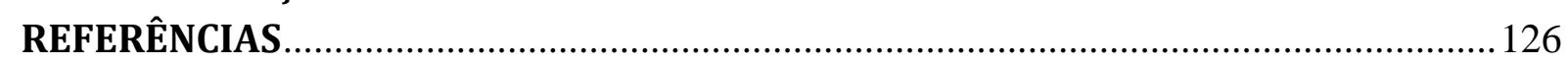

Anexo A Escala de Vitimização e Agressão entre Pares (EVAP) (versão adaptada) ....... 141

AnexoB Escala de Qualidade na Interação Familiar (EQIF) (versão adaptada) ..............143

Anexo C Autorização para o desenvolvimento da pesquisa (SEE) ................................... 145

Anexo D Parecer de aprovação por Comitê de Ética em Pesquisa.................................... 147

Apêndice A Roteiro para entrevista semiestruturada ................................................... 149

Apêndice B Termo de Consentimento Livre e Esclarecido (maiores de 18 anos)............ 151

Apêndice C Termo de Consentimento Livre e Esclarecido (responsáveis) ...................... 154

Apêndice D Termo de Assentimento (menores de 18 anos) ............................................ 157 
Você sabe o que faz pra virar poesia, João? - A gente é preciso de ser traste Poesia é a loucura das palavras: Na beira do rio o silêncio põe ovo Para expor a ferrugem das águas eu uso caramujos

Deus é quem mostra os veios É nos rotos que os passarinhos acampam! Só empós de virar traste que o homem é poesia...

(Com os loucos de água e estandarte) Manoel de Barros (2010, p. 153) 


\section{INTRODUÇÃO}

Esse estudo defende a tese de que a qualidade das interações familiares exerce influência no envolvimento de adolescentes em situações de bullying escolar enquanto agressores, vítimas ou vítimas-agressoras ${ }^{2}$. Modelos explicativos para o fenômeno, neste sentido, consideram que os sentimentos, os comportamentos e os eventos familiares possuem efeitos que são transferidos para outros espaços, como a escola. Aborda-se, dessa forma, questões complexas da vida cotidiana, num entendimento de que forças objetivas e subjetivas são interdependentes e se influenciam mutuamente na construção dos fenômenos sociais, do desenvolvimento humano e da saúde.

Configuram-se como objetos de investigação o bullying na escola entre adolescentes e as interações familiares, sendo, portanto, essencial apresentar a perspectiva adotada para a adolescência, momento do cilco vital circunscrita entre os 10 e os 19 anos (WORLD HEALTH ORGANIZATION, 2015) ${ }^{3}$, e compreendida como complexo processo de desenvolvimento biopsicossocial. 0 adolescer tem sido alvo de interesse e análises que incluem em sua compreensão a dinâmica existente entre os aspectos pertencentes à subjetividade dos adolescentes e às relações familiares, sociais, culturais, econômicas e políticas. A adolescência é, assim, um modo de vida significado, interpretado, produzido e construído pelos homens, estando associada às marcas de transformação do corpo, mas não determinada por elas (BOCK, 2007; SENNA; DESSEN, 2012; SILVA et al., 2013c).

O bullying, por seu turno, é uma manifestação perversa da violência que incide negativamente na saúde dos adolescentes. Ele é um fenômeno multifacetado definido consensual e internacionalmente. Sistematicamente, ele apresenta como critérios de definição e identificação 1) a intencionalidade de causar dor/dano físico ou psicológico ao outro, 2) a repetitividade dos episódios de agressão ao longo do tempo e 3) o desequilíbrio de poder existente entre as partes, em que pese ser a vítima incapaz de se defender do agressor (OLIVEIRA et al., 2016a; OLWEUS, 2013; SALMIVALLI, 2014). 0 bullying é, ainda,

\footnotetext{
2 Vítimas-agressoras são estudantes que não adotam comportamento exclusivo na dinâmica do bullying, ou seja, intimidam e são intimidados pelos colegas. Esses estudantes, também, são conhecidos como vítimas ativas, em contraposição às vítimas passivas/submissas, reativas ou provocativas (SHETGIRI, 2013).

3 No Brasil, o Estatuto da Criança e do Adolescente (ECA) compreende a adolescência como período cirscunscrito à faixa etária de 12 a 18 anos de idade.
} 
tipificado em físico, verbal e indireto, de acordo com as formas de manifestação que assume (OLWEUS, 2013; SILVA et al., 2014a; SILVA et al., 2013a).

Nota-se que se trata de um fenômeno construído nas relações, complexo e multideterminado, cuja experiência é nociva e acarreta prejuízos e danos aos estudantes nele implicados. Sua ocorrência se associa à manifestação de diversos desajustes psicossociais que interferem na qualidade de vida, saúde e rendimento escolar dos estudantes. Identifica-se que, de maneira geral, as vítimas e observadores sentem constante medo, insegurança, ansiedade, retraimento social, baixo desempenho escolar, diminuição da autoestima, sentimentos negativistas, depressão e, em casos mais graves, podem cometer suicídio. Os agressores podem se envolver em situações de violência doméstica, uso e abuso de drogas e prática de atos infracionais (FUNG, 2012; HANSEN et al, 2012; PEREIRA; SILVA; NUNES, 2009; ZAINE; REIS; PADOVANI, 2010).

O percentual de estudantes envolvidos em situações de bullying tem justificado pesquisas sobre a temática uma vez que estudos apontam para um aumento significativo de sua prevalência em realidades diversas. Entretanto, comumente, os estudos têm como foco as crianças, o que explica e justifica olhar este fenômeno na adolescência. As pesquisas, também, se concentram nas características individuais dos envolvidos, minimizando a construção de compreensões complexas sobre o tema. Neste sentido, outras investigações, sobremaneira internacionalmente, encontraram relações significativas entre experiências na família e a manifestação de comportamentos de bullying na escola.

A interação familiar, outra variavel em análise nesse estudo, é entendida como complexo sistema construído nas relações familiares, capaz de propiciar o desenvolvimento de repertórios comportamentais e de internalização ${ }^{4}$ das situações vivenciadas nesta dimensão da vida social. Essa interação diz respeito ao nível de envolvimento emocional dos filhos com os pais, à comunicação, ao clima conjugal, aos comportamentos, métodos de disciplina e controle dos pais, e aos sentimentos dos filhos em relação aos pais (CUNHA, 2009; WEBER; DESSEN, 2011; ZOTTIS et al., 2014).

Esses eixos em articulação - adolescência e interação familiar - associados ao debate sobre o bullying confirmam que a ocorrência do fenômeno possui determinações

\footnotetext{
${ }^{4}$ Internalização é um processo fundamental para o desenvolvimento psicológico e pelo qual a personalidade individual incorpora padrões de comportamento, sentimentos e aspectos que prevalecem no contexto social e cultural. Esse processo envolve uma atividade externa que, modificada, torna-se uma atividade interna (VANDER ZANDEN, 1995).
} 
diversas, sendo uma delas as interações familiares (PERRON, 2013; SAWYER et al., 2011). A literatura científica indica que a maneira como as relações familiares se desenvolvem podem se converter em fator de proteção ou de risco para a prática do bullying, a vitimização ${ }^{5}$ ou a construção de respostas para conflitos interpessoais e diferenças sociais (SAWYER et al., 2011; SENTENAC et al., 2011; TORTORELLI; CARREIRO; ARAÚJO, 2010; VLACHOU et al., 2011). Evidencia-se pois, que tal problemática exige compreensões e intervenções capazes de ultrapassar o ambiente escolar, e que abarquem as famílias (FREIRE; AIRES, 2012; VLACHOU et al., 2011; ZOTTIS et al, 2014).

Estas considerações introdutórias oportunizaram a construção das seguintes questões de pesquisa:

1) Quais as características do bullying entre pares em escolas públicas de Uberaba, interior de Minas Gerais?

2) Qual a qualidade das interações familiares de adolescentes envolvidos em situações de bullying?

3) A qualidade das interações familiares difere entre estudantes identificados como agressores, vítimas, vítimas-agressoras e não-envolvidos em situações de bullying?

4) Em que medida as interações familiares dos adolescentes podem contribuir para a ocorrência, no enfrentamento e para a prevenção do bullying escolar?

As respostas para essas questões favoreceram 1) a identificação dos participantes do estudo, levantando entre os adolescentes agressores, vítimas, vítimasagressoras ou não-envolvidos em situações de bullying, e 2) a identificação da qualidade das interações familiares dos adolescentes participantes. Foi possível, ainda, 3) estabelecer associações entre o bullying e dimensões da qualidade das interações familiares, ultrapassando as análises sobre as características individuais dos estudantes. Essa é a síntese dos principais resultados do estudo, que revelaram a ampliação da abordagem exclusiva da singularidade nos estudos sobre bullying com a inclusão de questões familiares (pluralidade). Aspecto aludido no título dessa tese.

0 estudo sobre as relações entre as variáveis em análise foi guiado a partir da percepção dos adolescentes, sendo referenciada analiticamente pela perspectiva da Teoria Bioecológica do Desenvolvimento (BRONFENBRENNER, 2011). Essa abordagem privilegiou o conjunto de processos por meio dos quais as singularidades e os contextos

\footnotetext{
50 termo "vitimização" é utilizado para se referir à condição das vítimas de bullying (SHETGIRI, 2013).
} 
interagem para produzir constância e mudança nas características das pessoas. As ocorrências do contexto familiar são atualizadas pelos adolescentes no contexto escolar e vice-versa. Assim sendo, abordar a dinâmica das famílias, numa perspectiva que integre saberes intersetoriais, contribui para mudanças que podem melhorar os processos de desenvolvimento e de saúde (BRONFENBRENNER, 2011; FREIRE; AIRES, 2012; HONG et al., 2013; SENNA; DESSEN, 2012). Numa compreensão ampliada e sistêmica, a perspectiva teórica adotada permitiu que os contextos sociais e familiares fossem percebidos como fonte de influências para o desenvolvimento, também, de comportamentos agressivos entre os adolescentes (FREIRE; AIRES, 2012; SENNA; DESSEN, 2012).

Esta perspectiva permite, ainda, conceber os sujeitos como singulares ao mesmo tempo em que são também sociais e coletivos em sua constituição. Logo, a subjetividade e o modus operandis das pessoas sempre se constroem na relação com o outro e na maneira como esta se configura ao longo do desenvolvimento. 0 adolescente, assim, suscita inúmeras questões idiossincráticas que são reveladas em seu cotidiano, nas suas relações, nos comportamentos e, sobretudo, nos contextos familiar e escolar.

Esboçam-se neste cenário as duas principais relevâncias do estudo: 1) a identificação de que o bullying é objeto de poucos estudos científicos no Brasil, abordado apenas indiretamente ou com vistas a identificar a ocorrência e as características individuais de vítimas e agressores; e 2) o estudo guarda em seus objetivos potencialidades para ampliar a abordagem do fenômeno e construir saberes que preenchem lacunas referentes aos fatores externos à escola quando se explora a temática do bullying, pois se percebe que as pesquisas e as intervenções focadas no contexto escolar não são suficientes para responderem às complexidades da problemática (OLWEUS, 2013; CUNHA, 2009).

Nos próximos subitens dessa seção serão apresentados aspectos conceituais do bullying, a compreensão de família adotada pelo estudo e a interface entre bullying e família, segundo a literatura científica. Os principais elementos e paradigmas do referencial teórico-metodológico, também, serão apresentados no último subitem dessa seção. 


\subsection{Características e expressões do bullying escolar}

O bullying é um fenômeno complexo, multidimensional e relacional entre pares, cuja ocorrência, geralmente, não possui causa ou motivo aparente (OLWEUS, 2013; SENTENAC et al., 2011; SILVA et al., 2016; ZOTTIS et al., 2014). A partir da maneira como os alunos se envolvem nas situações de bullying, suas manifestações podem ser categorizadas em três tipos: físico, verbal e indireto. 0 tipo físico se refere a agressões corporais (bater, chutar ou machucar) e o verbal consiste em ameaças, xingamentos, insultos e/ou apelidos pejorativos que ressaltam características pessoais negativas da vítima, e propagação de falsas informações para prejudicar a reputação do colega (OLWEUS, 2013; PEREIRA; SILVA; NUNES, 2009). 0 tipo indireto corresponde a condutas como, por exemplo, excluir alguém do grupo de pares, isolamento social e ameaças de acabar com uma amizade a menos que haja cumplicidade em relação a determinados comportamentos (ALMEIDA; CORREIA; MARINHO, 2009; FANTE, 2005; OLWEUS, 1993).

Atualmente este fenômeno tem se constituído em importante tema de estudo, dado suas características e os danos físicos e psicológicos aos envolvidos. Entrementes, sua ocorrência não é recente e acompanha a história do processo de institucionalização da educação. Dan Olweus $(2013 ; 2011 ; 1993 ; 1980)$, considerado pioneiro e um dos principais pesquisadores do bullying escolar no mundo, iniciou seus estudos na década de 1960, na Suécia, em parceria com outros pesquisadores, abordando situações de discriminação. No começo da década de 1970 ele propôs, ainda no contexto sueco, o primeiro projeto de pesquisa sistemática sobre bullying entre pares, e desde então, há mais de 40 anos, na Noruega, tem desenvolvido outros estudos sobre a temática.

Foi a atenção internacional sobre o tema e a necessidade de uma definição clara e objetiva sobre o que caracterizaria o fenômeno que Olweus, em pesquisa nacional (Noruega), construiu um questionário, utilizado e/ou adaptado ainda hoje para muitas pesquisas, que apresentava a definição assumida internacionalmente. Segundo o autor (OLWEUS, 2013), a definição básica de bullying ou vitimização entre pares ocorre pela identificação de situações em que os estudantes estejam sofrendo ações negativas de um ou mais colegas, repetidamente e ao longo do tempo. Além disso, a intencionalidade foi caracterizada e se identificou que o aluno vítima das agressões possui dificuldades para defender a si mesmo, apresentando um certo desequilíbrio de poder ou força em relação ao(s) agressor(es). Para a adolescência, o bullying se converte em uma prática adoecida 
de interação e constituição da própria subjetividade, cujas marcas podem acompanhar a vida dos envolvidos e direcionar a maneira como eles atribuem sentidos, significados e/ou respondem às relações e demandas sociais (PEREIRA; SILVA; NUNES, 2009; PIGOTI; MACHADO; 2015; VOLK et al., 2012).

0 foco na literatura cientifica sobre o assunto tem sido sua prevalência, as características dos envolvidos, a caracterização e descrição das ocorrências. Nesse sentido, uma pesquisa transversal e transcultural realizada com 162.305 estudantes com idades entre 11 e 15 anos, de 5.998 escolas de 35 países da Europa e América do Norte, identificou uma prevalência para vitimização variando em 4,1\% a 36,3\% (DUE et al, 2009). Outra investigação com o mesmo tipo de desenho, comparando a prevalência de bullying em 40 países revelou que, em média, 26\% de escolares adolescentes estavam envolvidos nesse tipo de violência, sendo 12,6\% como vítimas, 10,7\% como agressores e 3,6\% como vítimas-agressoras, em uma amostra de 202.056 estudantes. No conjunto dos países, a exposição ao bullying variou entre 8,6\% e 45,2\% entre os meninos, e de 4,8\% a $35,8 \%$ entre as meninas. Em todos os países os meninos apresentavam taxas mais elevadas de envolvimento com o bullying (CRAIG et al., 2009).

Em Portugal, uma pesquisa desenvolvida com 360 alunos de escolas públicas identificou uma taxa média de envolvimento em situações de bullying de 27,5\% (COSTA et al., 2013). Estudos no contexto italiano, como sumarizado por Gini (2004), indicam uma prevalência média de 35\% de intimidação nas escolas daquele país. Na América Latina, concretamente na Nicarágua, uma investigação em amostra representativa composta por 3.042 estudantes identificou que 50\% dos alunos estavam envolvidos em situações de bullying desempenhando algum papel (agressor, vítima ou vítima-agressora) (FÉLIX; ALAMILLO; RUIZ, 2011).

No Brasil, a Pesquisa Nacional de Saúde do Escolar (PeNSE), em sua terceira edição, desenvolvida com 102.301 escolares do 9o ano do Ensino Fundamental dos 27 estados brasileiros e Distrito Federal, verificou que 7,4\% era vítima de bullying e 19,8\% praticou agressões contra os colegas (BRASIL, 2016). Na segunda edição da Pesquisa, em 2012, que contou com a participação de 109.104 estudantes, identificou-se que 7,2\% sofreu bullying e 20,8\% dos estudantes praticou algum tipo de bullying (MALTA et al., 2014; OLIVEIRA et al., 2016a; OLIVEIRA et al., 2015b). Em sua primeira edição a PeNSE verificou, numa amostra total de 60.973 escolares, que 30,8\% estava envolvido em situações de bullying (MALTA et al., 2010). A pesquisa "Bullying escolar no Brasil" 
(FISCHER, 2010), também, revelou uma alta prevalência, pois 20\% de uma amostra de 5.168 adolescentes brasileiros estava envolvida em situações de bullying (entre vítimas e agressores).

Localmente, num estudo em que participaram 808 adolescentes de nove escolas de Aracaju/SE, Souza (2013) verificou que 32\% da amostra se definiram como vítimas de bullying, $12 \%$ como agressores, $22 \%$ como vítimas-agressoras e $34 \%$ como testemunhas. Outra pesquisa, correlacional e transversal, na cidade de Porto Alegre/RS, da qual participaram 465 estudantes, identificou em sua amostra que 67,5\% afirmaram ter sido vítima de bullying escolar (BANDEIRA; HUTZ, 2012).

As taxas de prevalência de bullying e vitimização, atribuídas às muitas categorias que compõem o fenômeno, não devem ser generalizadas, pois contemplam realidades socioculturais diversificadas. No entanto, os resultados da série de estudos apresentada sugerem que o bullying é uma ocorrência comum, mundial e amplamente prevalente na vida escolar dos estudantes. Outra constatação referente aos índices de prevalência do fenômeno se refere ao fato de que os meninos, em geral, estão mais diretamente envolvidos, sobretudo nas agressões físicas, e as meninas nas formas indiretas do bullying, como espalhar boatos e manipular amizades (CUNHA, 2009; FREIRE; AIRES, 2012; PEREIRA; SILVA; NUNES, 2009; SILVA et al., 2016).

Ao fornecer algumas informações sobre a prevalência de bullying, este trabalho problematiza a necessidade de se abordar fatores influentes ou associados ao fenômeno, incluindo nuances de contexto em sua abordagem, especialmente os familiares.

\subsection{Um contexto imediato de desenvolvimento: a(s) família(s)}

A família é compreendida como grupo em que as pessoas se desenvolvem e que determina as respostas de seus membros à sociedade. “Célula biológica e social dentro da qual o comportamento reprodutivo, os padrões de socialização, o desenvolvimento emocional e as relações com a comunidade são determinados" (ANDRADE; BUENO; BEZERRA, 2006, p. 805). Ela é, ainda, concebida como unidade aberta, dinâmica e complexa, cujos membros pertencem a um mesmo contexto social compartilhado, lugar do reconhecimento da diversidade e da prática da tolerância, sede das primeiras trocas afetivo-emocionais e da construção da identidade. 0 ambiente familiar é um espaço 
privilegiado de socialização, essencial para o cuidado de crianças e adolescentes, bem como para o desenvolvimento, a proteção integral e a saúde de seus membros (PRATTA; SANTOS, 2007; FERNANDES; CURRA, 2006).

Urie Bronfenbrenner $(2011 ; 1996)$ destaca que a família é um dos contextos essenciais para o desenvolvimento humano, assim como a escola. A variedade e a complexidade das relações que se desenvolvem nestes espaços favorecem o desenvolvimento de repertórios comportamentais para os processos de socialização ou podem se converter em condições adversas que prejudicam o desenvolvimento. As interações familiares, desta forma, são grandes responsáveis pelo desenvolvimento de repertórios comportamentais da criança ou do adolescente. Tais repertórios podem se caracterizar como adequados socialmente ou não, e o que leva as crianças/adolescentes a apresentarem um ou outro (proteção ou vulnerabilidade) é o tipo de qualidade na interação familiar (CUNHA, 2009; WEBER; DESSEN, 2011).

Nessa linha de pensamento, cada pessoa possui uma experiência diferente de família e esta experiência se constitui como parte da subjetividade humana. Região mais íntima de interação das crianças e adolescentes com o ambiente, a família se configura como realidade polissêmica na atualidade, com múltiplos arranjos e organizações. Ela tem sofrido cisões internas, interferências externas e, atualmente, suas singularidades estão atreladas às novas configurações no mundo do trabalho e na organização do modo de produção social do capital. Estas novidades sociais, marcadamente, apresentam outras configurações para os grupos familiares e novos arranjos são possíveis na dinâmica social vigente (PRATTA; SANTOS, 2007; VICENTE, 2002).

Szymanski (2000) amplia o olhar sobre as mudanças e o aumento na possibilidade de arranjos familiares ao considerar que cada unidade familiar possui, ainda, a sua forma de propiciar o cuidado aos seus membros, e esta forma muito depende das condições estruturais e sociais nas quais as famílias estão inseridas. A autora postula que "o mundo familiar mostra-se numa vibrante variedade de formas de organização, com crenças, valores e práticas desenvolvidas na busca de soluções para vicissitudes que a vida vai trazendo" (p. 27). Desconsiderar esse entendimento é adotar maneiras simplistas para interpretar e significar a organização das pessoas e seus afetos na contemporaneidade.

Nota-se que as mudanças na família, também, refletem as transformações ocorridas nos formatos da vivência afetivo-sexual que implicam em novos ideais de 
felicidade, novos costumes, novos arranjos relacionais, amorosos e familiares que provocam uma mudança social nas maneiras de se viver. Contudo, essa dimensão da vida humana permanece sendo compreendida como resultado do encontro entre pessoas, dependente ou não de vinculações biológicas nos primeiros anos, pois o laço social ultrapassa essa dimensão e se estende para o nível do simbólico e afetivo (BRONFENBRENNER, 2011).

Neste sentido, as teorias são repensadas e propostos novos formatos, também, para o entendimento das famílias. Numa lógica de valorização do processo de desenvolvimento das pessoas, sem a exclusão das condições materiais de vida e das mudanças no desempenho de papéis historicamente instituídos. Essa abordagem permite a compreensão das famílias a partir de seus movimentos. Movimentos de organização e reorganização que engendram múltiplas formas de desenvolvimento das pessoas e dos próprios grupos familiares.

Assim, esse estudo se vale do entendimento de família proposto por Szymanski (2002, p. 10): “[família] é um núcleo em torno do qual as pessoas se unem, primordialmente, por razões afetivas dentro de um projeto de vida em comum, em que compartilham um cotidiano, e, no decorrer das trocas intersubjetivas, transmitem tradições, planejam seu futuro". São consideradas famílias múltiplos formatos, maneiras de se organizar e desenhos que continuam sendo na contemporaneidade um importante espaço para a iniciação e o aprendizado de afetos e como se relacionar socialmente (OLIVEIRA, 2009). Considera-se como essencial a abordagem da família vivida, percebida, pelos adolescentes e não a idealizada.

Observa-se, ainda, que no estudo será utilizado o termo "arranjo familiar" para se referir às novas composições e maneiras de organização das famílias. Por exemplo, famílias nucleares com o pai e mãe vivendo na mesma casa, famílias recompostas em que há a inclusão de uma nova figura no lugar do pai ou da mãe, pais separados ou divorciados, filhos convivendo com irmãos, avós ou outros parentes/pessoas, entre outros arranjos possíveis. 0 termo "figura parental" se referirá ao exercício das funções materna e paterna pela mãe e pelo pai dos adolescentes, respectivamente. 


\subsection{Bullying e famílias: conexões possíveis}

Desde o início das pesquisas que investigaram o bullying, a relação entre o fenômeno e variáveis familiares foram abordadas. Por exemplo, Olweus (1980) destacou três fatores familiares relacionados ao bullying: 1) falta de carinho e apoio; 2) insensibilidade aos comportamentos agressivos dos filhos; e 3) uso de agressão física e/ou verbal como método de disciplina. Seguindo esta perspectiva, uma extensa lista de pesquisas, majoritariamente internacionais, que examina essa interface, indica que a família pode ser um dos elementos etiológicos desse tipo de experiência (BIBOU-NAKOU et al, 2013; LEREYA; WOLKE, 2013). Entendido, pois, como problema de relacionamento que emerge das relações primárias e se estabelece como padrão de comportamento na infância, adolescência e vida adulta, algumas características familiares podem contribuir para o desenvolvimento do fenômeno (SAWYER et al., 2011; SENTENAC et al., 2011; VLACHOU et al., 2011; VON MARÉES; PETERMANN, 2010).

No que se refere aos fatores protetivos do contexto familiar em relação ao envolvimento em situações de bullying escolar, observa-se que a conformação familiar é destaque em estudos que sugerem que as famílias que preservam as duas figuras parentais são protetivas em relação ao fenômeno (JANSEN et al., 2011; ROMANÍ; GUTIÉRREZ, 2010; ROMANÍ; GUTIÉRREZ; LAMA., 2011; SHETGIRI; LIN; FLORES, 2013). Ao passo que o efeito da monoparentalidade é inverso e as famílias monoparentais são mais associadas ao envolvimento dos alunos com o bullying, tanto no que se refere à vitimização quanto à prática de comportamentos de agressão (FU; LAND; LAMB, 2013; KIM et al., 2009; YANG et al., 2013). Este aspecto também é explorado na história familiar, ou seja, se houve antecedentes de relacionamento entre as figuras parentais, por exemplo.

Em outras perspectivas, pais que são percebidos como compreensivos, que apoiam os filhos, verificam a lição de casa e sabem como eles passam o tempo livre (ABDIRAHMAN et al., 2012; ABDIRAHMAN; FLEMING; JACOBSEN, 2013; HEALY; SANDERS; IYER, 2013; SHETGIRI et al., 2012; SHETGIRI; LIN; FLORES, 2013; WANG; IANNOTTI; NANSEL, 2009;), também são considerados como elementos que protegem os estudantes em relação ao bullying e à vitimização. Assim como a boa comunicação entre pais e filhos (SHETGIRI et al., 2012; SHETGIRI; LIN; FLORES, 2013; WANG et al., 2012; WANG; IANNOTTI; NANSEL, 2009;), sentimentos de envolvimento e proteção 
(GEORGIOU; FANTI, 2010; YAMAGATA et al., 2013), relações positivas com a figura materna e bom clima familiar (BOWES et al., 2010; YAMAGATA et al., 2013).

No campo da vulnerabilidade, o bullying tem sido relacionado com: tipo de envolvimento entre pais e filhos; tipo de afeto manifesto ou percebido; uso de punições severas e corporais na disciplina dos filhos; conflitos familiares; falta de supervisão; baixa qualidade do relacionamento pais/filhos; dificuldades de comunicação; percepções negativas sobre a família; violência doméstica; características individuais e os mecanismos de interação social utilizados na família (BARBOZA et al., 2009; BOWES et al., 2010; BOWES et al., 2009; MURRAY-HARVE; SLEE, 2010; SAWYER et al., 2011; SENTENAC, 2011; TORTORELLI; CARREIRO; ARAÚJO, 2010; TOTURA, et al., 2009; VLACHOU et al., 2011). Essas variáveis familiares, contextuais e articuladas entre si ou com outros fatores, são apontadas como preditoras ou fatores de vulnerabilidade para experiências como agressores ou vítimas em situações de bullying.

As experiências de violência(s) no contexto familiar são outros fatores explorados pela literatura sobre o bullying. Fortes evidências empíricas indicam que estudantes que vivenciaram violência doméstica, diretamente ou a ela foram expostos, tem maior probabilidade de se envolver com o fenômeno, respeitando-se nuances e diferenças entre os sexos. Assim, a violência e a família estão correlacionadas à produção da primeira nas escolas, pois quando expostos à violência, crianças e adolescentes podem considerá-la como algo natural, num processo de naturalização e banalização da violência (BIBOU-NAKOU et al., 2013; 2009; BOEL-STUDT; RENNER, 2014; BOEL-STUDT; RENNER, 2013; CHAUX; MOLANO; PODLESKY, 2009; EIDEN et al., 2010; FINKELHOR et al., 2009; FOSTER; BROOKS-GUNN, 2013; HONG; ESPELAGE, 2012; KNOUS-WESTFALL et al., 2012; LEE, 2011; LEPISTO; LUUKKAALA; PAAVILAINEN, 2011; MUSTANOJA et al., 2011; SEVDA \& SEVIM, 2012; TEISL et al., 2012).

Tortorelli, Carreiro e Araújo (2010) em uma pesquisa com 501 alunos do ensino fundamental de escolas públicas de São Paulo, verificaram que pais negligentes, agressivos, em conflito, que empreendem maus-tratos físicos e emocionais estão correlacionados com a expressão da violência no ambiente escolar. Pinheiro e Willians (2009), num estudo desenvolvido em três escolas públicas de um município do interior do estado de São Paulo, e que contou com a participação de 239 estudantes, também verificaram associações entre a violência doméstica e o bullying. Segundo as autoras, estar exposto à violência interparental esteve associado com ser vítima-agressora de bullying 
no caso das meninas e ser vítima ou vítima-agressora no caso dos meninos. Na Finlândia, uma pesquisa com 508 estudantes examinou que testemunhar violência doméstica aumentava o risco de ser uma vítima de bullying em até 2,5 vezes entre os meninos e, para as meninas ser vítima de violência doméstica foi 10 vezes um fator de risco para ser uma vítima-agressora na escola (MUSTANOJA et al., 2011).

Quando crianças e adolescentes são expostos à violência se favorece a experiência de um mundo pouco seguro, em que os únicos papéis sociais a serem desempenhados é o de agressor ou vítima. Tal concepção perpetua a violência como alternativa para as relações sociais e se reduz a possibilidade de relações positivas, numa lógica muito mais associada ao risco e à vulnerabilidade que à emancipação, à ressignificação de processos de vida e à melhora da dignidade e das condições de vida e saúde (BIBOU-NAKOU et al., 2013; CASTRO-MORALES, 2011; KNOUS-WESTFALL et al., 2012; SEVDA; SEVIM, 2012).

Nesse debate também se insere a questão dos estilos e das práticas parentais, pois o uso de castigos físicos ou medidas disciplinares severas são considerados pela literatura científica como tipos de práticas parentais ineficazes e que são fortemente associadas ao envolvimento em situações de bullying por escolares, principalmente no que se refere ao desenvolvimento de problemas de comportamento de agressividade (CHAUX; MOLANO; PODLESKY, 2009; GEORGIOU; FANTI, 2010; KNOUS-WESTFALL et al., 2012; TOTURA, 2009). Há evidências de que os agressores tendem a ter pais relativamente autoritários que usam de técnicas pouco assertivas de disciplina e castigo físico (BARBOZA et al., 2009), por exemplo.

O mal-estar provocado pela violência no contexto familiar se manifesta em problemas de comportamento, como o bullying escolar. Essa manifestação não se refere apenas à reprodução ou manutenção do ciclo de agressividade presente na primeira instituição de cuidado, mas representa o empobrecimento das relações familiares e os baixos níveis de apoio e proteção social. Ambientes marcados pela violência ou seu testemunho pouco estimulam o desenvolvimento dos adolescentes, e terminam fazendo das famílias instâncias disfuncionais para o desenvolvimento e a manutenção da saúde.

O bullying pode, assim, ser entendido como resposta que traduz um padrão global de interações negativas dos pais com os filhos, reunindo nessa seara diferentes abordagens. Perspectiva que permite problematizar a existência de um ciclo de violência, em que há uma transmissão e perpetuação intergeracional de comportamentos 
agressivos e suas manifestações. Considera-se, também, que comportamentos de bullying são reflexos de processos de internalização de valores e práticas parentais, onde o sujeito significa internamente as relações familiares e devolve para o meio com suas contribuições, numa perspectiva de construção histórica, social e subjetiva dos processos de violência e das interações familiares em si.

Ressalta-se que os fatores familiares apresentados, isoladamente, não explicam o bullying e, em geral, estão associados e relacionados entre si, e precisam ser considerados na produção científica nacional. Nesse sentido, identificou-se que a relação entre as variaveis bullying e família são pouco exploradas na realidade brasileira (OLIVEIRA et al., 2017; OLIVEIRA et al., 2016b; OLIVEIRA et al., 2015a; OLIVEIRA, et al., 2013). Assim, esse estudo fornece análises aprofundadas sobre a questão, preenchendo lacunas da literatura nacional e apontando para possíveis limites. A adoção de uma metodologia mista potencializou a geração de compreensões sobre o problema em investigação congregando diferentes fontes de informações, interpretações e significados (HONG; ESPELAGE, 2012; THORNBERG; JUNGERT, 2013).

\subsection{Um conjunto de bonecas russas: o paradigma biolecológico}

Essa investigação foi orientada analiticamente pela Teoria Bioecológica do Desenvolvimento de Bronfenbrenner (2011) para compreender os fatores e aspectos familiares relacionados ao envolvimento de adolescentes com o bullying escolar. Trata-se de uma abordagem sistêmica e ecológica do fenômeno social na medida em que examina como as relações e interações do contexto familiar influenciam nos comportamentos de bullying dos estudantes.

O paradigma bioecológico considera que o desenvolvimento humano é contextual e constante, não se referindo apenas às mudanças biológicas ou aquelas relacionadas aos modos de produção da vida. “O desenvolvimento humano é definido como o fenômeno de continuidade e de mudança nas características biopsicológicas dos seres humanos, como indivíduos e como grupos" (BRONFENBRENNER, 2011, p. 38). Tal fenômeno ocorre ao longo do ciclo vital, concebendo o homem como ser histórico, social, cultural e relacional.

De acordo com a compreensão desta Teoria, as pessoas em desenvolvimento interagem com ambientes ecológicos. Entendendo-se ambiente ecológico como um 
conjunto de estruturas (pessoas, instituições, sentimentos e relações) entrelaçadas e interconectadas. Numa indicação de que as características pessoais mantêm influência dinâmica sobre os comportamentos e sobre a maneira como o ser humano interage e se relaciona, sendo efeito e afetando os contextos (BRONFENBRENNER, 2011; LEE, 2011; PATTON et al., 2013).

O modelo teórico de Bronfenbrenner representa uma tentativa de superação de modelos unidimensionais de compreensão do desenvolvimento humano, abordando-o a partir da interação entre fatores micro (história de vida dos pais, funcionamento e estrutura familiar) e macro (sistema sócio-econômico-político). Neste sentido, uma das primeiras mudanças paradigmáticas propostas pelo modelo bioecológico é a concepção do desenvolvimento de forma integrada e integradora (BARBOZA et al., 2009; BOELSTUDT; RENNER, 2013; MARTINS; SZYMANSKI, 2004). A teoria discute a dinâmica das relações do desenvolvimento humano entre os indivíduos e seus ambientes, ao mesmo tempo em que inclui a atividade e o tempo presentes nessa dinâmica. Inerentemente complexo, o modelo bioecológico, assim, delineia a compreensão dos processos de vida das pessoas e como elas os protagonizam. Há também um destaque para a direção do desenvolvimento que é conduzida pelos elementos objetivos e subjetivos, sem que haja sobreposição de um ou de outro, mas uma interconexão.

Conhecida, também, como Teoria dos Sistemas Ecológicos, ela propõe análises acerca do desenvolvimento humano a partir dos contextos em que as pessoas vivem. Defendendo a tese de que as pessoas criam o ambiente que tonalizam o processo de desenvolvimento. Nota-se que esse desenvolvimento ocorre por meio de processos complexos de interações recíprocas e ativas, explicado a partir do modelo teórico Processo-Pessoa-Contexto-Tempo (PPCT) (BRONFENBRENNER, 2011; MARTINS; SZYMANSKI, 2004).

Esses núcleos dinâmicos e interdependentes (PPCT) abrangem a pessoa em desenvolvimento, os recursos, as relações, os ambientes e os processos que ocorrem próximos ou mais distantes da pessoa em desenvolvimento. Permitindo, assim, que o paradigma bioecológico seja estruturado em cinco componentes/sistemas interconectados que norteiam a teoria e as pesquisas que o utilizam como referencial teórico: 1) individuais, 2) microssistema, 3) mesossistema, 4) exossistema e 5) macrossistema. Esses sistemas são concebidos como encaixados, uns dentro dos outros, 
como "um conjunto de bonecas russas", nos termos de Bronfenbrenner (2011, p.86), e podem ser ilustrados em um modelo teórico como na Figura 1.

Figura 1 - Modelo bioecológico do desenvolvimento para a criança e o adolescente. Uberaba, 2014.

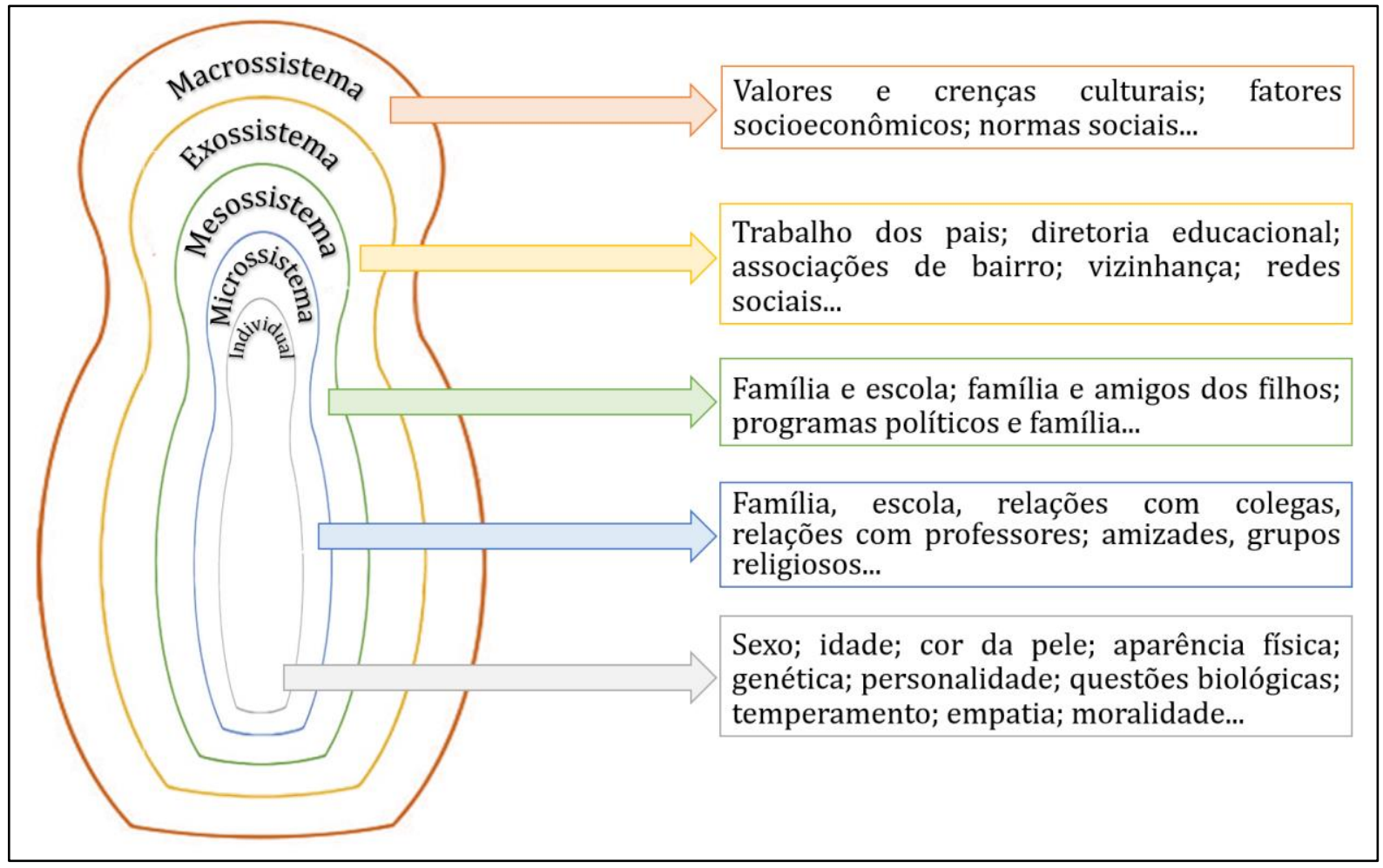

Fonte: Elaborado pelo autor (adaptado de Bronfenbrenner, 2011).

O microssistema se refere ao ambiente dentro do qual as pessoas se relacionam num contexto imediato (família e escola, separadamente, por exemplo). Bronfenbrenner propôs que a experiência nas relações interpessoais é o que melhor define o conceito de microssistema. 0 mesossistema é um conjunto de microssistemas, em interação, que influenciam no desenvolvimento e no comportamento das pessoas (família e escola em relação, por exemplo). Estes dois sistemas são considerados proximais, ao passo que os exossistemas (atividades profissionais dos pais, por exemplo), em que a pessoa em desenvolvimento não está inserida ativamente, mas aí podem ocorrer eventos que a afetam, e os macrossistemas, em que todos os outros ambientes formam uma rede de interconexões (sistema de crenças e cultura, as atitudes sociais, as políticas públicas, entre outras), são componentes mais distais do plano individual. Esses dois últimos sistemas são formados por ambientes e estruturas nos quais as pessoas em desenvolvimento não estão inseridas diretamente (BONFENBRENNER, 2011; 1996). 
Estudos identificaram ser no âmbito dos microssistemas que um maior número de variáveis assume papel na promoção ou inibição de comportamentos de bullying. 0 clima familiar, aspectos de envolvimento entre pais e filhos, métodos de comunicação e disciplina, modelos de interação e práticas de monitoria são os fatores mais relacionados ao fenômeno (HONG; ESPELAGE, 2012; LEE; SONG, 2012; LEE, 2011; SHETGIRI; LIN; FLORES, 2013; WANG et al., 2012). No nível do mesossistema, o fato dos pais conhecerem os amigos dos filhos esteve associado à diminuição dos relatos de bullying, enquanto que estudantes que percebiam que seus pais esperam resultados exagerados na escola se envolviam em situações de agressão (LEMSTRA et al., 2011; SHETGIRI et a., 2012).

De forma mais distal, a escolaridade e as horas de trabalho dos pais, bem como os níveis de violência das comunidades e vizinhança (exossistema), foram variáveis que se relacionaram com o envolvimento em situações de bullying (CHRISTIE-MIZEL et al., 2011; FU; LAND; LAMB, 2013; KIM et al., 2009; LIEN; WELANDER-VANT, 2013). No componente macrossistema, revelou-se que as crenças sociais e culturais sobre a violência, bem como a desigualdade social, contribuíam com a ocorrência do bullying (CHAUX; MOLANO; PODLESKY, 2009; CUERVO et al., 2012; FINKELHOR et al., 2009; JANSEN et al., 2012; JANSEN et al., 2011; LEREYA; WOLKE, 2013). Na Figura 2 são resumidos os principais achados na literatura sobre a interface entre a família e o bullying.

Figura 2 - Modelo bioecológico para a interface bullying e família. Uberaba, 2014.

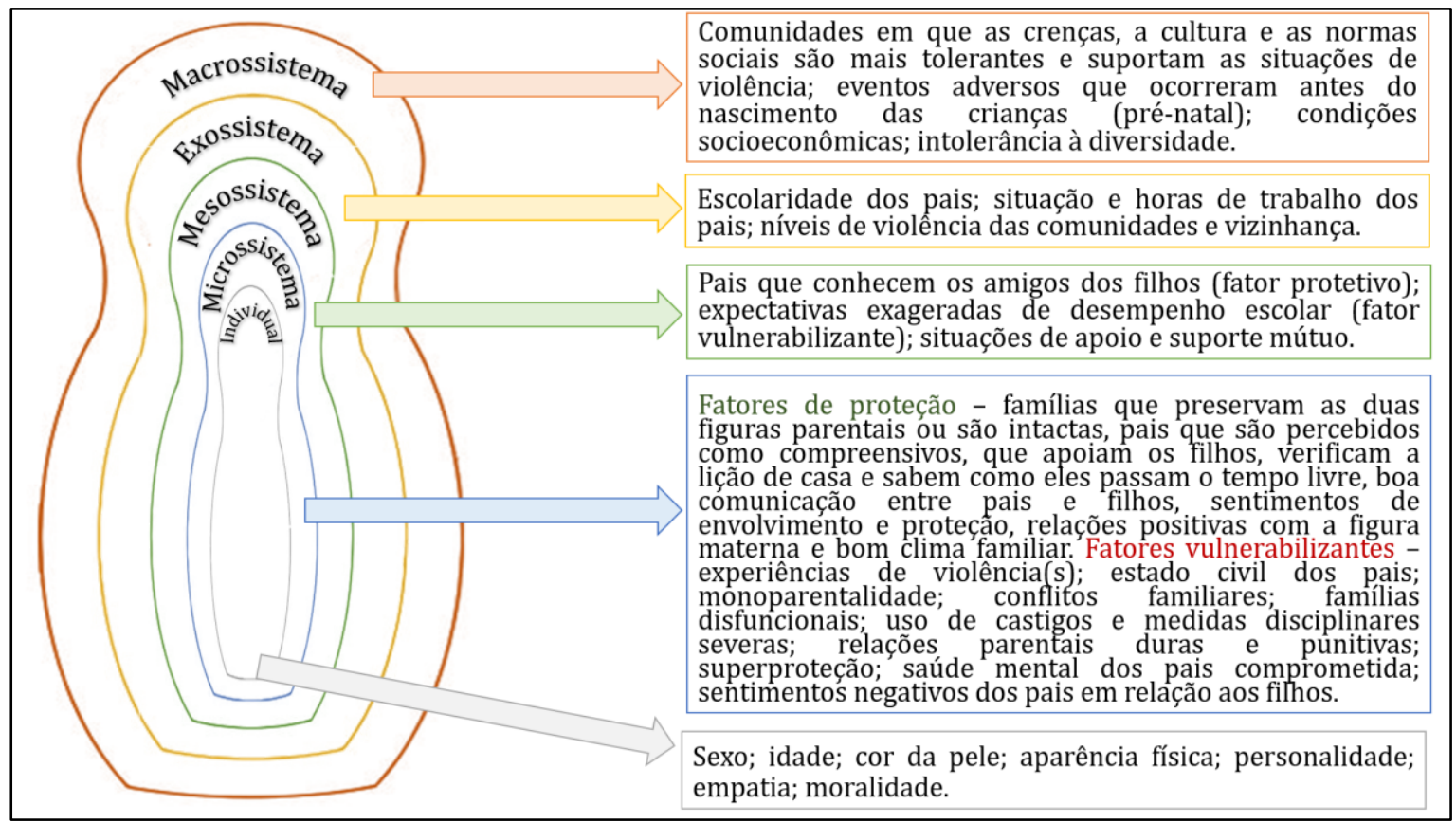

Fonte: Elaborado pelo autor. 
Destaca-se que, para a Teoria Bioecológica, o desenvolvimento, também, é determinado pelas experiências que ocorrem em determinado tempo e momento histórico, contextualizadas em um local. Aqui há outro conceito ampliado pela Teoria Bioecológica que incorpora em suas análises a noção de setting ${ }^{6}$ (ambiente, cenário, local, afetos) numa perspectiva que integra a força dos fenômenos que são percebidos, protagonizados e modificados pelas pessoas em todos os momentos do ciclo vital, e, a experiência, pertence à esfera subjetiva que reúne aspectos emocionais e afetivos, relacionados à pessoa em si, aos outros e à família (BONFENBRENNER, 2011).

Neste modelo contextual de compreensão do desenvolvimento, a experiência imediata de um indivíduo é mais crítica e produz mais influência em um microssistema. Dessa forma, para crianças e adolescentes, quatro microssistemas terminam sendo determinantes no processo de desenvolvimento: 1) família; 2) relações com professores; 3) relações com pares; e 4) contexto escolar. Nota-se que, segundo Bronfenbrenner (2011), a família é o setting mais importante para o desenvolvimento de crianças e adolescentes. A literatura científica (BARBOZA et al., 2009; BAYRAKTAR, 2012; GEORGIOU; FANTI, 2010; LEE, 2011; PATTON et al., 2013) indica, ainda, que as interações de escolares na família, com os colegas e nos contextos da escola são vistos como influências do microssistema para o desenvolvimento humano, saudável ou disruptivo (perturbado ou inadequado).

Especificamente, no que se refere à abordagem do bullying e das interações familiares, a partir do referencial bioecológico, percebe-se a oferta de dois benefícios epistemológicos. A teoria 1) sustenta a possibilidade de testar a influência do contexto familiar no envolvimento em situações de bullying, e 2) avalia de maneira contextual o clima e a violência escolar. São favorecidas, ainda, abordagens acerca das características individuais, experiências com o bullying e na família, envolvimento familiar e aspectos dos ambientes escolares investigados. Sopesando, também, o conceito de setting proposto pela Teoria Bioecológica, a ênfase na percepção dos adolescentes (nível individual) sobre seus contextos familiares numa investigação, corrobora a tese de que o que importa no processo de desenvolvimento das pessoas é o ambiente percebido e não a sua maneira de existir na realidade objetiva (BRONFENBRENNER, 2011). Esse modelo desvela a

\footnotetext{
${ }^{6} \mathrm{Na}$ teoria psicanalítica o conceito de setting se refere ao enquadre do processo analítico, reunindo todos os elementos e procedimentos que o organizam e normatizam. Trata-se de um espaço que serve de cenário para a reprodução ou a vivência de novas experiências emocionais em que os vínculos são essenciais em sua determinação (ZIMERMAN, 1999).
} 
importância de se pesquisar como o contexto, os fenômenos e a atividade humana são para as pessoas. Desse modo, os significados e a produção acadêmica baseada nesse modelo aborda fatores individuais e ambientais em correlação, superando paradigmas udimensionais (do singular para o plural).

Assim sendo, sumarizados aspectos teóricos sobre bullying, família e os principais elementos do referencial bioecológico, nas próximas seções serão apresentados os objetivos, hipóteses, pressupostos e o percurso metodológico adotado no presente estudo. 
Anos de estudo e pesquisas:

Era no amanhecer

Que as formigas escolhiam seus vestidos.

(A descoberta)

Manoel de Barros (2010, p. 163) 


\section{OBJETIVOS}

Objetivo geral: Analisar e compreender, a partir da perspectiva de estudantes adolescentes, a relação entre a qualidade das interações familiares e o envolvimento em práticas e vitimização por bullying escolar.

\section{Objetivos específicos:}

1. Caracterizar o bullying escolar entre adolescentes de escolas públicas para identificar agressores, vítimas, vítimas-agressoras e não-envolvidos;

2. Avaliar a qualidade das interações familiares dos adolescentes participantes;

3. Comparar as médias da qualidade das interações familiares entre os grupos de estudantes agressores, vítimas, vítimas-agressoras e não-envolvidos em situações de bullying;

4. Identificar dimensões da qualidade das interações familiares de adolescentes associadas e preditoras para o bullying escolar;

5. Identificar dimensões da qualidade das interações familiares protetivas para o bullying escolar;

6. Compreender os sentidos e significados atribuídos por adolescentes às interações familiares na construção de práticas e vitimização por bullying 
Depende a criatura para ter grandeza de sua infinita deserção. A gente é cria de frases! Escrever é cheio de casca e de pérola. Ai desde gema sou borra. Alegria é apanhar caracóis nas paredes bichadas!

Coisa que não faz nome para explicar. Como a luz que vegeta na roupa do pássaro.

Manoel de Barros (2010, p. 177) 


\section{HIPÓTESES E PRESSUPOSTOS}

Diante das inquietações que precederam a proposta de pesquisa, seguindo o modelo bioecológico do desenvolvimento como referencial teórico, e com base nos conhecimentos disseminados sobre a relação entre bullying e aspectos familiares, foram formuladas as seguintes hipóteses:

- Não há diferenças entre os grupos de estudantes agressores, vítimas, vítimasagressoras e não-envolvidos em situações de bullying no que se refere às dimensões de qualidade das interações familiares $\left(\mathrm{H}_{0}\right)$.

- Há diferenças entre os grupos de estudantes agressores, vítimas, vítimasagressoras e não-envolvidos em situações de bullying no que se refere às dimensões de qualidade das interações familiares $\left(\mathrm{H}_{1}\right)$.

- Estudantes não-envolvidos em situações de bullying apresentam melhores índices de qualidade das interações familiares $\left(\mathrm{H}_{2}\right)$.

- Comunicação negativa, clima conjugal negativo e punição física são dimensões da interação familiar associadas e preditoras para o status dos estudantes identificados como agressores, vítimas e vítimas-agressoras $\left(\mathrm{H}_{3}\right)$.

- Envolvimento, regras e monitoria, comunicação positiva, clima conjugal positivo, modelo e sentimento dos filhos em relação aos pais/responsáveis são dimensões da interação familiar protetivas e contribuem para o não envolvimento dos estudantes em situações de bullying escolar $\left(\mathrm{H}_{4}\right)$.

Além dessas hipóteses que foram testadas, em sua abordagem qualitativa, o estudo considerou os seguintes pressupostos teóricos:

1. Interações familiares em que o afeto é negligenciado, o clima conjugal e o sentimento dos filhos em relação aos pais são negativos contribuem para a gênese e/ou envolvimento de adolescentes com bullying;

2. Demonstrações de falta de controle emocional, comportamentos incoerentes e interações violentas são exemplos negativos para os filhos e se convertem em fatores de vulnerabilidade para o envolvimento em práticas de bullying;

3. A participação, o envolvimento com a vida dos filhos, a comunicação positiva e o favorecimento da autonomia são fatores de proteção para o bullying e a vitimização. 
Há quem receite a palavra ao ponto de osso, de oco; ao ponto de ninguém e de nuvem. Sou mais a palavra com febre, decaída, fodida, na sarjeta.

Sou mais a palavra ao ponto do entulho. Amo arrastar algumas no caco de vidro, envergá-las pro chão corrompe-las até que padeçam de mim e me sujem de branco.

Sonho exercer com elas o ofício criado: usá-las como quem usa brincos.

Manoel de Barros (2010, p. 172) 


\section{MÉTODO}

Este estudo transversal de base populacional foi fundamentado nas abordagens quantitativa e qualitativa. Nesse sentido, a perspectiva da triangulação de métodos, cuja tônica é a convergência de estratégias mistas, favoreceu a conjugação das abordagens adotadas, além de auxiliar na compreensão de dimensões de contexto, os significados mais profundos e nuances das inter-relações que propiciam o desenvolvimento do fenômeno social em análise. A triangulação se constitui como conceito central na integração metodológica e não se refere apenas às formas de combinar métodos qualitativos entre si ou de articular métodos quantitativos e qualitativos, mas à ampliação das atividades de pesquisa capaz de considerar as questões em estudo a partir de (pelo menos) dois pontos. A coleta de dados quantitativos e qualitativos foi concorrente e sua integração ocorreu na fase de interpretação e análise dos dados (FLICK, 2009; GOMES et al., 2005).

\subsection{Cenário do estudo}

A investigação foi desenvolvida em Uberaba/MG, cuja estimativa populacional era de 325.279 habitantes em 2014 (INSTITUTO BRASILEIRO DE GEOGRAFIA E ESTATÍSTICA, 2016). A partir de 1990, um estudo dividiu a cidade em três distritos sanitários que organizam os serviços e as equipes de atenção à saúde (SILVA; RAMIRES, 2008). Nesta pesquisa, foram incluídas escolas localizadas nos Distritos Sanitários I, II e III. A seleção da cidade ocorreu por conveniência pela facilidade de acesso às escolas, considerando a experiência do pesquisador responsável na localidade. Embora o município tenha sido selcionado pelo critério de conveniência, o fato da amostra ser probabilística preveniu a ocorrência de vieses sistemáticos de seleção no estudo.

Na época da coleta de dados a cidade contava com 34 escolas públicas e estaduais no meio urbano que ofereciam o ensino fundamental ( $6^{\circ}$ ao $9^{\circ}$ ano) e médio ( $1^{\circ}$ ao $3^{\circ}$ ano) no turno matutino, totalizando 12.140 estudantes matriculados nesse período. Para o estudo em tela foram excluídas as escolas cujas características produziriam vieses no 
trabalho (escolas militar, rural e de tempo integral). 0 turno matutino foi priorizado por se considerar a faixa etária dos participantes do estudo e sua concentração neste horário escolar. A concepção etária prevista pela Organização Mundial da Saúde, que compreende a adolescência como momento do desenvolvimento circunscrito entre os 10 e os 19 anos (WORLD HEALTH ORGANIZATION, 2015), foi adotada na seleção dos participantes.

\subsection{Participantes}

A amostra do estudo foi definida pela seleção de estratos (escolas), utilizando o método de "Amostragem com Probabilidade Proporcional ao Tamanho" - PPS (Probability Proportional to Size) (BOLFARINE; BUSSAB, 2005; SZWARCWALD; DAMACENA, 2008). A principal característica desse método de amostragem é a probabilidade de cada estrato (escola) ser selecionado para a amostra, considerando o tamanho (número de estudantes), as dimensões e organizações geográficas de cada estrato (BOLFARINE; BUSSAB, 2005; SZWARCWALD; DAMACENA, 2008).

O processo de definição da amostra seguiu os seguintes passos: 1) cálculo do tamanho da amostra pelo método de amostragem aleatória simples; 2) cálculo da variância do estimador do método de amostragem aleatória simples; 3) cálculo da variância do estimador do método de amostragem com probabilidade proporcional ao tamanho (PPT); 4) cálculo da perda de eficiência (deff); e 5) multiplicação do tamanho amostral obtido pela medida deff, dividido pelo número total de escolas (BOLFARINE; BUSSAB, 2005). Os parâmetros utilizados foram nível de significância (alfa de Cronbach) igual a 0,05 e precisão igual a 0,05. Nesse modelo de definição da amostragem não foram consideradas perdas, pois um estrato (escola) que não aceitasse participar do estudo seria substituto por outro sorteado sucessivamente. 0 cálculo foi realizado no software $\mathrm{R}$ versão 3.0.2 (R CORE TEAM, 2013).

Dessa forma, a amostra probabilística foi estratificada entre os três distritos sanitários do município e assim se configurou: duas escolas no Distrito I; cinco escolas no Distrito II; e quatro escolas no Distrito III. Em seguida, para o sorteio específico das instituições em cada distrito foi gerada uma tabela de números aleatórios atribuídos às escolas e seus respectivos distritos no software $R$ versão 3.0.2 (R CORE TEAM, 2013). Nas 
11 instituições componentes da amostra, por conveniência, todos os alunos foram convidados para participar do estudo, sendo informados e esclarecidos sobre os objetivos da pesquisa. Cada membro da população total tinha uma chance conhecida para compor a amostra final, mas foram considerados os seguintes critérios de inclusão: 1) ter idade entre 10 e 19 anos; e 2) estar regularmente matriculado em um dos anos escolares compreendidos pelo estudo, ou sejam, do sexto ao nono ano do Ensino Fundamental e do primeiro ao terceiro ano do Ensino Médio. Os critérios de exclusão observados foram: 1) ter menos de 10 anos ou mais de 19 anos; 2) estar regularmente matriculado em anos escolares inferiores aos definidos para o estudo ( $<6^{\circ}$ ano do ensino fundamental); e 3 ) deixar questionários incompletos.

Os dados consolidados ${ }^{7}$ da Secretaria Regional de Educação de Minas Gerais de 2012 indicavam que essas escolas contavam com 3.161 estudantes matriculados no turno matutino e cursando do $6^{\circ}$ ano do ensino fundamental ao $3^{\circ}$ ano do ensino médio, número estimativo da população do estudo. Estavam presentes nas aulas nos dias em que a coleta de dados ocorreu 2.729 estudantes, totalizando 432 perdas por falta. Outros 71 estudantes se recusaram a participar do estudo. Perdas relacionadas à falta de entrega dos termos de consentimento e/ou assentimento somaram 304. Não houve perdas por erros no preenchimento das escalas utilizadas no estudo. Assim a amostra do estudo foi composta por 2.354 estudantes.

Do total de participantes, cinco estudantes de cada escola foram sorteados aleatoriamente para a etapa qualitativa $(n=55)$. Os critérios para participação nessa etapa da pesquisa foram: 1) ter completado o preenchimento das escalas na etapa quantitativa; e 2) estar presente em aula no dia da entrevista. Não houve recusas entre os estudantes sorteados para as entrevistas semiestruturadas.

\subsection{Procedimentos}

Previamente foi solicitado à Secretaria Estadual de Educação de Minas Gerais (SEE/MG) autorização para o desenvolvimento da pesquisa em Uberaba/MG, bem como

\footnotetext{
7 Dados não divulgados publicamente (mediante solicitação) e fornecidos para uso exclusivo nessa pesquisa.
} 
os dados relacionados ao número de escolas e estudantes matriculados no município. Determinada a população alvo a partir desses elementos, passou-se à definição do grupo amostral. Empiricamente, as 11 escolas selecionadas foram contatadas separadamente e os objetivos, bem como os procedimentos de pesquisa, foram apresentados aos diretores e coordenadores pedagógicos que autorizaram seu desenvolvimento em suas instituições. Não houve recusas. A coleta de dados ocorreu, em média, durante uma semana em cada escola e durante o horário das aulas no turno matutino, entre os meses de agosto e outubro de 2014. O pesquisador responsável conduziu a coleta e orientou alunos, responsáveis e corpo docente sobre aspectos referentes ao projeto de pesquisa, seus objetivos, instrumentos e aos termos de consentimento e assentimento. A coleta de dados contou, ainda, com a colaboração voluntária de três estudantes do curso de Psicologia da Universidade de Uberaba.

No primeiro contato com os estudantes se apresentava os objetivos e os procedimentos do estudo. Em seguida, eram apresentados os termos de consentimento livre e esclarecido (TCLE) (Apêndice C) e assentimento (Apêndice D) para que os estudantes levassem para casa, avaliassem a pertinência de adesão ao estudo e retornassem com os termos assinados. Foram disponibilizados, também, termos de consentimento (Apêndice B) para que os adolescentes maiores de 18 anos manifestassem a concordância de participação na investigação com suas assinaturas. Todos os estudantes presentes eram convidados a participar da pesquisa. Na sequência eram aplicadas a "Escala de Vitimização e Agressão entre Pares" (EVAP) (CUNHA; WEBER; STEINER NETO 2011) (Anexo A) em todos os adolescentes em condições de adesão ao estudo para que fossem identificados aqueles envolvidos em situações de bullying (agressores, vítimas e vítimas-agressoras). Em seguida, eles respondiam a "Escala de Qualidade na Interação Familiar" (EQIF) (WEBER; SALVADOR; BRANDENBURG, 2011) (Anexo B). A aplicação das escalas durava, em média, 50 minutos (1 aula), em cada turma.

Os questionários obtidos a partir da aplicação das escalas foram submetidos a uma revisão pelo pesquisador responsável, com o objetivo de identificar inconsistências ou erros. Optou-se por uma validação via dupla digitação e todos os questionários foram digitados e redigitados no programa Excel para que, em caso de discordâncias, o pesquisador responsável realizasse a correção. A análise dos dados ocorreu no Statistical Package for Social Sciences versão 21.0 (SPSS INC, 2012) e contou com assessoria específica. 
Do grupo de respondentes das escalas, foram sorteados os estudantes para as entrevistas semiestruturadas que ocorreram, também, nas escolas, conduzidas pelo pesquisador responsável, em salas reservadas, sem a presença de professores ou outros estudantes. As entrevistas seguiram um roteiro (Apêndice A) previamente definido de acordo com a literatura científica, discussão em banca de qualificação e com as orientadoras da pesquisa. Nesse momento, procurou-se analisar os sentidos e significados atribuídos pelos adolescentes às suas interações familiares na construção de práticas de violência, na prevenção ou no enfrentamento destas. 0 tempo médio de cada entrevista foi de 12 minutos, com variação entre 6 e 26 minutos. As entrevistas foram gravadas em um smartphone e transcritas na íntegra. $\mathrm{Na}$ análise das narrativas se utilizou o software Atlas.TI (FRIESE, 2015).

Na Figura 3 está apresentado o fluxograma dos procedimentos adotados na pesquisa.

Figura 3 - Fluxograma dos procedimentos de pesquisa. Uberaba, 2014.

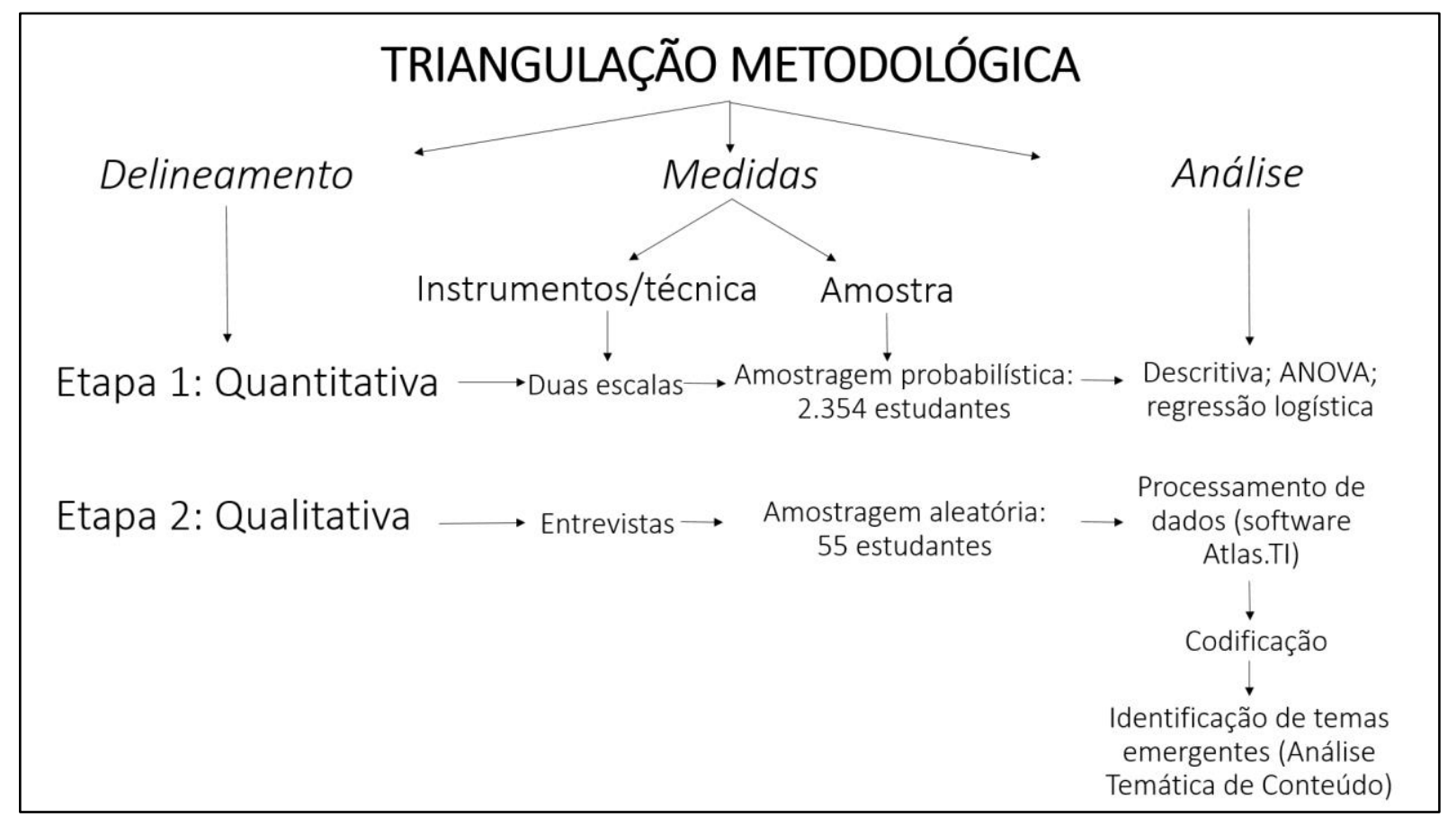

Fonte: Elaborado pelo autor. 


\subsection{Instrumentos e técnica de pesquisa}

\subsubsection{Escala de Agressão e Vitimização entre Pares (EVAP)}

Instrumento nacional, validado e publicado de auto-relato desenvolvido para investigar a agressão entre pares no contexto escolar. As principais características da EVAP são: a) o uso de enunciados descrevendo comportamentos agressivos específicos que podem ocorrer no contexto escolar, delimitando os últimos seis meses como período de avaliação; b) a escala contém 18 questões afirmativas (eu provoquei colegas; eu xinguei colegas; colegas roubaram, mexeram ou estragaram minhas coisas; eu incentivei colegas a brigarem, por exemplo), distribuídas em quatro dimensões (agressão direta, agressão relacional, ataques à propriedade e vitimização); c) os itens da escala são avaliadas em sistema Likert de 5 pontos medindo a frequência dos comportamentos estudados (1nunca; 2-quase nunca; 3-às vezes; 4-sempre; 5-quase sempre) (CUNHA; WEBER; STEINER NETO, 2011). 0 instrumento não permite identificar estudantes que observaram ou testemunharam situações de bullying na escola. 0 uso desse instrumento, disponível em publicação de livre circulação, foi autorizado pela autora principal.

Para sua aplicação nesse estudo, ainda, a escala foi adaptada, com autorização da autora, e se inseriu a seguinte definição de bullying em seu cabeçalho: "O que é bullying? Bullying são comportamentos e atitudes agressivas, intencionais e repetitivas, que ocorrem sem motivação evidente, que causam dor e angústia, tais como: apelidar, bater, ignorar, ameaçar, humilhar, empurrar, amedrontar, xingar, roubar, isolar, maltratar, fofocas, espalhar mensagens que ridicularizam os colegas etc.. Não é bullying quando dois colegas, que tenham mais ou menos a mesma força, lutam ou brigam entre si”. Essa adaptação ocorreu para atender perspectivas da literatura internacional que orientam a inclusão da definição do fenômeno nos estudos exploratórios sobre a questão (BREIVIK; OLWEUS, 2015; CARAVITA; GINI, 2010; KUBISZEWSKI et al., 2014; OLWEUS, 1993).

A estrutura da escala, em relação ao grupo amostral, foi testada por meio de análise fatorial. 0 grau de ajuste dos dados à análise fatorial foi verificado pelos testes KMO $(0,90 \text { e } 0,89)^{8}$ e Bartlett's Test $(\mathrm{p}=0,000)^{9}$ que indicaram a adequação do método

\footnotetext{
${ }^{8}$ Para interpretação dos valores do teste KMO (Kaiser-Meyer-Olkin) se considera que valores próximos a 1,00 indicam que o método da análise fatorial é perfeitamente adequado para o tratamento dos dados e valores menores que 0,05 indicam a inadequação do uso do método.

${ }^{9}$ Baseado na distribuição estatística do qui-quadrado, o Bartlett's Test testa a hipótese nula de que a matriz de correlação é uma matriz identidade, ou seja, de que não há correlação entre as variáveis. Valores de
} 
para o tratamento das escalas. Nessa análise, os 10 itens que avaliam a agressividade dos estudantes alcançaram índice de consistência interna (alfa de Cronbach) no valor 0,83, e os nove itens da escala de vitimização apresentaram alfa de Cronbach no valor de 0,84.

Na Tabela 1 é apresentada uma síntese dessa análise.

Tabela 1 - Resultados da análise fatorial exploratória dos itens da Escala de Agressão e Vitimização entre Pares (EVAP). Uberaba, 2014.

\begin{tabular}{lcccccc}
\hline \multicolumn{1}{c}{ Escalas } & M & DP & $\begin{array}{c}\text { Variância } \\
\text { explicada }\end{array}$ & Teste KMO & $\begin{array}{c}\text { Bartlett's } \\
\text { Test }\end{array}$ & $\alpha$ \\
\hline Agressão & & & 40,15 & 0,90 & 0,000 & 0,83 \\
1. Agressão verbal & 2,19 & 1,12 & & & & \\
2. Agressão física & 2,04 & 1,27 & & & & \\
3. Agressão física & 1,58 & 1,00 & & & & \\
4. Agressão verbal & 1,50 &, 093 & & & & \\
5. Agressão física & 1,26 & 0,78 & & & & \\
6. Agressão verbal & 2,41 & 1,25 & & & & \\
7. Agressão indireta & 1,69 & 1,02 & & & & \\
8. Agressão verbal & 2,05 & 1,25 & & & & \\
9. Agressão indireta & 1,72 & 1,17 & & & \\
10. Agressão verbal & 2,39 & 1,35 & & & & \\
Vitimização & & & 48,51 & 0,89 & & \\
11. Vitimização & 2,65 & 1,35 & & & \\
12. Vitimização & 1,49 & 0,96 & & & \\
13. Vitimização & 1,51 & 0,96 & & & \\
14. Vitimização & 2,02 & 1,30 & & & \\
15. Vitimização & 2,22 & 1,29 & & & \\
16. Vitimização & 1,67 & 1,03 & & & \\
17. Vitimização & 2,26 & 1,36 & & & \\
18. Vitimização & 2,44 & 1,35 & & & \\
\hline
\end{tabular}

Fonte: Elaborado pelo autor.

Notas: M = Média; DP = Desvio Padrão

\subsubsection{Escala de Qualidade de Interação Familiar (EQIF)}

Instrumento nacional, validado e publicado que avalia aspectos do relacionamento da família por meio do relato de crianças ou adolescentes, sobre a interação com os pais (combinados ou pai e mãe separadamente), abordando nove fatores da interação familiar (WEBER; SALVADOR; BRANDENBURG, 2011):

significância maiores que 0,01 indicam que os dados não são adequados para o tratamento com o método de análise fatorial. Já valores menores que 0,01 permitem rejeitar a hipótese nula e indicam a adequação do método de análise fatorial no tratamento dos dados. 
1. Envolvimento: os itens dessa dimensão investigam se os pais apoiam os filhos, são sensíveis às suas demandas e estão presentes em seu dia a dia. Nessa dimensão, também, está incluída a demonstração de afeto, carinho e amor dos pais em relação aos filhos.

2. Regras e monitoria: são medidos dois aspectos nessa dimensão: i) existência de normas e regras estabelecidas para que o filho cumpra em casa; e ii) a supervisão do cumprimento das normas estabelecidas e monitoramento das atividades dos filhos;

3. Punição corporal: corresponde à avaliação sobre técnicas de disciplina e correção de comportamentos inadequados utilizadas pelos pais e baseadas na agressão física;

4. Comunicação positiva: verifica a existência de diálogos construtivos e se há abertura para que os filhos possam conversar com os pais;

5. Comunicação negativa: investiga maneiras inadequadas (forma e conteúdo) dos pais dialogarem com os filhos, bem como a falta de controle emocional dos pais;

6. Clima conjugal positivo: avalia a boa relação entre o casal parental;

7. Clima conjugal negativo: avalia se o casal parental interage de forma agressiva ou negativa;

8. Modelo parental: verifica se os pais são exemplos positivos para os filhos.

9. Sentimento dos filhos: de nível subjetivo, avalia como os filhos se sentem em relação aos pais.

No total, são quarenta itens, mensurados por meio de um sistema Likert de 5 pontos (1-nunca; 2-quase nunca; 3-às vezes; 4-sempre; 5-quase sempre). São exemplos de questões afirmativas da escala: meus pais fazem carinho um no outro; meus pais costumam me xingar ou falar palavrões para mim; quando ajudo meus pais eles me agradecem; meus pais costumam me criticar de forma negativa. Os escores brutos das respostas dos participantes sobre seus pais e mães são computados e subsidiam análises que permitem mensurar a qualidade das interações familiares nas dimensões da escala (WEBER; SALVADOR; BRANDENBURG, 2011). 0 uso desse instrumento, disponível em publicação de livre circulação, também foi autorizado pela autora principal.

Nessa escala foi realizada uma adaptação para incluir no estudo estudantes que não viviam com os pais ou viviam em famílias recompostas (pai e madrasta, mãe e padrasto, por exemplo). Nesse sentido, foi incluída uma coluna para que os estudantes respondessem a escala se referindo a "outra pessoa", que era nomeada no cabeçalho do instrumento. Essa adaptação contou com a autorização da autora principal. 
A estrutura da escala para a amostra do estudo também foi testada por meio da análise fatorial que verificou o grau de ajuste dos dados (KMO - 0,86 e 060; Bartlett's Test - $\mathrm{p}=0,000$ ). Resultados dessa análise estão apresentados na Tabela 4.

Tabela 2 - Resultados da análise fatorial exploratória dos itens da Escala de Qualidade de Interação Familiar (EQIF). Uberaba, 2014.

\begin{tabular}{lrccccc}
\hline \multicolumn{1}{c}{ Escalas } & M & DP & $\begin{array}{c}\text { Variância } \\
\text { explicada }\end{array}$ & Teste KMO & $\begin{array}{c}\text { Bartlett's } \\
\text { Test }\end{array}$ & $\alpha$ \\
\hline Positiva & & & 59,52 & 0,86 & 0,00 & 0,84 \\
$\quad$ Envolvimento & 3,90 & 0,92 & & & & \\
$\quad$ Regras e monitoria & 4,14 & 0,80 & & & & \\
$\quad$ Comunicação positiva & 2,97 & 1,11 & & & & \\
$\quad$ Clima conjugal positivo & 3,17 & 1,25 & & & & \\
$\quad$ Modelo & 3,93 & 0,91 & & & & \\
$\quad$ Sentimentos dos filhos & 4,41 & 0,80 & & & 0,65 \\
Negativa & & & 58,98 & 0,60 & & \\
$\quad$ Comunicação negativa & 2,16 & 0,92 & & & & \\
$\quad$ Clima conjugal negativo & 2,05 & 0,98 & & & & \\
$\quad$ Punição física & 1,60 & 0,82 & & & & \\
\hline Fonte: Elaborado pelo autor & & & & & \\
\hline
\end{tabular}

Fonte: Elaborado pelo autor.

Notas: $\mathrm{M}$ = Média; $\mathrm{DP}=$ Desvio Padrão

Os índices de consistência interna (alfa de Cronbach) das nove dimensões avaliadas nas duas escalas atingiram 0,65 (escala negativa) e 0,84 (escala positiva), apresentando índices satisfatórios de confiabilidade para o tamanho amostral e o tipo de estudo desenvolvido (exploratório e transversal) (HAIR et al., 2009).

\subsubsection{Entrevistas semiestruturadas}

A entrevista é uma técnica utilizada na coleta de dados como prática discursiva oriunda de ações contextualizadas que provocam a construção de sentidos, reflexões e interpretações, além de favorecer a construção de inferências científicas (MINAYO, 2012). Um roteiro baseado em estudos relacionados à pesquisa qualitativa e ao bullying (MINAYO, 2014; MINAYO, 2012; MINAYO, 2010; THORNBERG, 2011; THORNBERG; KNUTSEN, 2011) foi construído para orientar as entrevistas e sintetizou indicadores do estudo, quais sejam: 1) tipos de interação familiar, a forma como se configuram e os sentimentos a elas relacionados; 2) o que consideram bullying; 4) sentimentos relacionados à prática do bullying ou vitimização; 5) como resolvem seus problemas ou as situações de bullying (se recorrem a adultos e/ou amigos); 6) as percepções de si, da 
vida e sobre possíveis figuras de apego do contexto familiar. São exemplos de perguntas constantes no roteiro:

- Fale-me como é sua relação com seus pais?

- Para você o que é bullying?

- Você alguma vez ameaçou, maltratou, humilhou ou agrediu outro colega na escola?

- Você contou para alguém quando esses fatos aconteceram?

- Você acha que a maneira como as coisas acontecem na sua casa influencia no que acontece na escola com você?

Também, foram utilizadas perguntas de acompanhamento para esclarecer, ilustrar ou aprofundar as respostas dos participantes (Como assim? Você poderia me dizer mais sobre isso? 0 que você quer dizer? Você poderia me dar exemplos?).

\subsection{Análise dos dados}

\subsubsection{Análise quantitativa}

Todos os dados coletados nas duas escalas aplicadas foram digitados no programa Excel e posteriormente importados para o software Statistical Package for the Social Sciences versão 21.0 (SPSS INC, 2012). Optou-se pela recomendação teórica e se presumiu a distribuição normal das variáveis considerando o grande conjunto de dados (LUMLEY et al., 2002).

O plano analítico se iniciou com a exploração descritiva dos dados para caracterizar o grupo amostral em termos de frequências absolutas e relativas (\%), medidas de tendência central (média, moda e mediana, por exemplo) e medidas de variabilidade (desvio padrão) (DANCEY; REIDY, 2013). Para identificar as categorias de envolvimento em situações de bullying entre os estudantes foi utilizada a análise de agrupamento K-means clustering que permitiu a divisão dos participantes em quatro grupos (clusters) (CUNHA; WEBER; STEINER NETO 2011; DANCEY; REIDY, 2013).

As diferenças e igualdades entre as médias dos grupos de envolvimento em situações de bullying (agressor, vítima, vítima-agressora e não-envolvimento), em relação às nove dimensões da qualidade de interação familiar (envolvimento, regras e monitoria, punição física, comunicação positiva, comunicação negativa, clima conjugal positivo, 
clima conjugal negativo, modelo e sentimento dos filhos), foram verificadas pela análise de variância ANOVA e o post hoc de Turkey (Z) (FIELD, 2009). Nessas análises, adotou-se o nível de significância $\mathrm{p}<0,05$.

Fatores preditores para o bullying e a vitimização foram analisados por meio de modelos de regressão logística (DANCEY; REIDY, 2013; FIELD, 2009). Nesse sentido, quatro modelos de regressão foram testados para entender a relação entre as variáveis independentes (sexo, idade e as nove dimensões de qualidade da interação familiar envolvimento, regras e monitoria, punição física, comunicação positiva, comunicação negativa, clima conjugal positivo, clima conjugal negativo, modelo e sentimento dos filhos) e os quatro diferentes grupos de envolvimento com situações de bullying (agressor, vítima, vítima-agressora e não-envolvimento), incluídos nos modelos como variáveis dependentes. Ajustes indicaram que somente a forma combinada (qualidade da interação familiar geral) era adequada para uso nos modelos. Foram calculados as razões de chances, intervalo de confiança de 95\% e valor $p$ resultante do teste de Wald, para cada variável independente. Também foram computados o $X^{2}$ e $\mathrm{r}^{2}$ de Nagelkerke ${ }^{10}$ para determinar se os modelos eram significativos e para estimar a variância da variável dependente que pode ser explicada pelas variáveis independentes.

\subsubsection{Análise qualitativa}

As transcrições das entrevistas foram importadas para o software Atlas.TI versão 7 (FRIESE, 2015) e o processo de análise envolveu dois níveis: 1) desenvolvimento de códigos a partir da leitura exaustiva das entrevistas (138 códigos criados a partir da seleção de 477 citações); e 2) construção de categorias temáticas segundo os princípios da análise de conteúdo, em sua modalidade temática (BARDIN, 2011; CHAVEZ; YAMAMOTO, 2014). 0 pesquisador responsável assumiu o papel de codificador principal (primary coder) e aplicou o esquema de desenvolvimento dos códigos, e um segundo investigador voluntário (shadow coder) revisou a codificação e as decisões tomadas pelo codificador principal. Os dois pesquisadores se reuniram para chegar a um consenso sobre a decisão de codificação em casos de discordância.

$\mathrm{Na}$ fase de construção das categorias temáticas os códigos foram agrupados por semelhança temática em categorias mínimas que expressavam uma ideia central,

\footnotetext{
10 Teste cujo limite teórico é 1 , sendo utilizado para avaliar o poder explanatório e a capacidade de
} determinação do modelo. 
seguindo-se os seguintes passos: i) pré-análise; ii) descrição analítica; iii) interpretação inferencial (BARDIN, 2011). Seguindo as recomendações da técnica de análise de dados qualitativos adotados, o pesquisador não se fixou exclusivamente no conteúdo manifesto das informações coletadas nas entrevistas, mas procurou desvelar o conteúdo latente presente nas narrativas dos participantes (MINAYO, 2014; TRIVINOS, 2009). Dessa forma, do conjunto de dados, emergiram três categorias temáticas: 1) Inter-relações e influências familiares no que ocorre na escola; 2) Família como espaço para o desenvolvimento ético e moral; 3) Sinergias ${ }^{11}$ e enfrentamento de base familiar e escolar. Bullying e escola foram as variáveis centrais e em relação com as categorias construídas ${ }^{12}$.

\subsubsection{Referencial teórico de análise}

0 processo de análise e interpretação dos resultados foi orientado pelos aportes da Teoria Bioecológica do Desenvolvimento de Urie Bronfenbrenner $(2011 ; 1996)$. Neste sentido, a percepção dos adolescentes, referenciada analiticamente por essa perspectiva, favoreceu a compreensão do bullying a partir de uma visão relacional e contextual, ao mesmo tempo em que incorporou ao estudo análises não somente das características individuais dos adolescentes (singular), mas também das interações familiares (plural) e suas influências concorrentes ao fenômeno (SENNA; DESSEN, 2012). 0 referencial teórico, também, foi constitutivo e auxiliou no processo de triangulação dos dados quantitativos e qualitativos na análise.

\subsection{Questões éticas}

Todas as fases do estudo seguiram as orientações, exigências e recomendações da Resolução 466/2012. Previamente foi solicitada à Secretaria Estadual de Educação de Minas Gerais autorização para o desenvolvimento da pesquisa em Uberaba/MG (Anexo

\footnotetext{
${ }^{11} 0$ termo sinergismo se refere a ocorrência de círculos viciosos ou benignos, no qual a operação conjunta de duas ou mais forças produz um efeito maior que a soma dos efeitos individuais. Por exemplo, a combinação dos aspectos familiares positivos e o aumento da percepção de ajuda e suporte (BRONFENBRENNER, 2011).

${ }_{12}$ Análises sobre as concepções dos adolescentes sobre bullying e sua ocorrência nas escolas não são exploradas nessa tese, mas poderão ser verificadas no artigo "Modos de explicar o bullying: análise dimensional das concepções de adolescentes" (OLIVEIRA et al., no prelo).
} 
C). 0 projeto foi submetido e aprovado pelo Comitê de Ética em Pesquisa da Escola de Enfermagem de Ribeirão Preto (EERP) da Universidade de São Paulo (USP) (Parecer: 484.912/2013 - Anexo D). Os adolescentes e seus responsáveis também forneceram, por escrito, assentimentos e consentimentos livre e esclarecido, respectivamente, para participação na pesquisa.

As escolas foram numeradas de 1 a 11 para impedir a identificação desses espaços e, além disso, foi atribuído para cada participante um número aleatório e sequencial para resguardar suas identidades. No tratamento dos dados qualitativos os nomes dos adolescentes foram substituídos por códigos relacionados ao sexo, ao número da entrevista, à idade e ao tipo de envolvimento em situações de bullying (por exemplo, participante 1: Menino 1, 17 anos, observador; participante 2: Menina 2, 12 anos, observador; participante 3: Menino 3, 13 anos, agressor; e assim sucessivamente). Doravante, esses códigos serão utilizados para fazer referências às escolas e aos participantes do estudo. 
Poeta, s.m. ef. Indivíduo que enxerga semente germinar e engole céu Espécie de um vazadouro para contradições Sabiá com trevas Sujeito inviável: aberto aos desentendimentos como um rosto

Manoel de Barros (2010, p. 182) 


\section{RESULTADOS}

\subsection{Caracterização dos participantes na etapa quantitativa}

Participaram da etapa quantitativa do estudo 2.354 estudantes do ensino fundamental e médio, com idades entre 10 e 19 anos (meninas = 50, 7\%; idade média $M$ $=14,5$ anos, $D P=2,0$ anos). Na Tabela 3 está sintetizada a caraterização dessa amostra de forma geral e por sexo considerando as idades dos participantes, o ano escolar, os arranjos familiares e as escolas selecionadas segundo os distritos sanitários do munícipio pesquisado.

A diferença de participação entre meninos e meninas foi pequena, somando apenas $1,0 \%$. No que se refere ao número de participantes por ano escolar, verificou-se que os procedimentos para definição da amostragem foram validos, uma vez que há uma distribuição uniforme, com pequenas variações entre cada grupo. Entrementes, a maioria dos estudantes estava no ensino fundamental (58,9\%), e somente os participantes que cursavam o $8^{\circ}$ e $9^{\circ}$ ano do ensino fundamental e o $1^{0}$ ano do ensino médio somaram $48,3 \%$. As maiores variações se referiram às instituições escolares (estratos), mas de acordo com o método de amostragem utilizado este aspecto não se configura como negativo. 
Tabela 3 - Caracterização dos estudantes do Ensino Fundamental e Ensino Médio de escolas públicas participantes da etapa quantitativa do estudo (total e por sexo). Uberaba, 2014.

\begin{tabular}{|c|c|c|c|c|c|c|c|c|}
\hline & \multicolumn{4}{|c|}{ Total } & \multicolumn{4}{|c|}{ Sexo } \\
\hline & \multirow{2}{*}{$\mathrm{N}$} & \multirow{2}{*}{$\%$} & \multirow{2}{*}{ Fac } & \multirow{2}{*}{ Fra } & \multicolumn{2}{|c|}{ Masculino } & \multicolumn{2}{|c|}{ Feminino } \\
\hline & & & & & $\mathrm{n}$ & $\%$ & $\mathrm{n}$ & $\%$ \\
\hline \multicolumn{9}{|l|}{ Idade } \\
\hline 10 & 15 & 0,70 & 15 & 0,70 & 12 & 0,60 & 3 & 0,10 \\
\hline 11 & 186 & 7,90 & 201 & 8,60 & 90 & 3,80 & 96 & 4,10 \\
\hline 12 & 262 & 11,10 & 463 & 19,70 & 143 & 6,00 & 119 & 5,10 \\
\hline 13 & 306 & 13,00 & 769 & 32,70 & 156 & 6,60 & 150 & 6,40 \\
\hline 14 & 361 & 15,30 & 1130 & 48,00 & 176 & 7,50 & 185 & 7,90 \\
\hline 15 & 387 & 16,40 & 1517 & 64,40 & 192 & 8,20 & 195 & 8,30 \\
\hline 16 & 403 & 17,10 & 1920 & 81,50 & 191 & 8,10 & 212 & 9,00 \\
\hline 17 & 320 & 13,60 & 2240 & 95,10 & 150 & 6,40 & 170 & 7,20 \\
\hline 18 & 98 & 4,10 & 2338 & 99,20 & 43 & 1,70 & 55 & 2,30 \\
\hline 19 & 16 & 0,80 & 2354 & 100 & 9 & 0,40 & 7 & 0,30 \\
\hline \multicolumn{9}{|l|}{ Ano escolar } \\
\hline 6o ano Ensino Fundamental & 332 & 14,10 & 332 & 14,10 & 189 & 8,00 & 143 & 6,10 \\
\hline 7o ano Ensino Fundamental & 307 & 13,00 & 639 & 27,10 & 170 & 7,20 & 137 & 5,80 \\
\hline 8o ano Ensino Fundamental & 362 & 15,40 & 1001 & 42,50 & 192 & 8,20 & 170 & 7,20 \\
\hline 9o ano Ensino Fundamental & 387 & 16,40 & 1388 & 58,90 & 183 & 7,70 & 204 & 8,70 \\
\hline 1o ano Ensino Médio & 389 & 16,50 & 1777 & 75,40 & 190 & 8,00 & 199 & 8,50 \\
\hline 2o ano Ensino Médio & 337 & 14,30 & 2114 & 89,70 & 151 & 6,40 & 186 & 7,90 \\
\hline 3o ano Ensino Médio & 240 & 10,30 & 2354 & 100 & 87 & 3,80 & 153 & 6,50 \\
\hline \multicolumn{9}{|l|}{ Arranjo familiar } \\
\hline Pai e mãe & 598 & 25,40 & 598 & 25,40 & 342 & 14,50 & 256 & 10,90 \\
\hline Pai, mãe e irmão(s) & 638 & 27,10 & 1236 & 52,50 & 286 & 12,20 & 352 & 15,00 \\
\hline Pai, mãe, irmão(s) e/ou outras pessoas & 110 & 4,70 & 1346 & 57,20 & 61 & 2,70 & 49 & 2,00 \\
\hline Somente com o pai & 43 & 1,80 & 1389 & 59,00 & 27 & 1,10 & 16 & 0,70 \\
\hline Somente com a mãe & 263 & 11,20 & 1652 & 70,20 & 149 & 6,30 & 114 & 4,80 \\
\hline Pai e outras pessoas & 67 & 3,10 & 1719 & 73,30 & 37 & 1,80 & 30 & 1,30 \\
\hline Mãe e outras pessoas & 513 & 21,60 & 2232 & 94,90 & 193 & 8,20 & 320 & 13,40 \\
\hline Outras pessoas & 122 & 5,10 & 2354 & 100 & 67 & 2,90 & 55 & 2,20 \\
\hline \multicolumn{9}{|l|}{ Distritos Sanitários } \\
\hline \multicolumn{9}{|l|}{ Distrito Sanitário I } \\
\hline Escola 1 & 111 & 4,70 & 111 & 4,70 & 63 & 2,70 & 48 & 2,00 \\
\hline Escola 2 & 454 & 19,30 & 565 & 24,00 & 217 & 9,20 & 237 & 10,10 \\
\hline \multicolumn{9}{|l|}{ Distrito Sanitário II } \\
\hline Escola 3 & 54 & 2,30 & 619 & 26,30 & 29 & 1,60 & 25 & 0,70 \\
\hline Escola 4 & 284 & 12,10 & 903 & 38,40 & 162 & 6,90 & 122 & 5,20 \\
\hline Escola 5 & 244 & 10,40 & 1147 & 48,80 & 108 & 4,60 & 136 & 5,80 \\
\hline Escola 6 & 102 & 4,30 & 1249 & 53,10 & 50 & 2,10 & 52 & 2,20 \\
\hline Escola 7 & 199 & 8,50 & 1448 & 61,60 & 104 & 4,40 & 95 & 4,00 \\
\hline \multicolumn{9}{|l|}{ Distrito Sanitário III } \\
\hline Escola 8 & 124 & 5,30 & 1572 & 66,90 & 81 & 3,40 & 43 & 1,80 \\
\hline Escola 9 & 111 & 4,70 & 1683 & 71,60 & 56 & 2,40 & 55 & 2,30 \\
\hline Escola 10 & 133 & 5,60 & 1816 & 77,20 & 55 & 2,30 & 78 & 3,30 \\
\hline Escola 11 & 538 & 22,80 & 2354 & 100 & 237 & 10,10 & 301 & 12,90 \\
\hline
\end{tabular}

Fonte: Elaborado pelo autor.

Notas: $\mathrm{Fac}=$ Frequência absoluta acumulada; Fra $=$ Frequência relativa absoluta 
Foram identificados, ainda, oito tipos de arranjos familiares entre os adolescentes, contudo a maioria dos participantes tinha em casa a presença do pai e da mãe $(57,2 \%)$. A figura materna, considerando-se todos os arranjos verificados, estava presente em $90 \%$ das famílias dos estudantes. Adolescentes que referiram viver com outras pessoas citaram avós, tios, irmãos, primos, sobrinhos, marido ou amigos.

\subsection{Caracterização dos participantes na etapa qualitativa}

$\mathrm{Na}$ fase qualitativa, participaram 55 estudantes que foram sorteados entre os partícipes da etapa quantitativa. Nesse grupo, as idades variaram entre 11 e 19 anos (Meninas $=47,0 \%$, idade média $M=15$ anos, $D P=2,0$ anos) e foram compreendidos todos os anos e instituições escolares investigadas (cinco estudantes de cada escola). Sete arranjos familiares foram referidos, sendo que a maioria dos adolescentes morava com as duas figuras parentais e em 92,0\% dos casos a mãe estava presente no contexto familiar. Outras pessoas referidas como compondo o arranjo familiar dos participantes foram: avós, tios, irmãos e primos.

Na Tabela 2 está sintetizada a caraterização desse grupo de forma geral e por sexo considerando suas idades, o ano escolar que cursavam, os arranjos familiares e as escolas selecionadas segundo os distritos sanitários do munícipio pesquisado. 
Tabela 4 - Caracterização dos estudantes do Ensino Fundamental e Ensino Médio de escolas públicas participantes da etapa qualitativa do estudo (geral e por sexo). Uberaba, 2014.

\begin{tabular}{|c|c|c|c|c|c|c|c|c|}
\hline & \multicolumn{4}{|c|}{ Total } & \multicolumn{4}{|c|}{ Sexo } \\
\hline & \multirow{2}{*}{$\mathrm{N}$} & \multirow{2}{*}{$\%$} & \multirow{2}{*}{ Fac } & \multirow{2}{*}{ Fra } & \multicolumn{2}{|c|}{ Masculino } & \multicolumn{2}{|c|}{ Feminino } \\
\hline & & & & & $\mathrm{n}$ & $\%$ & $\mathrm{n}$ & $\%$ \\
\hline \multicolumn{9}{|l|}{ Idade } \\
\hline 11 & 2 & 4,00 & 2 & 4,00 & 1 & 1,90 & 1 & 1,90 \\
\hline 12 & 7 & 13,00 & 8 & 17,00 & 2 & 3,70 & 5 & 9,60 \\
\hline 13 & 9 & 16,00 & 18 & 33,00 & 5 & 9,40 & 4 & 7,60 \\
\hline 14 & 7 & 13,00 & 24 & 46,00 & 2 & 3,70 & 5 & 9,60 \\
\hline 15 & 6 & 11,00 & 30 & 57,00 & 4 & 7,00 & 2 & 3,60 \\
\hline 16 & 11 & 19,00 & 41 & 76,00 & 8 & 14,80 & 3 & 5,60 \\
\hline 17 & 6 & 11,00 & 49 & 87,00 & 4 & 7,00 & 2 & 3,60 \\
\hline 18 & 6 & 11,00 & 54 & 98,00 & 4 & 5,50 & 2 & 3,60 \\
\hline 19 & 1 & 2,00 & 55 & 100 & 0 & 0,00 & 1 & 1,90 \\
\hline \multicolumn{9}{|l|}{ Ano escolar } \\
\hline $6^{0}$ ano Ensino Fundamental & 3 & 6,00 & 3 & 6,00 & 1 & 1,90 & 2 & 3,60 \\
\hline 7ํano Ensino Fundamental & 8 & 15,00 & 11 & 21,00 & 4 & 7,20 & 4 & 7,20 \\
\hline 8o ano Ensino Fundamental & 12 & 22,00 & 23 & 43,00 & 6 & 11,10 & 6 & 10,60 \\
\hline 9o ano Ensino Fundamental & 3 & 6,00 & 26 & 49,00 & 2 & 3,70 & 1 & 2,00 \\
\hline 1 o ano Ensino Médio & 9 & 15,00 & 35 & 64,00 & 4 & 7,00 & 5 & 9,00 \\
\hline $2^{\circ}$ ano Ensino Médio & 17 & 30,00 & 52 & 94,00 & 10 & 18,40 & 7 & 12,60 \\
\hline 3o ano Ensino Médio & 3 & 6,00 & 55 & 100 & 2 & 3,70 & 1 & 2,00 \\
\hline \multicolumn{9}{|l|}{ Arranjo familiar } \\
\hline Pai e mãe & 13 & 24,00 & 13 & 24,00 & 8 & 14,80 & 5 & 9,00 \\
\hline Pai, mãe e irmão(s) & 17 & 30,00 & 30 & 54,00 & 8 & 14,80 & 9 & 16,00 \\
\hline Pai, mãe, irmão(s) e/ou outras pessoas & 3 & 6,00 & 33 & 60,00 & 2 & 3,70 & 1 & 2,00 \\
\hline Somente com a mãe & 4 & 7,00 & 37 & 67,00 & 3 & 5,50 & 1 & 2,00 \\
\hline Pai e outras pessoas & 1 & 2,00 & 38 & 69,00 & 1 & 1,90 & 0 & 0,00 \\
\hline Mãe e outras pessoas & 14 & 25,00 & 52 & 94,00 & 7 & 12,30 & 7 & 12,60 \\
\hline Outras pessoas & 3 & 6,00 & 55 & 100 & 0 & 0,00 & 3 & 5,40 \\
\hline \multicolumn{9}{|l|}{ Distritos Sanitários } \\
\hline \multicolumn{9}{|l|}{ Distrito Sanitário I } \\
\hline Escola 1 & 5 & 9,09 & 5 & 9,09 & 3 & 5,50 & 2 & 3,60 \\
\hline Escola 2 & 5 & 9,09 & 10 & 18,18 & 3 & 5,50 & 2 & 3,60 \\
\hline \multicolumn{9}{|l|}{ Distrito Sanitário II } \\
\hline Escola 3 & 5 & 9,09 & 15 & 27,27 & 2 & 3,70 & 3 & 5,40 \\
\hline Escola 4 & 5 & 9,09 & 20 & 36,36 & 2 & 3,70 & 3 & 5,40 \\
\hline Escola 5 & 5 & 9,09 & 25 & 45,45 & 2 & 3,70 & 3 & 5,40 \\
\hline Escola 6 & 5 & 9,09 & 30 & 54,54 & 2 & 3,70 & 3 & 5,40 \\
\hline Escola 7 & 5 & 9,09 & 35 & 63,63 & 4 & 7,00 & 1 & 2,00 \\
\hline \multicolumn{9}{|l|}{ Distrito Sanitário III } \\
\hline Escola 8 & 5 & 9,09 & 40 & 72,72 & 3 & 5,50 & 2 & 3,60 \\
\hline Escola 9 & 5 & 9,09 & 45 & 81,81 & 3 & 5,50 & 2 & 3,60 \\
\hline Escola 10 & 5 & 9,09 & 50 & 90,90 & 3 & 5,50 & 2 & 3,60 \\
\hline Escola 11 & 5 & 9,10 & 55 & 100 & 2 & 3,70 & 3 & 5,40 \\
\hline
\end{tabular}

Fonte: Elaborado pelo autor.

Notas: Fac = Frequência absoluta acumulada; Fra $=$ Frequência relativa absoluta

* Observa-se que foram realizados arredondamentos nas operações de porcentagem entre meninos e meninas, considerando o número de participantes e a diferença numérica entre esses dois grupos nessa etapa da pesquisa. 


\subsection{Descobertas da etapa quantitativa}

Um total de 2.354 estudantes de 11 escolas públicas de Uberaba/MG participaram do estudo. Número que correspondente a uma taxa de participação de 19,40\% em relação ao número total (12.140) de estudantes matriculados no turno matutino das 34 escolas estaduais do munícipio. Para investigar as categorias de envolvimento em agressão e vitimização (bullying) entre os estudantes foi utilizada a análise de agrupamento K-means clustering. Os participantes foram, então, divididos em quatro grupos (clusters): 1) agressores; 2) vítimas; 3) vítimas-agressoras; 4) nãoenvolvidos (Tabela 5).

Tabela 5 - Distribuição dos participantes $(\mathrm{N}=2.354)$ segundo o tipo de envolvimento em situações de bullying (geral e por sexo). Uberaba, 2014.

\begin{tabular}{lcccccccc}
\hline \multirow{2}{*}{ Cluster } & \multicolumn{4}{c}{ Total } & \multicolumn{2}{c}{ Masculino } & \multicolumn{2}{c}{ Feminino } \\
& $\mathrm{N}$ & $\%$ & Fac & Fra & n & $\%$ & n & $\%$ \\
\hline Agressor & 243 & 10,30 & 243 & 10,30 & 174 & 7,40 & 69 & 2,90 \\
Vítima & 237 & 10,10 & 480 & 20,40 & 115 & 4,90 & 122 & 5,20 \\
Vítima-agressora & 127 & 5,40 & 607 & 25,80 & 92 & 3,90 & 35 & 1,50 \\
Não-envolvidos & 1747 & 74,20 & 2354 & 100 & 781 & 33,20 & 966 & 41,00 \\
\hline
\end{tabular}

Fonte: Elaborado pelo autor.

Notas: Fac $=$ Frequência absoluta acumulada; Fra $=$ Frequência relativa absoluta

A maioria dos participantes se concentrou no grupo sem nenhum tipo de envolvimento com as situações de bullying (74,20\%) e 25,80\% dos estudantes haviam praticado (agressor), sofrido (vítima) ou praticado e sofrido (vítima-agressora) alguma violência desse tipo segundo os dados coletados com a "Escala de Vitimização e Agressão Entre Pares" (EVAP). 0 grupo de não-envolvimento se constituiu com as médias mais baixas em todas as escalas de agressão e vitimização. Os estudantes do grupo de agressores apresentaram altas médias nas escalas de agressividade e menores frequências nas escalas de vitimização, sendo que o inverso ocorreu com os estudantes do grupo de vítimas. 0 grupo de vítimas-agressoras foi caracterizado por níveis altos de agressão e de vitimização. Os meninos foram mais agressores $(7,4 \%)$ e vítimas-agressoras $(3,9 \%)$ do que as meninas, ao passo que as meninas foram mais vítimas $(5,2 \%)$ que eles. Na Tabela 6 está apresentada de forma detalhada a distribuição da amostra do estudo segundo os quatro clusters identificados. 
Tabela 6 - Caracterização do grupo de participantes $(\mathrm{N}=2.354)$ segundo o tipo de envolvimento em situações de bullying e por sexo.

Uberaba, 2014.

\begin{tabular}{|c|c|c|c|c|c|c|c|c|c|c|c|c|c|c|c|c|c|c|}
\hline & \multicolumn{2}{|c|}{ Total } & \multicolumn{4}{|c|}{ Agressor } & \multicolumn{4}{|c|}{ Vítima } & \multicolumn{4}{|c|}{ Vítima-agressora } & \multicolumn{4}{|c|}{ Não-envolvimento } \\
\hline & \multirow{2}{*}{$\mathrm{N}$} & \multirow{2}{*}{$\%$} & \multicolumn{2}{|c|}{ Masculino } & \multicolumn{2}{|c|}{ Feminino } & \multicolumn{2}{|c|}{ Masculino } & \multicolumn{2}{|c|}{ Feminino } & \multicolumn{2}{|c|}{ Masculino } & \multicolumn{2}{|c|}{ Feminino } & \multicolumn{2}{|c|}{ Masculino } & \multicolumn{2}{|c|}{ Feminino } \\
\hline & & & $\mathrm{n}$ & $\%$ & $\mathrm{n}$ & $\%$ & $\mathrm{n}$ & $\%$ & $\mathrm{n}$ & $\%$ & $\mathrm{n}$ & $\%$ & $\mathrm{n}$ & $\%$ & $\mathrm{n}$ & $\%$ & $\mathrm{n}$ & $\%$ \\
\hline \multicolumn{19}{|l|}{ Idade } \\
\hline 10 & 15 & 0,70 & 2 & 0,10 & 0 & 0,00 & 3 & 0,15 & 0 & 0,00 & 2 & 0,10 & 0 & 0,00 & 5 & 0,20 & 3 & 0,15 \\
\hline 11 & 186 & 7,90 & 1 & 0,05 & 0 & 0,00 & 17 & 0,75 & 14 & 0,60 & 4 & 0,15 & 3 & 0,15 & 68 & 2,95 & 79 & 3,30 \\
\hline 12 & 262 & 11,10 & 11 & 0,45 & 5 & 0,20 & 18 & 0,75 & 12 & 0,50 & 15 & 0,65 & 2 & 0,10 & 99 & 4,25 & 100 & 4,20 \\
\hline 13 & 306 & 13,00 & 20 & 0,85 & 7 & 0,30 & 25 & 1,10 & 17 & 0,70 & 9 & 0,40 & 10 & 0,40 & 102 & 4,30 & 116 & 4,85 \\
\hline 14 & 361 & 15,30 & 39 & 1,70 & 19 & 0,80 & 20 & 0,85 & 25 & 1,05 & 7 & 0,30 & 7 & 0,30 & 110 & 4,50 & 134 & 5,60 \\
\hline 15 & 387 & 16,40 & 42 & 1,80 & 14 & 0,60 & 11 & 0,45 & 18 & 0,75 & 18 & 0,75 & 3 & 0,15 & 121 & 5,20 & 160 & 6,70 \\
\hline 16 & 403 & 17,10 & 30 & 1,30 & 9 & 0,40 & 11 & 0,45 & 21 & 0,90 & 14 & 0,60 & 8 & 0,35 & 136 & 5,50 & 174 & 7,40 \\
\hline 17 & 320 & 13,60 & 24 & 1,05 & 13 & 0,55 & 7 & 0,30 & 11 & 0,45 & 18 & 0,75 & 2 & 0,10 & 101 & 4,35 & 144 & 6,10 \\
\hline 18 & 98 & 4,20 & 5 & 0,20 & 1 & 0,05 & 2 & 0,10 & 3 & 0,15 & 5 & 0,20 & 0 & 0,00 & 31 & 1,35 & 51 & 2,15 \\
\hline 19 & 16 & 0,70 & 0 & 0,00 & 1 & 0,05 & 1 & 0,05 & 1 & 0,05 & 0 & 0,00 & 0 & 0,00 & 8 & 0,35 & 5 & 0,20 \\
\hline \multicolumn{19}{|l|}{ Ano escolar } \\
\hline $6^{0}$ ano Ensino Fundamental & 332 & 14,10 & 10 & 0,45 & 1 & 0,05 & 35 & 1,50 & 21 & 0,90 & 18 & 0,75 & 6 & 0,25 & 126 & 5,20 & 115 & 4,85 \\
\hline 7ํa ano Ensino Fundamental & 307 & 13,05 & 29 & 1,25 & 9 & 0,40 & 12 & 0,50 & 20 & 0,85 & 14 & 0,60 & 4 & 0,15 & 115 & 4,95 & 104 & 4,45 \\
\hline 8o ano Ensino Fundamental & 362 & 15,45 & 41 & 1,75 & 15 & 0,65 & 30 & 1,30 & 13 & 0,55 & 10 & 0,45 & 8 & 0,35 & 111 & 4,80 & 134 & 5,60 \\
\hline 9o ano Ensino Fundamental & 387 & 16,45 & 30 & 1,30 & 17 & 0,70 & 16 & 0,70 & 28 & 1,15 & 12 & 0,50 & 8 & 0,35 & 125 & 5,20 & 151 & 6,40 \\
\hline 1o ano Ensino Médio & 389 & 16,50 & 29 & 1,25 & 13 & 0,55 & 11 & 0,45 & 18 & 0,75 & 17 & 0,75 & 4 & 0,15 & 133 & 5,40 & 164 & 7,00 \\
\hline 2o ano Ensino Médio & 337 & 14,25 & 23 & 1,00 & 6 & 0,25 & 9 & 0,40 & 16 & 0,65 & 13 & 0,55 & 4 & 0,15 & 106 & 4,55 & 160 & 6,70 \\
\hline 3o ano Ensino Médio & 240 & 10,20 & 12 & 0,50 & 8 & 0,35 & 2 & 0,10 & 6 & 0,25 & 8 & 0,35 & 1 & 0,05 & 65 & 2,80 & 138 & 5,80 \\
\hline \multicolumn{19}{|l|}{ Arranjo familiar } \\
\hline Pai e mãe & 598 & 25,70 & 49 & 2,05 & 15 & 0,35 & 32 & 1,35 & 14 & 0,60 & 23 & 1,00 & 9 & 0,40 & 238 & 10,00 & 218 & 9,25 \\
\hline Pai, mãe e irmão(s) & 638 & 27,15 & 46 & 1,95 & 18 & 0,75 & 28 & 1,15 & 26 & 1,05 & 19 & 0,80 & 8 & 0,35 & 193 & 8,40 & 300 & 12,80 \\
\hline Pai, mãe, irmão(s) e/ou outras pessoas & 110 & 4,70 & 6 & 0,25 & 4 & 0,15 & 8 & 0,35 & 9 & 0,40 & 5 & 0,20 & 1 & 0,05 & 42 & 1,80 & 35 & 1,50 \\
\hline Somente com o pai & 43 & 1,90 & 8 & 0,35 & 0 & 0,00 & 3 & 0,15 & 1 & 0,05 & 2 & 0,10 & 0 & 0,00 & 14 & 0,60 & 15 & 0,65 \\
\hline Somente com a mãe & 263 & 11,05 & 23 & 1,00 & 5 & 0,20 & 16 & 0,65 & 20 & 0,85 & 18 & 0,75 & 2 & 0,10 & 92 & 3,85 & 87 & 3,65 \\
\hline Pai e outras pessoas & 67 & 2,85 & 5 & 0,20 & 2 & 0,10 & 7 & 0,30 & 1 & 0,05 & 3 & 0,15 & 1 & 0,05 & 22 & 0,95 & 26 & 1,05 \\
\hline Mãe e outras pessoas & 513 & 21,50 & 30 & 1,30 & 21 & 0,90 & 19 & 0,80 & 40 & 1,70 & 12 & 0,50 & 12 & 0,50 & 132 & 5,55 & 247 & 10,45 \\
\hline Outras pessoas & 122 & 5,15 & 7 & 0,30 & 4 & 0,15 & 2 & 0,10 & 11 & 0,45 & 10 & 0,40 & 2 & 0,10 & 48 & 2,00 & 38 & 1,65 \\
\hline
\end{tabular}




\begin{tabular}{|c|c|c|c|c|c|c|c|c|c|c|c|c|c|c|c|c|c|c|}
\hline & \multicolumn{2}{|c|}{ Total } & \multicolumn{4}{|c|}{ Agressor } & \multicolumn{4}{|c|}{ Vítima } & \multicolumn{4}{|c|}{ Vítima-agressora } & \multicolumn{4}{|c|}{ Não-envolvimento } \\
\hline & \multirow{2}{*}{$\mathrm{N}$} & \multirow{2}{*}{$\%$} & \multicolumn{2}{|c|}{ Masculino } & \multicolumn{2}{|c|}{ Feminino } & \multicolumn{2}{|c|}{ Masculino } & \multicolumn{2}{|c|}{ Feminino } & \multicolumn{2}{|c|}{ Masculino } & \multicolumn{2}{|c|}{ Feminino } & \multicolumn{2}{|c|}{ Masculino } & \multicolumn{2}{|c|}{ Feminino } \\
\hline & & & $\mathrm{n}$ & $\%$ & $\mathrm{n}$ & $\%$ & $\mathrm{n}$ & $\%$ & $\mathrm{n}$ & $\%$ & $\mathrm{n}$ & $\%$ & $\mathrm{n}$ & $\%$ & $\mathrm{n}$ & $\%$ & $\mathrm{n}$ & $\%$ \\
\hline \multicolumn{19}{|c|}{ Distritos Sanitários } \\
\hline \multicolumn{19}{|c|}{ Distrito Sanitário I } \\
\hline Escola 1 & 111 & 4,70 & 13 & 0,55 & 4 & 0,15 & 5 & 0,20 & 6 & 0,25 & 10 & 0,45 & 5 & 0,20 & 35 & 1,50 & 33 & 1,40 \\
\hline Escola 2 & 454 & 19,30 & 30 & 1,30 & 13 & 0,55 & 19 & 0,80 & 14 & 0,60 & 8 & 0,35 & 10 & 0,40 & 160 & 6,70 & 200 & 8,60 \\
\hline \multicolumn{19}{|c|}{ Distrito Sanitário II } \\
\hline Escola 3 & 54 & 2,35 & 3 & 0,15 & 1 & 0,05 & 2 & 0,10 & 5 & 0,20 & 3 & 0,15 & 1 & 0,05 & 21 & 0,90 & 18 & 0,75 \\
\hline Escola 4 & 284 & 12,10 & 21 & 0,90 & 4 & 0,15 & 22 & 0,95 & 15 & 0,65 & 11 & 0,45 & 2 & 0,10 & 108 & 4,65 & 101 & 4,25 \\
\hline Escola 5 & 244 & 10,30 & 10 & 0,45 & 5 & 0,20 & 8 & 0,35 & 20 & 0,85 & 6 & 0,25 & 2 & 0,10 & 84 & 3,60 & 109 & 4,55 \\
\hline Escola 6 & 102 & 4,35 & 9 & 0,40 & 7 & 0,30 & 5 & 0,20 & 11 & 0,45 & 6 & 0,25 & 3 & 0,15 & 30 & 1,30 & 31 & 1,30 \\
\hline Escola 7 & 199 & 8,45 & 14 & 0,60 & 9 & 0,40 & 11 & 0,45 & 7 & 0,30 & 13 & 0,55 & 0 & 0,00 & 66 & 2,85 & 79 & 3,35 \\
\hline \multicolumn{19}{|c|}{ Distrito Sanitário III } \\
\hline Escola 8 & 124 & 5,30 & 8 & 0,35 & 2 & 0,10 & 16 & 0,70 & 8 & 0,35 & 3 & 0,15 & 4 & 0,15 & 54 & 2,10 & 29 & 1,20 \\
\hline Escola 9 & 111 & 4,70 & 13 & 0,55 & 5 & 0,20 & 12 & 0,50 & 13 & 0,55 & 7 & 0,30 & 1 & 0,05 & 24 & 1,10 & 36 & 1,50 \\
\hline Escola 10 & 133 & 5,65 & 9 & 0,40 & 3 & 0,15 & 5 & 0,20 & 5 & 0,20 & 5 & 0,20 & 2 & 0,10 & 36 & 1,40 & 68 & 2,85 \\
\hline Escola 11 & 538 & 22,80 & 44 & 1,90 & 16 & 0,65 & 10 & 0,45 & 18 & 0,75 & 20 & 0,85 & 5 & 0,20 & 163 & 6,80 & 262 & 11,00 \\
\hline
\end{tabular}


Observou-se que a maior parte dos agressores apresentavam idades entre 13 e 17 anos, enquanto maior número de vítimas e vítimas-agressoras foi constatado entre os 11 e 17 anos. Além disso, foi nos anos do Ensino Fundamental e no 1ํo ano do Ensino Médio que se identificou maiores taxas de agressão e vitimização entre os estudantes. Cálculos de correlação de Pearson constataram correlações significativas entre a idade $(p=0,00)$ e ano escolar $(p=0,01)$ com a vitimização, indicando que quanto mais novo e inserido nas séries iniciais, maior a chance do participante ser vítima de bullying. Para os outros grupos não houve correlações significativas na análise dessas variáveis. No que se refere aos arranjos familiares dos participantes a partir dessa divisão, verificou-se que se sobressaíram, nos quatro grupos, os arranjos nucleares, em que as duas figuras parentais estavam presentes.

Os resultados da análise de diferenças entre as médias (ANOVA) comparou os dados relacionados ao tipo de envolvimento dos estudantes com as situações de bullying (não-envolvimento, agressor, vítima e vítima-agressora) com as nove dimensões de interação familiar contempladas pela escala utilizada na coleta de dados (envolvimento, regras e monitoria, punição física, comunicação positiva, comunicação negativa, clima conjugal positivo, clima conjugal negativo, modelo e sentimento dos filhos). A comparação, também, ocorreu de forma combinada (qualidade da interação familiar geral) e separadamente em relação ao pai, à mãe e à outra pessoa.

Pela análise de variância (ANOVA) se verificou diferenças estatísticas significativas $(\mathrm{p}<0,05)$ entre os quatro grupos de estudantes no que se refere à qualidade da interação familiar (geral, pai, mãe e outra pessoa), e nas comparações post hoc (Z) entre elas. Os dados relacionados à outra pessoa apresentaram menores diferenças estatísticas entre os grupos.

A seguir, na Tabela 7, são apresentados os dados da ANOVA em relação às dimensões da qualidade da interação familiar geral dos adolescentes e o tipo de envolvimento em situações de bullying. 
Tabela 7 - ANOVA de acordo com o tipo de envolvimento em situações de bullying e em relação à qualidade da interação familiar geral. Uberaba, 2014.

\begin{tabular}{|c|c|c|c|c|c|c|c|c|c|c|}
\hline \multirow{3}{*}{$\begin{array}{l}\text { Dimensões - qualidade } \\
\text { da interação familiar }\end{array}$} & \multicolumn{8}{|c|}{ Clusters } & \multirow[b]{3}{*}{$\mathrm{Z}$} & \multirow[b]{3}{*}{$\mathrm{p}$} \\
\hline & \multicolumn{2}{|c|}{$\begin{array}{l}\text { Não- } \\
\text { envolvimento }\end{array}$} & \multicolumn{2}{|c|}{ Agressores } & \multicolumn{2}{|c|}{ Vítimas } & \multicolumn{2}{|c|}{$\begin{array}{l}\text { Vítimas- } \\
\text { agressoras }\end{array}$} & & \\
\hline & $\mathrm{M}$ & DP & $\mathrm{M}$ & $\mathrm{DP}$ & $\mathrm{M}$ & DP & $\mathrm{M}$ & $\mathrm{DP}$ & & \\
\hline Envolvimento & $3,94 b$ & 0,89 & $3,62 \mathrm{a}$ & 0,91 & $3,73 a$ & 1,04 & $3,71 \mathrm{a}$ & 1,04 & 12,39 & 0,000 \\
\hline Regras e monitoria & $4,21 \mathrm{c}$ & 0,78 & $3,85 a$ & 0,82 & $4,06 \mathrm{bc}$ & 0,87 & $4,00 \mathrm{ab}$ & 0,85 & 17,07 & 0,000 \\
\hline Punição física & $1,51 \mathrm{a}$ & 0,74 & $1,72 b$ & 0,85 & $1,96 \mathrm{c}$ & 1,00 & $2,06 \mathrm{c}$ & 1,20 & 38,52 & 0,000 \\
\hline Comunicação positiva & $3,03 b$ & 1,11 & $2,66 a$ & 1,08 & $2,88 a b$ & 1,15 & $2,82 \mathrm{ab}$ & 1,07 & 9,35 & 0,000 \\
\hline Comunicação negativa & $2,02 \mathrm{a}$ & 0,84 & $2,51 b$ & 0,92 & $2,54 b$ & 1,09 & $2,70 \mathrm{~b}$ & 1,09 & 56,24 & 0,000 \\
\hline Clima conjugal positivo & $3,22 b$ & 1,24 & $3,00 \mathrm{a}$ & 1,25 & $3,02 \mathrm{ab}$ & 1,28 & $3,06 a b$ & 1,29 & 3,80 & 0,001 \\
\hline Clima conjugal negativo & $1,96 a$ & 0,92 & $2,33 b$ & 1,05 & $2,25 b$ & 1,12 & $2,42 b$ & 1,20 & 20,48 & 0,000 \\
\hline Modelo & $3,98 b$ & 0,89 & $3,73 a$ & 0,96 & $3,84 a b$ & 0,94 & $3,79 a b$ & 1,13 & 7,86 & 0,000 \\
\hline Sentimento dos filhos & $4,46 \mathrm{~b}$ & 0,74 & $4,24 a$ & 0,89 & $4,31 \mathrm{ab}$ & 0,85 & $4,21 \mathrm{a}$ & 1,06 & 10,42 & 0,000 \\
\hline
\end{tabular}

Fonte: Elaborado pelo autor.

Notas: Nas linhas, as médias com letras iguais não se diferenciam entre si pelo pós teste de Tukey $(\mathrm{p}<$ 0,005), sendo $\mathrm{a}<\mathrm{b}<\mathrm{c} ; \mathrm{M}=$ Média; $\mathrm{DP}=$ Desvio Padrão

Observa-se que os estudantes não envolvidos com as situações de bullying apresentaram maiores médias em todas as escalas positivas (envolvimento, regras e monitoria, comunicação positiva, clima conjugal positivo, modelo e sentimento dos filhos), diferenciando-se dos demais grupos segundo ANOVA. Analisando as diferenças significativas entre os grupos se percebe que esse grupo se diferencia sobretudo do grupo dos agressores. Sobre as escalas negativas (punição física, comunicação negativa e clima conjugal negativo), observa-se um movimento inverso. Nesses casos, agressores, vítimas e vítimas-agressoras apresentaram maior média em relação aos estudantes não envolvidos. $\mathrm{Na}$ análise da qualidade da interação familiar geral as vítimas e as vítimasagressoras se diferenciaram significativamente dos outros dois grupos no que se refere à "punição física”. A “comunicação negativa” dos agressores, vítimas e vítimas-agressoras apresentou diferença significativa em relação ao grupo dos estudantes não envolvidos. 0 mesmo ocorreu com a dimensão "clima conjugal negativo".

Separadamente, na Tabela 8, a qualidade da interação familiar com o pai dos estudantes está sumarizada. 
Tabela 8 - ANOVA de acordo com o tipo de envolvimento em situações de bullying e em relação à qualidade da interação familiar com a figura paterna. Uberaba, 2014 .

\begin{tabular}{|c|c|c|c|c|c|c|c|c|c|c|}
\hline \multirow{3}{*}{$\begin{array}{l}\text { Dimensões - qualidade } \\
\text { da interação familiar }\end{array}$} & \multicolumn{8}{|c|}{ Clusters } & \multirow[b]{3}{*}{ Z } & \multirow[b]{3}{*}{$\mathrm{p}$} \\
\hline & \multicolumn{2}{|c|}{$\begin{array}{c}\text { Não- } \\
\text { envolvimento }\end{array}$} & \multicolumn{2}{|c|}{ Agressores } & \multicolumn{2}{|c|}{ Vítimas } & \multicolumn{2}{|c|}{$\begin{array}{l}\text { Vítimas- } \\
\text { agressoras }\end{array}$} & & \\
\hline & M & DP & M & $\mathrm{DP}$ & M & DP & M & $\mathrm{DP}$ & & \\
\hline Envolvimento & $3,87 \mathrm{~b}$ & 0,96 & $3,51 a$ & 1,01 & $3,70 \mathrm{ab}$ & 1,05 & $3,64 a b$ & 1,17 & 7,10 & 0,000 \\
\hline Regras e monitoria & $4,12 \mathrm{~b}$ & 0,86 & $3,77 \mathrm{a}$ & 0,96 & $3,97 \mathrm{ab}$ & 1,00 & $3,80 \mathrm{a}$ & 1,00 & 9,25 & 0,000 \\
\hline Punição física & $1,50 \mathrm{a}$ & 0,74 & $1,63 a$ & 0,83 & $1,96 b$ & 1,07 & $1,99 \mathrm{~b}$ & 1,25 & 19,21 & 0,000 \\
\hline Comunicação positiva & $2,81 \mathrm{a}$ & 1,15 & $2,51 \mathrm{a}$ & 1,18 & $2,65 a$ & 1,23 & $2,76 a$ & 1,22 & 3,23 & 0,002 \\
\hline Comunicação negativa & $1,97 \mathrm{a}$ & 0,85 & $2,31 b$ & 0,94 & $2,32 b$ & 1,10 & $2,69 c$ & 1,10 & 23,25 & 0,000 \\
\hline Clima conjugal positivo & $3,55 a$ & 1,13 & $3,36 \mathrm{a}$ & 1,16 & $3,49 \mathrm{a}$ & 1,10 & $3,45 a$ & 1,21 & 1,43 & 0,233 \\
\hline Clima conjugal negativo & $1,99 a$ & 0,91 & $2,33 b$ & 1,08 & $2,14 \mathrm{ab}$ & 1,00 & $2,37 b$ & 1,19 & 9,23 & 0,000 \\
\hline Modelo & $3,97 \mathrm{a}$ & 0,94 & $3,69 a$ & 1,10 & $3,88 \mathrm{a}$ & 0,96 & $3,75 a$ & 1,21 & 4,69 & 0,000 \\
\hline Sentimento dos filhos & $4,43 \mathrm{~b}$ & 0,84 & $4,23 a b$ & 1,03 & $4,27 \mathrm{ab}$ & 0,98 & $4,1 \mathrm{a}$ & 1,18 & 4,92 & 0,000 \\
\hline
\end{tabular}

Fonte: Elaborado pelo autor.

Notas: Nas linhas, as médias com letras iguais não se diferenciam entre si pelo pós teste de Tukey $(\mathrm{p}<$ 0,005), sendo $\mathrm{a}<\mathrm{b}<\mathrm{c} ; \mathrm{M}=$ Média; DP = Desvio Padrão

Das nove dimensões da interação familiar dos adolescentes com pais analisadas, oito apresentaram diferenças estatísticas significativas entre os grupos de envolvimento e não envolvimento nas situações de bullying. Excetuou-se nessa análise a dimensão do "clima conjugal positivo". Na escala positiva de "envolvimento", os estudantes não envolvidos em situações de bullying se diferenciaram dos estudantes agressores. $\mathrm{Na}$ escala "regras e monitoria" a diferença entre o grupo de não-envolvidos ocorreu em relação aos grupos de agressores e vítimas-agressoras. No que se refere às escalas "comunicação positiva" e "modelo" houve diferenças significativas entre os grupos, porém o teste post hoc não determinou o nível da diferença. Na escala relacionada aos "sentimentos dos filhos", os estudantes não envolvidos se diferenciaram sobretudo dos estudantes identificados como vítimas-agressoras. "Punição física", "comunicação negativa" e "clima conjugal negativo" (escalas negativas) diferenciaram o grupo das vítimas-agressoras em relação aos demais grupos, principalmente em relação ao grupo dos não-envolvidos.

A seguir, apresenta-se a qualidade da interação familiar com a mãe dos estudantes (Tabela 9). 
Tabela 9 - ANOVA de acordo com o tipo de envolvimento em situações de bullying e em relação à qualidade da interação familiar com a figura materna. Uberaba, 2014.

\begin{tabular}{|c|c|c|c|c|c|c|c|c|c|c|}
\hline \multirow{3}{*}{$\begin{array}{l}\text { Dimensões - qualidade } \\
\text { da interação familiar }\end{array}$} & \multicolumn{8}{|c|}{ Clusters } & \multirow[b]{3}{*}{$\mathrm{Z}$} & \multirow[b]{3}{*}{$\mathrm{p}$} \\
\hline & \multicolumn{2}{|c|}{$\begin{array}{c}\text { Não- } \\
\text { envolvimento }\end{array}$} & \multicolumn{2}{|c|}{ Agressores } & \multicolumn{2}{|c|}{ Vítimas } & \multicolumn{2}{|c|}{$\begin{array}{l}\text { Vítimas- } \\
\text { agressoras }\end{array}$} & & \\
\hline & M & DP & M & DP & M & DP & M & DP & & \\
\hline Envolvimento & $4,06 \mathrm{~b}$ & 0,87 & $3,78 \mathrm{a}$ & 0,90 & $3,84 a$ & 1,02 & $3,78 a$ & 1,07 & 11,10 & 0,000 \\
\hline Regras e monitoria & $4,32 \mathrm{c}$ & 0,73 & $3,93 a$ & 0,80 & $4,14 b$ & 0,86 & $4,09 a b$ & 0,83 & 21,03 & 0,000 \\
\hline Punição física & $1,54 \mathrm{a}$ & 0,77 & $1,73 b$ & 0,89 & $2,05 c$ & 1,06 & $2,10 \mathrm{c}$ & 1,22 & 36,32 & 0,000 \\
\hline Comunicação positiva & $3,22 b$ & 1,18 & $2,76 a$ & 1,12 & $3,05 b$ & 1,20 & $3,01 \mathrm{ab}$ & 1,16 & 10,62 & 0,000 \\
\hline Comunicação negativa & $2,06 a$ & 0,88 & $2,57 \mathrm{~b}$ & 1,00 & $2,62 b$ & 1,14 & $2,66 b$ & 1,11 & 46,72 & 0,000 \\
\hline Clima conjugal positivo & $3,26 a$ & 1,24 & $3,07 a$ & 1,27 & $3,00 \mathrm{a}$ & 1,26 & $3,16 \mathrm{a}$ & 1,29 & 3,86 & 0,001 \\
\hline Clima conjugal negativo & $1,97 \mathrm{a}$ & 0,92 & $2,35 b$ & 1,09 & $2,30 \mathrm{~b}$ & 1,14 & $2,43 b$ & 1,15 & 20,07 & 0,000 \\
\hline Modelo & $4,06 \mathrm{~b}$ & 0,86 & $3,80 \mathrm{a}$ & 0,96 & $3,85 a$ & 0,95 & $3,82 \mathrm{a}$ & 1,19 & 9,69 & 0,000 \\
\hline Sentimento dos filhos & $4,56 \mathrm{~b}$ & 0,68 & $4,33 \mathrm{a}$ & 0,84 & $4,38 \mathrm{a}$ & 0,83 & $4,21 \mathrm{a}$ & 1,10 & 14,18 & 0,000 \\
\hline
\end{tabular}

Fonte: Elaborado pelo autor.

Notas: Nas linhas, as médias com letras iguais não se diferenciam entre si pelo pós teste de Tukey $(\mathrm{p}<$ 0,005), sendo $\mathrm{a}<\mathrm{b}<\mathrm{c} ; \mathrm{M}=$ Média; $\mathrm{DP}=$ Desvio Padrão

$\mathrm{Na}$ análise da qualidade da interação familiar com a mãe, o grupo dos estudantes não envolvidos se diferenciaram significativamente dos demais grupos no que se refere ao "envolvimento", "regras e monitoria", "comunicação positiva", "modelo" e "sentimento dos filhos". Os agressores foram os que apresentaram menor pontuação em todas as escalas positivas. Nas escalas negativas o mesmo efeito foi observado e os grupos de agressores, vítimas e vítimas-agressoras se diferenciaram do grupo dos estudantes sem envolvimento com situações de bullying.

Os dados relacionados à interação familiar com outra pessoa que ocupasse o papel de responsável ou cuidador dos adolescentes estão sintetizados na Tabela 10. 
Tabela 10 - ANOVA de acordo com o tipo de envolvimento em situações de bullying e em relação à qualidade da interação familiar com outra pessoa. Uberaba, 2014.

\begin{tabular}{lccccccccccc}
\hline $\begin{array}{c}\text { Dimensões - qualidade } \\
\text { da interação familiar }\end{array}$ & \multicolumn{3}{c}{$\begin{array}{c}\text { Não- } \\
\text { envolvimento }\end{array}$} & \multicolumn{1}{c}{ Agressores } & \multicolumn{2}{c}{ Vítimas } & \multicolumn{7}{c}{$\begin{array}{c}\text { Vítimas- } \\
\text { agressoras }\end{array}$} \\
& M & DP & M & DP & M & DP & M & DP & Z & p \\
\hline Outra pessoa & & & & & & & & & & \\
$\quad$ Envolvimento & 3,61 & 1,10 & 3,17 & 1,08 & 3,38 & 1,23 & 3,57 & 1,05 & 1,57 & 0,196 \\
Regras e monitoria & 3,89 & 1,14 & 3,64 & 1,02 & 3,94 & 0,83 & 3,77 & 1,08 & 0,53 & 0,659 \\
Punição física & $1,38 \mathrm{a}$ & 0,69 & $1,90 \mathrm{~b}$ & 1,23 & $1,43 \mathrm{a}$ & 0,63 & $1,93 \mathrm{~b}$ & 1,21 & 6,09 & 0,000 \\
Comunicação positiva & 2,67 & 1,16 & 2,47 & 1,22 & 2,56 & 1,23 & 2,43 & 1,01 & 0,51 & 0,677 \\
Comunicação negativa & $1,87 \mathrm{a}$ & 0,82 & $2,46 \mathrm{~b}$ & 1,05 & $2,40 \mathrm{~b}$ & 1,08 & $2,53 \mathrm{~b}$ & 1,20 & 8,66 & 0,000 \\
Clima conjugal positivo & 3,36 & 1,10 & 3,21 & 1,09 & 3,39 & 1,22 & 2,99 & 1,24 & 0,86 & 0,463 \\
Clima conjugal negativo & 1,99 & 0,92 & 2,35 & 0,81 & 2,16 & 1,02 & 2,45 & 1,18 & 2,62 & 0,051 \\
Modelo & 3,82 & 1,04 & 3,65 & 1,12 & 3,80 & 1,10 & 3,73 & 1,06 & 0,23 & 0,875 \\
Sentimento dos filhos & 4,11 & 1,10 & 3,73 & 1,27 & 4,04 & 1,02 & 4,27 & 1,07 & 1,17 & 0,320 \\
\hline
\end{tabular}

Fonte: Elaborado pelo autor.

Notas: Nas linhas, as médias com letras iguais não se diferenciam entre si pelo pós teste de Tukey $(\mathrm{p}<$ 0,005), sendo $\mathrm{a}<\mathrm{b}<\mathrm{c} ; \mathrm{M}=$ Média; DP = Desvio Padrão

Dados relativos à outra pessoa não apresentaram diferenças significativas entre os grupos nas escalas positivas. Os grupos de agressores, vítimas e vítimas-agressoras se diferenciaram do grupo dos estudantes não-envolvidos nas escalas negativas sobre "punição física" e "comunicação negativa”.

As diferenças entre as médias (ANOVA) das nove dimensões de interação familiar contempladas pelo estudo comparadas entre os quatro grupos de estudantes, também, foram testadas por sexo. Essa comparação ocorreu de forma combinada (qualidade da interação familiar geral) e separadamente em relação ao pai, à mãe e à outra pessoa. Nesse sentido, os dados da ANOVA em relação à qualidade da interação familiar geral dos meninos e das meninas estão apresentados nas Tabela 11 e Tabela 12. 
Tabela 11 - ANOVA de acordo com o tipo de envolvimento em situações de bullying e em relação à qualidade da interação familiar geral, sexo masculino. Uberaba, 2014.

\begin{tabular}{|c|c|c|c|c|c|c|c|c|c|c|}
\hline \multirow{3}{*}{$\begin{array}{l}\text { Dimensões - qualidade } \\
\text { da interação familiar }\end{array}$} & \multicolumn{8}{|c|}{ Clusters } & \multirow[b]{3}{*}{$\mathrm{Z}$} & \multirow[b]{3}{*}{$\mathrm{p}$} \\
\hline & \multicolumn{2}{|c|}{$\begin{array}{l}\text { Não- } \\
\text { envolvidos }\end{array}$} & \multicolumn{2}{|c|}{ Agressores } & \multicolumn{2}{|c|}{ Vítimas } & \multicolumn{2}{|c|}{$\begin{array}{l}\text { Vítimas- } \\
\text { agressoras }\end{array}$} & & \\
\hline & $\mathrm{M}$ & DP & $\mathrm{M}$ & DP & $\mathrm{M}$ & $\mathrm{DP}$ & $\mathrm{M}$ & $\mathrm{DP}$ & & \\
\hline Envolvimento & $4,03 b$ & 0,79 & $3,69 a$ & 0,87 & $4,01 b$ & 0,80 & $3,88 \mathrm{ab}$ & 1,01 & 8,30 & 0,000 \\
\hline Regras e monitoria & $4,14 b$ & 0,82 & $3,81 \mathrm{a}$ & 0,83 & $4,19 b$ & 0,79 & $3,96 a b$ & 0,90 & 8,75 & 0,000 \\
\hline Punição física & $1,57^{\circ}$ & 0,77 & $1,72 \mathrm{a}$ & 0,83 & $1,97 b$ & 1,02 & $2,05 b$ & 1,20 & 14,59 & 0,000 \\
\hline Comunicação positiva & $2,96 \mathrm{~b}$ & 1,06 & $2,63 a$ & 1,09 & $2,97 \mathrm{~b}$ & 1,11 & $2,83 a b$ & 1,08 & 5,02 & 0,000 \\
\hline Comunicação negativa & $1,88^{\circ}$ & 0,73 & $2,39 a b$ & 0,91 & $2,33 b$ & 1,01 & $2,59 \mathrm{c}$ & 1,08 & 39,40 & 0,000 \\
\hline Clima conjugal positivo & 3,32 & 1,23 & 3,14 & 1,21 & 3,15 & 1,25 & 3,16 & 1,31 & 1,70 & 0,165 \\
\hline Clima conjugal negativo & $1,85^{\circ}$ & 0,84 & $2,13 b$ & 0,96 & $2,23 b$ & 1,12 & $2,30 \mathrm{~b}$ & 1,16 & 13,52 & 0,000 \\
\hline Modelo & $4,05^{\circ}$ & 0,88 & $3,79 a$ & 0,90 & $4,02 \mathrm{a}$ & 0,86 & $3,97 a$ & 1,05 & 4,13 & 0,006 \\
\hline Sentimento dos filhos & $4,51^{\circ}$ & 0,70 & $4,32 \mathrm{a}$ & 0,82 & $4,50 \mathrm{a}$ & 0,65 & $4,34 \mathrm{a}$ & 0,99 & 4,05 & 0,007 \\
\hline
\end{tabular}

Fonte: Elaborado pelo autor.

Notas: Nas linhas, as médias com letras iguais não se diferenciam entre si pelo pós teste de Tukey $(\mathrm{p}<$ $0,005)$, sendo $\mathrm{a}<\mathrm{b}<\mathrm{c} ; \mathrm{M}=$ Média; $\mathrm{DP}=$ Desvio Padrão

Tabela 12 - ANOVA de acordo com o tipo de envolvimento em situações de bullying e em relação à qualidade da interação familiar geral, sexo feminino. Uberaba, 2014 .

\begin{tabular}{lcccccccccc}
\hline \multirow{2}{*}{$\begin{array}{c}\text { Dimensões - qualidade } \\
\text { da interação familiar }\end{array}$} & $\begin{array}{c}\text { Não- } \\
\text { envolvidos }\end{array}$ & \multicolumn{1}{c}{ Agressores } & \multicolumn{1}{c}{ Vítimas } & \multicolumn{7}{c}{$\begin{array}{c}\text { Vítimas- } \\
\text { agressoras }\end{array}$} \\
& M & DP & M & DP & M & DP & M & DP & Z & p \\
\hline Envolvimento & $3,87 \mathrm{~b}$ & 0,95 & $3,44 \mathrm{a}$ & 0,97 & $3,47 \mathrm{a}$ & 1,17 & $3,28 \mathrm{a}$ & 1,03 & 12,42 & 0,000 \\
Regras e monitoria & $4,26 \mathrm{~b}$ & 0,75 & $3,94 \mathrm{a}$ & 0,78 & $3,93 \mathrm{a}$ & 0,93 & $4,10 \mathrm{ab}$ & 0,70 & 9,77 & 0,000 \\
Punição física & $1,46 \mathrm{a}$ & 0,70 & $1,74 \mathrm{ab}$ & 0,90 & $1,95 \mathrm{bc}$ & 1,00 & $2,09 \mathrm{c}$ & 1,24 & 22,82 & 0,000 \\
Comunicação positiva & $3,09 \mathrm{a}$ & 1,15 & $2,75 \mathrm{a}$ & 1,03 & $2,81 \mathrm{a}$ & 1,18 & $2,80 \mathrm{a}$ & 1,08 & 4,22 & 0,006 \\
Comunicação negativa & $2,15 \mathrm{a}$ & 0,90 & $2,80 \mathrm{~b}$ & 0,88 & $2,75 \mathrm{~b}$ & 1,12 & $2,99 \mathrm{~b}$ & 1,09 & 31,05 & 0,000 \\
Clima conjugal positivo & $3,14 \mathrm{a}$ & 1,25 & $2,68 \mathrm{a}$ & 1,30 & $2,89 \mathrm{a}$ & 1,29 & $2,83 \mathrm{a}$ & 1,24 & 4,45 & 0,004 \\
Clima conjugal negativo & $2,06 \mathrm{a}$ & 0,98 & $2,82 \mathrm{~b}$ & 1,10 & $2,26 \mathrm{a}$ & 1,12 & $2,72 \mathrm{~b}$ & 1,26 & 17,21 & 0,000 \\
Modelo & $3,93 \mathrm{~b}$ & 0,89 & $3,56 \mathrm{a}$ & 1,09 & $3,67 \mathrm{ab}$ & 0,98 & $3,314 \mathrm{a}$ & 1,21 & 10,14 & 0,000 \\
Sentimento dos filhos & $4,42 \mathrm{~b}$ & 0,78 & $4,04 \mathrm{a}$ & 1,00 & $4,12 \mathrm{ab}$ & 0,97 & $3,85 \mathrm{a}$ & 1,17 & 13,15 & 0,000 \\
\hline
\end{tabular}

Fonte: Elaborado pelo autor.

Notas: Nas linhas, as médias com letras iguais não se diferenciam entre si pelo pós teste de Tukey $(p<0,05)$, sendo $\mathrm{a}<\mathrm{b}<\mathrm{c} ; \mathrm{M}=$ Média; DP = Desvio Padrão

Entre os meninos, as maiores médias se concentraram no grupo dos estudantes não-envolvidos em todas as escalas positivas. A diferença estatística, via de regra, nessas escalas, referia-se a esse grupo em relação aos demais grupos. Não foram observadas diferenças entre os grupos na escala sobre o clima conjugal positivo.

As meninas, apresentaram diferenças estatisticamente significativas entre os quatro grupos investigados e em todas dimensões de interação familiar. Avaliando as 
escalas positivas, observou-se que o grupo das estudantes não-envolvidas apresentavam maiores médias nas dimensões "envolvimento", "regras e monitoria", "modelo" e "sentimento dos filhos", diferenciando-se significativamente em relação aos demais grupos. Nas escalas negativas as maiores médias foram observadas nos grupos de agressores, vítimas e vítimas-agressoras, sendo as diferenças estatísticas observadas em relação ao grupo dos não-envolvidos com situações de bullying.

Os dados particularizados da ANOVA para a interação familiar de meninos e meninas com os pais estão apresentados nas Tabelas 13 e 14.

Tabela 13 - ANOVA de acordo com o tipo de envolvimento em situações de bullying e em relação à qualidade da interação familiar com a figura paterna, sexo masculino. Uberaba, 2014.

\begin{tabular}{|c|c|c|c|c|c|c|c|c|c|c|}
\hline \multirow{3}{*}{$\begin{array}{c}\text { Dimensões - qualidade } \\
\text { da interação familiar }\end{array}$} & \multicolumn{8}{|c|}{ Clusters } & \multirow[b]{3}{*}{$\mathrm{Z}$} & \multirow[b]{3}{*}{$\mathrm{p}$} \\
\hline & \multicolumn{2}{|c|}{$\begin{array}{c}\text { Não- } \\
\text { envolvidos }\end{array}$} & \multicolumn{2}{|c|}{ Agressores } & \multicolumn{2}{|c|}{ Vítimas } & \multicolumn{2}{|c|}{$\begin{array}{l}\text { Vítimas- } \\
\text { agressoras }\end{array}$} & & \\
\hline & M & DP & M & $\mathrm{DP}$ & M & DP & $\mathrm{M}$ & DP & & \\
\hline Envolvimento & $3,94 b$ & 0,89 & $3,56 a$ & 0,98 & $3,87 \mathrm{ab}$ & 0,98 & $3,79 \mathrm{ab}$ & 1,16 & 5,44 & 0,001 \\
\hline Regras e monitoria & $4,08^{\circ}$ & 0,89 & $3,76 a$ & 0,96 & $4,06 \mathrm{a}$ & 0,94 & $3,83 a$ & 1,05 & 4,51 & 0,004 \\
\hline Punição física & $1,60^{\circ}$ & 0,78 & $1,65 a$ & 0,85 & $2,06 \mathrm{~b}$ & 1,07 & $2,057 b$ & 1,28 & 9,82 & 0,000 \\
\hline Comunicação positiva & $2,88^{\circ}$ & 1,13 & $2,52 \mathrm{a}$ & 1,17 & $2,78 \mathrm{a}$ & 1,23 & $2,91 \mathrm{a}$ & 1,22 & 3,24 & 0,022 \\
\hline Comunicação negativa & $1,86^{\circ}$ & 0,76 & $2,29 b$ & 0,93 & $2,18 b$ & 1,07 & $2,59 c$ & 1,12 & 18,47 & 0,000 \\
\hline Clima conjugal positivo & 3,64 & 1,09 & 3,50 & 1,08 & 3,55 & 1,13 & 3,53 & 1,25 & 0,63 & 0,594 \\
\hline Clima conjugal negativo & $1,86^{\circ}$ & 0,82 & $2,19 b$ & 0,99 & $2,06 a b$ & 0,97 & $2,29 b$ & 1,18 & 7,58 & 0,000 \\
\hline Modelo & 4,06 & 0,93 & 3,80 & 1,01 & 4,03 & 0,92 & 3,92 & 1,17 & 2,29 & 0,077 \\
\hline Sentimento dos filhos & 4,49 & 0,79 & 4,35 & 0,92 & 4,40 & 0,91 & 4,26 & 1,11 & 1,92 & 0,126 \\
\hline
\end{tabular}

Fonte: Elaborado pelo autor.

Notas: Nas linhas, as médias com letras iguais não se diferenciam entre si pelo pós teste de Tukey ( $\mathrm{p}<$ 0,005), sendo $\mathrm{a}<\mathrm{b}<\mathrm{c} ; \mathrm{M}=$ Média; $\mathrm{DP}=$ Desvio Padrão 
Tabela 14 - ANOVA de acordo com o tipo de envolvimento em situações de bullying e em relação à qualidade da interação familiar com a figura paterna, sexo feminino. Uberaba, 2014.

\begin{tabular}{|c|c|c|c|c|c|c|c|c|c|c|}
\hline \multirow{3}{*}{$\begin{array}{l}\text { Dimensões - qualidade } \\
\text { da interação familiar }\end{array}$} & \multicolumn{8}{|c|}{ Clusters } & \multirow[b]{3}{*}{ Z } & \multirow[b]{3}{*}{$\mathrm{p}$} \\
\hline & \multicolumn{2}{|c|}{$\begin{array}{l}\text { Não- } \\
\text { envolvidos }\end{array}$} & \multicolumn{2}{|c|}{ Agressores } & \multicolumn{2}{|c|}{ Vítimas } & \multicolumn{2}{|c|}{$\begin{array}{l}\text { Vítimas- } \\
\text { agressoras }\end{array}$} & & \\
\hline & M & $\mathrm{DP}$ & M & DP & $\mathrm{M}$ & DP & M & DP & & \\
\hline Envolvimento & $3,80 \mathrm{a}$ & 1,01 & $3,39 a$ & 1,09 & $3,43 a$ & 1,11 & $3,23 a$ & 1,12 & 5,39 & 0,001 \\
\hline Regras e monitoria & $4,15 a$ & 0,84 & $3,81 \mathrm{a}$ & 0,96 & $3,84 a$ & 1,08 & $3,71 \mathrm{a}$ & 0,89 & 5,05 & 0,002 \\
\hline Punição física & $1,41 \mathrm{a}$ & 0,70 & $1,55 a$ & 0,76 & $1,80 \mathrm{a}$ & 1,05 & $1,80 \mathrm{a}$ & 1,17 & 5,96 & 0,001 \\
\hline Comunicação positiva & 2,74 & 1,17 & 2,50 & 1,22 & 2,45 & 1,20 & 2,35 & 1,15 & 1,97 & 0,118 \\
\hline Comunicação negativa & $2,06 a$ & 0,90 & $2,37 a$ & 0,97 & $2,54 \mathrm{ab}$ & 1,12 & $2,94 b$ & 1,00 & 10,31 & 0,000 \\
\hline Clima conjugal positivo & 3,48 & 1,16 & 2,97 & 1,30 & 3,41 & 1,05 & 3,26 & 1,11 & 2,61 & 0,051 \\
\hline Clima conjugal negativo & $2,10 \mathrm{a}$ & 0,97 & $2,73 b$ & 1,23 & $2,27 a b$ & 1,05 & $2,60 \mathrm{ab}$ & 1,22 & 6,48 & 0,000 \\
\hline Modelo & $3,91 b$ & 0,95 & $3,37 a b$ & 1,28 & $3,67 a b$ & 0,99 & $3,29 a$ & 1,23 & 6,35 & 0,000 \\
\hline Sentimento dos filhos & $4,38 \mathrm{a}$ & 0,87 & $3,89 a$ & 1,26 & 4,07a & 1,06 & $3,88 \mathrm{a}$ & 1,36 & 6,38 & 0,000 \\
\hline
\end{tabular}

Fonte: Elaborado pelo autor.

Notas: Nas linhas, as médias com letras iguais não se diferenciam entre si pelo pós teste de Tukey $(\mathrm{p}<$ 0,005), sendo $\mathrm{a}<\mathrm{b}<\mathrm{c} ; \mathrm{M}=$ Média; DP = Desvio Padrão

Entre os meninos, no que se refere às dimensões "clima conjugal positivo", "modelo", e "sentimento dos filhos", não foram encontradas diferenças estatísticas entre os grupos. Referente à "punição física", o grupo das vítimas e vítimas-agressoras apresentaram as maiores médias, sendo que os resultados desse grupo eram significativamente diferentes em relação aos outros dois grupos de meninos.

No conjunto de dados das meninas, o grupo das vítimas-agressoras se diferenciaram dos grupos de agressoras e não envolvidos na avaliação da escala negativa “comunicação negativa”, e o grupo das agressoras se diferenciou das estudantes nãoenvolvidas na escala sobre o "clima conjugal negativo".

Dados da ANOVA relacionados à figura materna são apresentados nas Tabela 15 e Tabela 16. 
Tabela 15 - ANOVA de acordo com o tipo de envolvimento em situações de bullying e em relação à qualidade da interação familiar com a figura materna, sexo masculino. Uberaba, 2014.

\begin{tabular}{|c|c|c|c|c|c|c|c|c|c|c|}
\hline \multirow{3}{*}{$\begin{array}{l}\text { Dimensões - qualidade } \\
\text { da interação familiar }\end{array}$} & \multicolumn{8}{|c|}{ Clusters } & \multirow[b]{3}{*}{$\mathrm{Z}$} & \multirow[b]{3}{*}{$\mathrm{p}$} \\
\hline & \multicolumn{2}{|c|}{$\begin{array}{l}\text { Não- } \\
\text { envolvidos }\end{array}$} & \multicolumn{2}{|c|}{ Agressores } & \multicolumn{2}{|c|}{ Vítimas } & \multicolumn{2}{|c|}{$\begin{array}{l}\text { Vítimas- } \\
\text { agressoras }\end{array}$} & & \\
\hline & M & DP & M & DP & M & DP & M & $\mathrm{DP}$ & & \\
\hline Envolvimento & $4,15 b$ & 0,78 & $3,85 a$ & 0,84 & $4,09 \mathrm{ab}$ & 0,78 & $3,99 \mathrm{ab}$ & 1,03 & 6,06 & 0,000 \\
\hline Regras e monitoria & $4,23 \mathrm{bc}$ & 0,79 & $3,86 a$ & 0,80 & $4,26 c$ & 0,72 & $4,02 \mathrm{ab}$ & 0,89 & 10,75 & 0,000 \\
\hline Punição física & $1,59 \mathrm{a}$ & 0,81 & $1,66 a$ & 0,76 & $2,02 b$ & 1,09 & $2,13 b$ & 1,22 & 14,85 & 0,000 \\
\hline Comunicação positiva & $3,06 \mathrm{~b}$ & 1,10 & $2,65 a$ & 1,09 & $3,12 b$ & 1,13 & $3,01 b$ & 1,13 & 6,18 & 0,000 \\
\hline Comunicação negativa & $1,88 \mathrm{a}$ & 0,76 & $2,39 b$ & 0,92 & $2,40 \mathrm{~b}$ & 1,06 & $2,52 b$ & 1,11 & 31,95 & 0,000 \\
\hline Clima conjugal positivo & 3,36 & 1,24 & 3,20 & 1,22 & 3,13 & 1,24 & 3,30 & 1,32 & 1,45 & 0,226 \\
\hline Clima conjugal negativo & $1,86 \mathrm{a}$ & 0,84 & $2,12 b$ & 0,99 & $2,32 b$ & 1,15 & $2,30 \mathrm{~b}$ & 1,13 & 12,56 & 0,000 \\
\hline Modelo & $4,12 b$ & 0,87 & $3,83 a$ & 0,91 & $4,00 \mathrm{ab}$ & 0,87 & $4,04 \mathrm{ab}$ & 1,10 & 4,52 & 0,004 \\
\hline Sentimento dos filhos & $4,60 \mathrm{~b}$ & 0,66 & $4,39 \mathrm{ab}$ & 0,76 & $4,55 \mathrm{ab}$ & 0,61 & $4,36 \mathrm{a}$ & 1,04 & 5,79 & 0,001 \\
\hline
\end{tabular}

Fonte: Elaborado pelo autor.

Notas: Nas linhas, as médias com letras iguais não se diferenciam entre si pelo pós teste de Tukey $(\mathrm{p}<$ 0,005), sendo $\mathrm{a}<\mathrm{b}<\mathrm{c} ; \mathrm{M}=$ Média; $\mathrm{DP}=$ Desvio Padrão

Tabela 16 - ANOVA de acordo com o tipo de envolvimento em situações de bullying e em relação à qualidade da interação familiar com a figura materna, sexo feminino. Uberaba, 2014.

\begin{tabular}{|c|c|c|c|c|c|c|c|c|c|c|}
\hline \multirow{3}{*}{$\begin{array}{l}\text { Dimensões - qualidade } \\
\text { da interação familiar }\end{array}$} & \multicolumn{8}{|c|}{ Clusters } & \multirow[b]{3}{*}{$\mathrm{Z}$} & \multirow[b]{3}{*}{ p } \\
\hline & \multicolumn{2}{|c|}{$\begin{array}{l}\text { Não- } \\
\text { envolvidos }\end{array}$} & \multicolumn{2}{|c|}{ Agressores } & \multicolumn{2}{|c|}{ Vítimas } & \multicolumn{2}{|c|}{$\begin{array}{l}\text { Vítimas- } \\
\text { agressoras }\end{array}$} & & \\
\hline & M & DP & $\mathrm{M}$ & DP & $\mathrm{M}$ & DP & $\mathrm{M}$ & $\mathrm{DP}$ & & \\
\hline Envolvimento & $3,99 \mathrm{~b}$ & 0,93 & $3,61 \mathrm{ab}$ & 1,01 & $3,61 a b$ & 1,15 & $3,28 \mathrm{a}$ & 1,00 & 12,53 & 0,000 \\
\hline Regras e monitoria & $4,39 \mathrm{~b}$ & 0,68 & $4,10 \mathrm{a}$ & 0,75 & $4,03 a$ & 0,96 & $4,26 a b$ & 0,66 & 10,96 & 0,000 \\
\hline Punição física & $1,50 \mathrm{a}$ & 0,74 & $1,89 \mathrm{~b}$ & 1,15 & $2,09 \mathrm{~b}$ & 1,04 & $2,02 \mathrm{~b}$ & 1,24 & 22,84 & 0,000 \\
\hline Comunicação positiva & $3,35 a$ & 1,23 & $3,04 a$ & 1,17 & $2,99 a$ & 1,26 & $3,02 \mathrm{a}$ & 1,25 & 4,26 & 0,005 \\
\hline Comunicação negativa & $2,20 \mathrm{a}$ & 0,95 & $3,02 \mathrm{~b}$ & 1,04 & $2,82 \mathrm{~b}$ & 1,18 & $3,00 \mathrm{~b}$ & 1,07 & 29,72 & 0,000 \\
\hline Clima conjugal positivo & $3,18 \mathrm{a}$ & 1,24 & $2,74 a$ & 1,33 & $2,87 \mathrm{a}$ & 1,28 & $2,82 \mathrm{a}$ & 1,16 & 4,67 & 0,003 \\
\hline Clima conjugal negativo & $2,06 a$ & 0,97 & $2,91 \mathrm{~b}$ & 1,15 & $2,29 a$ & 1,14 & $2,74 \mathrm{~b}$ & 1,17 & 18,88 & 0,000 \\
\hline Modelo & $4,02 b$ & 0,85 & $3,70 \mathrm{~b}$ & 1,07 & $3,70 \mathrm{~b}$ & 1,01 & $3,30 \mathrm{a}$ & 1,27 & 11,65 & 0,000 \\
\hline Sentimento dos filhos & $4,52 \mathrm{c}$ & 0,69 & $4,18 \mathrm{~b}$ & 0,99 & $4,22 \mathrm{~b}$ & 0,97 & $3,86 a$ & 1,18 & 14,58 & 0,000 \\
\hline
\end{tabular}

Fonte: Elaborado pelo autor.

Notas: Nas linhas, as médias com letras iguais não se diferenciam entre si pelo pós teste de Tukey ( $\mathrm{p}<$ 0,005), sendo $\mathrm{a}<\mathrm{b}<\mathrm{c} ; \mathrm{M}=$ Média; DP = Desvio Padrão

$\mathrm{Na}$ interação familiar com a figura materna, entre os meninos, foram registradas diferenças significativas entre os grupos em oito dimensões. Observa-se que as diferenças mais significativas se concentram entre os estudantes não-envolvidos e os agressores. Inversamente, os grupos de agressores, vítimas e vítimas-agressoras se diferenciam do grupo de não-envolvidos nas escalas negativas. No caso das meninas, as diferenças entre 
os grupos indicam que as vítimas-agressoras se diferenciam do grupo dos estudantes nãoenvolvidos nas escalas "envolvimento", "modelo" e "sentimentos dos filhos". No que se refere às "regras e monitoria" as diferenças estão entre o grupo de não-envolvidos e os grupos de agressores e vítimas. No caso das escalas negativas, agressores, vítimas e vítimas-agressoras se diferenciam do grupo de não-envolvidos.

Não foram encontradas diferenças entre os grupos para ambos os sexos na análise sobre a interação familiar com outra pessoa que ocupasse alguma função parental. No caso das meninas, somente "punição física" diferenciou o grupo das vítimas dos demais grupos. Os dados relacionados à interação familiar com outra pessoa estão sumarizados nas Tabela 17 e Tabela 18.

Tabela 17 - ANOVA de acordo com o tipo de envolvimento em situações de bullying e em relação à qualidade da interação familiar com outra pessoa, sexo masculino. Uberaba, 2014.

\begin{tabular}{|c|c|c|c|c|c|c|c|c|c|c|}
\hline \multirow{3}{*}{$\begin{array}{l}\text { Dimensões - qualidade } \\
\text { da interação familiar }\end{array}$} & \multicolumn{8}{|c|}{ Clusters } & \multirow[b]{3}{*}{ Z } & \multirow[b]{3}{*}{ p } \\
\hline & \multicolumn{2}{|c|}{$\begin{array}{l}\text { Não- } \\
\text { envolvidos }\end{array}$} & \multicolumn{2}{|c|}{ Agressores } & \multicolumn{2}{|c|}{ Vítimas } & \multicolumn{2}{|c|}{$\begin{array}{l}\text { Vítimas- } \\
\text { agressoras }\end{array}$} & & \\
\hline & $\mathrm{M}$ & DP & $\mathrm{M}$ & DP & $\mathrm{M}$ & DP & $\mathrm{M}$ & DP & & \\
\hline Envolvimento & 3,73 & 1,03 & 3,31 & 1,05 & 3,71 & 0,89 & 3,51 & 0,98 & 0,89 & 0,449 \\
\hline Regras e monitoria & 3,84 & 1,12 & 3,42 & 1,11 & 4,15 & 0,69 & 3,71 & 1,09 & 1,10 & 0,350 \\
\hline Punição física & $1,46 a$ & 0,78 & $2,44 a$ & 1,40 & $1,66 \mathrm{a}$ & 0,83 & $1,74 a$ & 1,09 & 5,45 & 0,001 \\
\hline Comunicação positiva & 2,72 & 1,06 & 2,78 & 1,45 & 2,44 & 1,22 & 2,24 & 0,80 & 1,21 & 0,310 \\
\hline Comunicação negativa & $1,89 \mathrm{a}$ & 0,81 & $2,49 a$ & 1,22 & $2,18 \mathrm{a}$ & 0,94 & $2,54 a$ & 1,12 & 4,11 & 0,008 \\
\hline Clima conjugal positivo & 3,45 & 1,13 & 3,39 & 1,07 & 3,65 & 1,04 & 3,11 & 1,12 & 0,64 & 0,590 \\
\hline Clima conjugal negativo & 1,92 & 0,92 & 2,40 & 0,91 & 1,94 & 0,78 & 2,43 & 1,06 & 2,38 & 0,072 \\
\hline Modelo & 3,93 & 1,05 & 3,87 & 0,95 & 3,92 & 1,17 & 3,76 & 1,01 & 0,13 & 0,945 \\
\hline Sentimento dos filhos & 4,13 & 1,10 & 3,72 & 1,33 & 4,45 & 0,60 & 4,31 & 1,08 & 1,19 & 0,315 \\
\hline
\end{tabular}


Tabela 18 - ANOVA de acordo com o tipo de envolvimento em situações de bullying e em relação à qualidade da interação familiar com outra pessoa, sexo feminino. Uberaba, 2014 .

\begin{tabular}{|c|c|c|c|c|c|c|c|c|c|c|}
\hline \multirow{3}{*}{$\begin{array}{l}\text { Dimensões - qualidade } \\
\text { da interação familiar }\end{array}$} & \multicolumn{8}{|c|}{ Clusters } & \multirow[b]{3}{*}{$\mathrm{Z}$} & \multirow[b]{3}{*}{$\mathrm{p}$} \\
\hline & \multicolumn{2}{|c|}{$\begin{array}{l}\text { Não- } \\
\text { envolvidos }\end{array}$} & \multicolumn{2}{|c|}{ Agressores } & \multicolumn{2}{|c|}{ Vítimas } & \multicolumn{2}{|c|}{$\begin{array}{l}\text { Vítimas- } \\
\text { agressoras }\end{array}$} & & \\
\hline & M & $\mathrm{DP}$ & M & DP & M & DP & $\mathrm{M}$ & $\mathrm{DP}$ & & \\
\hline \multicolumn{11}{|l|}{ Outra pessoa } \\
\hline Envolvimento & 3,50 & 1,15 & 2,99 & 1,13 & 3,21 & 1,36 & 3,81 & 1,46 & 1,08 & 0,360 \\
\hline Regras e monitoria & 3,94 & 1,16 & 3,92 & 0,85 & 3,84 & 0,89 & 4,06 & 1,13 & 0,07 & 0,976 \\
\hline Punição física & $1,31 \mathrm{a}$ & 0,59 & $1,22 \mathrm{a}$ & 0,43 & $1,31 \mathrm{a}$ & 0,48 & $2,75 b$ & 1,52 & 7,76 & 0,000 \\
\hline Comunicação positiva & 2,62 & 1,25 & 2,08 & 0,75 & 2,61 & 1,26 & 3,25 & 1,50 & 1,09 & 0,356 \\
\hline Comunicação negativa & $1,85 a$ & 0,83 & $2,43 a$ & 0,84 & $2,50 \mathrm{a}$ & 1,15 & $2,50 \mathrm{a}$ & 1,72 & 4,82 & 0,003 \\
\hline Clima conjugal positivo & 3,29 & 1,06 & 2,98 & 1,13 & 3,26 & 1,30 & 2,50 & 1,76 & 0,87 & 0,459 \\
\hline Clima conjugal negativo & 2,05 & 0,93 & 2,29 & 0,71 & 2,27 & 1,12 & 2,56 & 1,78 & 0,80 & 0,498 \\
\hline Modelo & 3,72 & 1,02 & 3,39 & 1,29 & 3,74 & 1,09 & 3,58 & 1,40 & 0,38 & 0,764 \\
\hline Sentimento dos filhos & 4,09 & 1,11 & 3,73 & 1,26 & 3,84 & 1,13 & 4,10 & 1,18 & 0,60 & 0,615 \\
\hline
\end{tabular}

Fonte: Elaborado pelo autor.

Notas: Nas linhas, as médias com letras iguais não se diferenciam entre si pelo pós teste de Tukey (p < 0,005), sendo $\mathrm{a}<\mathrm{b}<\mathrm{c} ; \mathrm{M}=$ Média; DP = Desvio Padrão

Em resumo, a análise de variância (ANOVA) indicou diferenças estatisticamente significativas entre os quatro grupos de participantes e em relação às nove dimensões da qualidade de interação familiar avaliadas, sendo possível refutar a hipótese zero $\left(\mathrm{H}_{0}\right)$ do estudo de que não haveria diferenças entre os grupos de estudantes em relação às dimensões de qualidade das interações familiares. Confirmando, dessa forma, a primeira hipótese $\left(\mathrm{H}_{1}\right)$ da pesquisa de que haveriam diferenças entre os grupos no que se refere à análise da qualidade das interações familiares.

Nas comparações post hoc foi possível verificar que o grupo de estudantes nãoenvolvidos em situações de bullying se diferenciaram em relação aos outros três grupos na análise das escalas positivas e, inversamente, agressores, vítimas e vítimas-agressoras se diferenciaram em relação aos não-envolvidos nas escalas negativas. Análises que permaneceram semelhantes tanto entre meninos quanto meninas, salvaguardadas algumas especificidades. Esses dados sugerem melhor qualidade nas interações familiares entre os estudantes do grupo não-envolvidos. Confirmando a segunda hipótese $\left(\mathrm{H}_{2}\right)$ do estudo de que os estudantes não-envolvidos em situações de bullying apresentam melhores índices de qualidade das interações familiares.

A regressão logística comparando os quatro grupos de estudantes identificados pelo estudo (variáveis dependentes) em relação ao sexo, à idade e às noves dimensões de qualidade da interação familiar (variáveis independentes) permitiu que fossem observadas algumas diferenças estatísticas entre os grupos (Tabela 19). 
Tabela 19 - Fatores da qualidade de interação familiar associados ao envolvimento ou não envolvimento de estudantes em situações de bullying. Uberaba, 2014.

\begin{tabular}{|c|c|c|c|c|c|c|c|c|c|c|c|c|c|c|c|c|}
\hline & \multicolumn{4}{|c|}{ Agressores } & \multicolumn{4}{|c|}{ Vítimas } & \multicolumn{4}{|c|}{ Vítimas-agressoras } & \multicolumn{4}{|c|}{ Sem envolvimento } \\
\hline & \multirow{2}{*}{ OR } & \multicolumn{2}{|c|}{ IC $95 \%$} & \multirow{2}{*}{$\mathrm{p}$} & \multirow{2}{*}{$\mathrm{OR}$} & \multicolumn{2}{|c|}{ IC $95 \%$} & \multirow{2}{*}{$\mathrm{p}$} & \multirow{2}{*}{$\mathrm{OR}$} & \multicolumn{2}{|c|}{ IC $95 \%$} & \multirow{2}{*}{$\mathrm{p}$} & \multirow{2}{*}{ OR } & \multicolumn{2}{|c|}{ IC $95 \%$} & \multirow{2}{*}{$\mathrm{p}$} \\
\hline & & L.I. & L.S. & & & L.I. & L.S. & & & L.I. & L.S. & & & L.I. & L.S. & \\
\hline Intercépito & 0,01 & & & 0,00 & 0,12 & & & 0,00 & 0,00 & & & 0,00 & 12,47 & & & 0,00 \\
\hline Sexo & 3,69 & 2,83 & 4,80 & 0,00 & 1,57 & 1,23 & 2,00 & 0,00 & 3,23 & 2,12 & 4,90 & 0,00 & 0,41 & 0,33 & 0,50 & 0,00 \\
\hline Idade & 1,05 & 0,99 & 1,12 & 0,11 & 0,87 & 0,81 & 0,92 & 0,00 & 1,00 & 0,91 & 1,11 & 0,96 & 1,07 & 1,01 & 1,12 & 0,02 \\
\hline Envolvimento & 1,07 & 0,84 & 1,35 & 0,58 & 1,05 & 0,83 & 1,33 & 0,68 & 1,27 & 0,87 & 1,84 & 0,21 & 0,98 & 0,80 & 1,19 & 0,83 \\
\hline Regras e monitoria & 0,80 & 0,67 & 0,94 & 0,01 & 0,97 & 0,81 & 1,15 & 0,70 & 0,98 & 0,75 & 1,29 & 0,90 & 1,21 & 1,04 & 1,40 & 0,01 \\
\hline Punição física & 1,09 & 0,94 & 1,26 & 0,27 & 1,26 & 1,09 & 1,45 & 0,00 & 1,22 & 0,99 & 1,51 & 0,06 & 0,84 & 0,74 & 0,95 & 0,01 \\
\hline Comunicação positiva & 0,92 & 0,80 & 1,05 & 0,20 & 1,00 & 0,88 & 1,14 & 0,98 & 0,96 & 0,78 & 1,18 & 0,71 & 1,05 & 0,94 & 1,17 & 0,40 \\
\hline Comunicação negativa & 1,69 & 1,43 & 2,01 & 0,00 & 1,81 & 1,52 & 2,15 & 0,00 & 1,80 & 1,38 & 2,34 & 0,00 & 0,53 & 0,46 & 0,62 & 0,00 \\
\hline Clima conjugal positivo & 1,04 & 0,93 & 1,16 & 0,53 & 0,97 & 0,87 & 1,08 & 0,57 & 1,01 & 0,85 & 1,21 & 0,91 & 1,01 & 0,92 & 1,10 & 0,92 \\
\hline Clima conjugal negativo & 1,17 & 1,02 & 1,33 & 0,02 & 1,01 & 0,89 & 1,16 & 0,82 & 1,08 & 0,88 & 1,33 & 0,44 & 0,91 & 0,81 & 1,02 & 0,09 \\
\hline Modelo & 0,97 & 0,80 & 1,16 & 0,71 & 1,03 & 0,85 & 1,24 & 0,77 & 0,99 & 0,74 & 1,32 & 0,93 & 1,00 & 0,85 & 1,17 & 0,96 \\
\hline Sentimento dos filhos & 1,14 & 0,90 & 1,44 & 0,29 & 1,09 & 0,86 & 1,39 & 0,46 & 0,92 & 0,64 & 1,32 & 0,66 & 0,84 & 0,68 & 1,03 & 0,09 \\
\hline
\end{tabular}

Fonte: Elaborado pelo autor. 
A variável independente "sexo" se manteve associada significativamente com os quatro grupos de estudantes. 0 sexo masculino foi mais associado com os grupos dos agressores (OR:3,69; $\mathrm{p}=0,00)$, vítimas (OR:1,57; $\mathrm{p}=0,00)$ e vítimas-agressoras (OR:3,23; $\mathrm{p}=0,00)$. As meninas se associaram com o grupo dos estudantes não-envolvidos (OR:0,41; $\mathrm{p}=0,00$ ). Esses dados demonstram maior vulnerabilidade do sexo masculino para o envolvimento em situações de bullying em relação às meninas.

A variável "idade" se manteve associada significativamente apenas com os grupos das vítimas (OR:0,87; $p=0,00$ ) e dos estudantes não-envolvidos (OR:1,07; $p=0,02$ ). Nesses casos, quanto menor a idade dos estudantes maior a possibilidade de ocorrer a vitimização e, na medida em que a idade aumenta, menores a chance dos estudantes serem qualificados em um dos três grupos de envolvimento com as situações de bullying.

0 primeiro modelo de regressão, realizado para determinar os efeitos do sexo, da idade e das nove dimensões da qualidade de interação familiar na probabilidade dos participantes se tornarem agressores, foi estatisticamente significativo, $X^{2}(11)=222,831$, p<0,01. O modelo explicou 15,5\% ( $R^{2}$ de Nagelkerke) da variância da agressão e classificou corretamente $84 \%$ dos casos. No que se refere às variáveis da qualidade de interação familiar, observou-se que a dimensão "regras e monitoria" (OR:0,80; p=0,01) possui caráter protetivo em relação ao comportamento agressivo na escola. Por outro lado, “comunicação negativa" (OR:1,69; p=0,00) e "clima conjugal negativo" (OR:1,17; $p=0,02$ ) aumentavam as chances dos estudantes serem inseridos no grupo de estudantes identificados como agressores.

O segundo modelo foi desenvolvido para determinar os efeitos do sexo, da idade e das nove dimensões da qualidade de interação familiar na probabilidade dos participantes serem vitimizados. 0 modelo foi estatisticamente significativo, $X^{2}(11)=$ 156,926, p<0,01, e explicou 11,2\% ( $\mathrm{R}^{2}$ de Nagelkerke) da variância da vitimização e classificou corretamente $85 \%$ dos casos. As dimensões da qualidade de interação familiar "punição física" (OR:1,26; p=0,00) e “comunicação negativa" (OR:1,81; p=0,00) se mantiveram associadas significativamente com a condição de vítimas dos estudantes, indicando que sua ocorrência no ambiente doméstico aumentavam a chance de vitimização.

0 terceiro modelo de regressão logística, também, foi estatisticamente significativo, $\mathrm{X}^{2}(11)=89,176, \mathrm{p}<0,01$, explicando $10,8 \%\left(\mathrm{R}^{2}\right.$ de Nagelkerke $)$ da variância da agressão e da vitimização, e classificando corretamente $95 \%$ dos casos. Nesse modelo, 
determinou-se que a dimensão da qualidade de interação familiar "comunicação negativa" (OR:1,80; $p=0,00)$ se manteve associada significativamente com a condição de vítima-agressora.

Em relação ao último modelo testado para determinar os efeitos do sexo, da idade e das nove dimensões da qualidade de interação familiar na probabilidade dos participantes não se envolverem com bullying, verificou-se que ele foi estatisticamente significativo, $\mathrm{X}^{2}(11)=271,763, \mathrm{p}<0,01$, explicou $16 \%\left(\mathrm{R}^{2}\right.$ de Nagelkerke) da variância da agressão vitimização, e classificou corretamente $76 \%$ dos casos. Esse modelo demonstrou, ainda, que a dimensão da qualidade de interação familiar "regras e monitoria" (OR:1,21; p=0,01) possuía poder protetivo, na medida em que o aumento de sua pontuação diminuía a possibilidade de qualificação em um dos grupos de envolvimento com as situações de bullying. Por outro lado, as dimensões "punição física" (OR:0,84; $\mathrm{p}=0,01)$ e "comunicação negativa" (OR:0,53; p=0,00) aumentavam a condição de vulnerabilidade para o bullying ou a vitimização.

A partir dos dados analisados nos modelos testados, confirmou-se a terceira hipótese $\left(\mathrm{H}_{3}\right)$ do estudo de que a comunicação negativa, o clima conjugal negativo e a punição física estariam associadas e seriam preditoras para o status dos estudantes identificados como agressores, vítimas e/ou vítimas-agressoras. Comunicação e clima conjugal negativos aumentavam as chances da prática do bullying, ao passo que punição física e comunicação negativa na família aumentavam as chances dos estudantes serem vítimas de bullying. A probabilidade de inclusão em situações de vitimização e agressão (vítimas-agressoras) foi predita, apenas, pela dimensão "comunicação negativa". Entrementes, a quarta hipótese $\left(\mathrm{H}_{4}\right)$ da pesquisa foi rejeitada parcialmente, pois somente a dimensão "regras e monitoria" apresentou poder protetivo em relação ao não envolvimento dos estudantes em situações de bullying, sobretudo no que se refere à sua prática. 


\subsection{Descobertas da etapa qualitativa}

No que se refere ao conjunto qualitativo de dados, a maioria dos entrevistados (n=24;44,0\%) manifestou já ter testemunhado alguma agressão ou vitimização por bullying entre os colegas. Dezesseis estudantes (29,0\%) revelaram já ter sofrido bullying na escola e oito adolescentes (15,0\%) declaram ter praticado algum tipo de agressão dessa natureza contra outros colegas. Nesse grupo, sete estudantes $(12,0 \%)$ referiram nunca ter praticado, sofrido ou testemunhado situações de bullying na escola. Essa condição foi declarada pelos participantes durante as entrevistas e não se referem às respostas que eles apresentaram na "Escala de Vitimização e Agressão Entre Pares (EVAP)" da etapa quantitativa do estudo. Nota-se que, nesse nível da análise, não se registrou a ocorrência de vítimas-agressoras como ocorreu na etapa quantitativa.

O grupo de participantes dessa etapa, ainda, caracterizou-se por uma maior participação do sexo masculino (53,0\%) em relação ao sexo feminino $(47,0 \%)$ e todos os anos e instituições escolares selecionadas para a pesquisa foram compreendidos. Estudantes que se declararam agressores e observadores estavam bem distribuídos de acordo com faixa etária compreendida pelo estudo (11 a 19 anos). A maioria das vítimas, por seu turno, concentrou-se entre os 11 e 13 anos $(n=10)$. Os estudantes não envolvidos eram mais velhos, mas dentro da média de idade do grupo de participantes entrevistados $(M=15$ anos $)$.

A figura materna era a mais presente na configuração dos arranjos familiares dos entrevistados, sendo citada por 51 adolescentes. A maioria dos estudantes que declararam ser agressores $(n=4)$, vítimas $(n=7)$ ou observadores de situações de bullying $(n=13)$ conviviam com o pai e a mãe em casa. A ocorrência de famílias recompostas (em que havia a inserção de outra parceira/o do pai ou da mãe) foi mais referida pelas vítimas $(n=5)$, sendo em todos os casos o padrasto a nova figura. Dois participantes vitimizados referiram morar apenas com os avós.

$\mathrm{Na}$ análise das entrevistas emergiram três categorias temáticas: 1) Inter-relações e influências familiares no que ocorre na escola; 2) Família como espaço para o desenvolvimento ético e moral; 3) Sinergias e enfrentamento de base familiar e escolar. No âmbito das três categorias temáticas foi possível identificar relações entre o bullying e as interações familiares. 0 processo de análise e construção das categorias foram 
norteados a partir do referencial teórico-metodológico da Teoria Bioecológica do Desenvolvimento (BRONFENBRENNER, 2011). Na Figura 3 se apresenta a dispersão das categorias temáticas de acordo com tipo de envolvimento em situações de bullying e informações por sexo sobre o número de ocorrências da seleção de citações nas narrativas. 
Figura 4 - Dispersão das categorias temáticas de acordo com tipo de envolvimento em situações de bullying e ocorrência de citação selecionada por sexo. Uberaba, 2014.

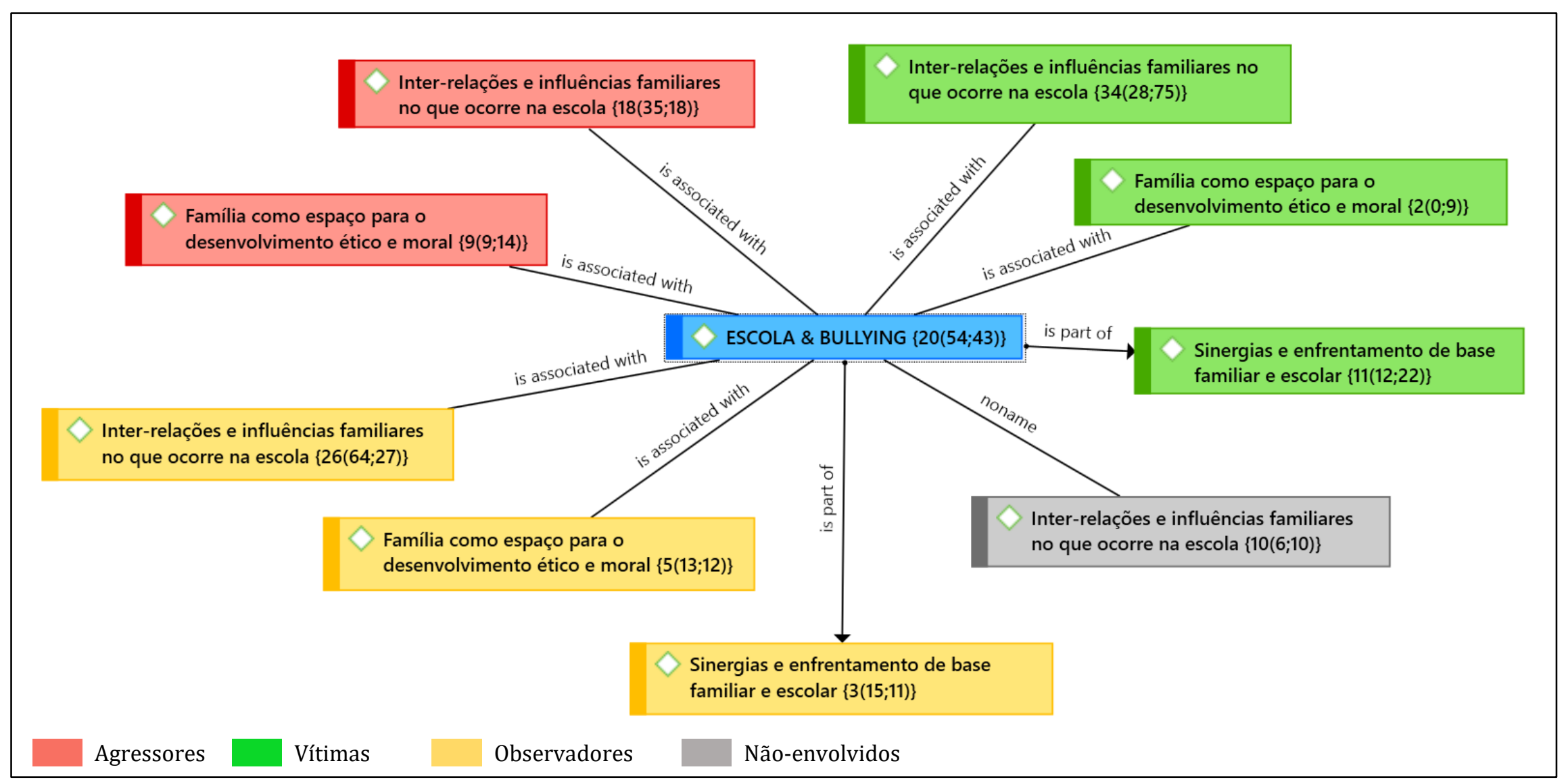

Fonte: Elaborado pelo autor (software Atlas.Ti versão 7).

Leia-se: \{número de códigos aglutinados na categoria(número de ocorrência de citações selecionadas entre os meninos; número de ocorrência de citações selecionadas entre as meninas)\}. 
Observa-se que dados dos estudantes identificados como agressores e nãoenvolvidos com o bullying não ofereceram resultados para a terceira categoria por não manifestaram em suas narrativas desejo ou ações concretas de apoiar ou dar suporte às vítimas. Os estudantes não-envolvidos, também, não estão incluídos nas análises sobre o desenvolvimento ético e moral, temáticas da segunda categoria, por não terem apresentado questões a ela relacionadas. A seguir, as descobertas da etapa qualitativa serão apresentadas de acordo com as três categorias temáticas identificadas.

\section{Categoria temática 1: Inter-relações e influências familiares no que ocorre na escola}

A experiência familiar dos adolescentes era valorizada pelo que guardava de singular, de idiossincrático e privado. No conjunto, a análise dos dados revelou que as famílias eram percebidas como positivas, com relações de reciprocidade e com boa qualidade de interação familiar. Essa constatação foi independente do tipo de envolvimento em situações de bullying ou sexo do participante, como demonstrado nos fragmentos das entrevistas a seguir:

O meu pai e minha mãe nunca discutiram. Eles não me batem, não brigam comigo, só me põe de castigo quando preciso. (Menino 16, 12 anos, vítima) A minha relação com os meus avós é boa. Temos bom convívio e a gente brinca entre si. Não tem discussão: tudo se resolve conversando. (Menina 38, 17 anos, agressora)

Os momentos com a minha família. Conversas e até os momentos difíceis não poderiam faltar [num filme sobre mim]. Porque é o que eu vivo com eles. É quem eu gosto, quem é essencial na minha vida. (Menino 42, 16 anos, vítima)

Minha relação com minha família é boa, legal, normal. Minha mãe é um pouquinho estressada, mas é normal. Eles são educados, carinhosos. $O$ tempo que a gente está junto na sala vendo televisão, se eu deito, eles vêm e fazem carinho. Tudo o que eu faço eu conto para eles, eles também para mim. As experiências deles eles contam para mim. (Menina 46, 14 anos, observadora)

A partir dessa identificação das experiências positivas, objetivas e subjetivas dos adolescentes no contexto familiar, inferiu-se que elas são pontos fortes a serem explorados na discussão sobre fatores de proteção em relação ao bullying escolar. Dessa 
forma, foram exploradas informações sobre as interações familiares positivas como envolvimento, comunicação positiva e clima conjugal positivo que apresentam um potencial protetivo segundo a literatura.

Em geral, o envolvimento familiar dos participantes era positivo, com relatos de manifestação verbal e física de carinho e sensibilidade dos pais ou responsáveis para apoiar e reconhecer os problemas dos filhos, como destacado nos seguintes fragmentos:

Eu tenho uma relação com meu pai mais afetiva. Gosto muito dele. A relação com ele é sempre de amigo. Com minha mãe também é, porque ela fica mais em casa. (Menino 9, 17 anos, agressor)

Meus pais não me maltratam, fazem carinho, me elogiam quando eu faço as coisas. (Menina 21, 12 anos, vítima)

Eu tenho uma boa relação com os dois [pai e mãe]. Natural. Eu não moro com meu pai. Eles são separados, meu pai e minha mãe, desde pequeno. Mas eu vou para lá quase todo final de semana, tenho um bom contato com meu pai, ele passa sempre em casa quando dá para ele, me ajuda bastante. (Menino 17, 15 anos, vítima)

Eu gosto muito deles e eles de mim. (Menino 16, 12 anos, vítima)

Ao qualificarem as relações familiares, a abertura para o diálogo foi uma das questões que se destacaram. Enunciados revelaram a boa comunicação como: "conversamos sobre tudo"; "conto tudo para os meus pais"; "toda hora tem gente para conversar"; "não temos segredos"; "desde pequeno tudo que acontecia eu contava para eles"; "tudo que eu faço falo pra eles". Independentemente do sexo ou tipo de envolvimento com situações de bullying dos participantes foi possível delinear padrões de comunicação positiva nos contextos familiares.

Destacam-se que nos dados dos estudantes que se identificaram como agressores a comunicação positiva na família, também, evidenciou-se. A comunicação não era um problema para esses estudantes que referiram existir diálogos construtivos com as figuras parentais, com quem eles poderiam falar sobre qualquer assunto. Esse destaque é exemplificado nos trechos a seguir:

Todo mundo conversa. Toda hora tem gente para conversar, tem os meus tios que moram lá também. (Menina 38, 17 anos, agressora)

Eu e minha mãe conversamos bastante. Eu conto tudo para ela. Ela me dá bastante carinho, me dá bronca quando precisa. (Menino 3, 13 anos, agressor) 
Final de semana a gente conversa muito, sai para algum lugar, para comer um lanche, alguma coisa assim. São hobbies do dia a dia. A gente faz muita coisa juntos. (Menino 40, 18 anos, agressor)

A boa relação entre as figuras parentais, incluindo a manifestação de afeto, diálogo e respeito entre a dupla foram outros aspectos observados nas narrativas. Pais que não brigavam, demonstravam carinho entre si, compartilhavam aspectos do cotidiano, elogiavam-se mutuamente e falavam bem um do outro foram comportamentos relatados pelos participantes como exemplificado a seguir:

Meus pais não brigam. Nunca brigaram. (Menina 13, 13 anos, vítima)

A convivência é muito boa [dos pais]. Todo mundo está sempre unido. Não pode faltar carinho. (Menino 8, 17 anos, agressor)

Gosto [dos meus pais] porque é muito difícil você ver uma família unida hoje, como meu pai com minha mãe que tem vinte e cinco anos de casados já. (Menino 9, 17 anos, agressor)

Eles [mãe e padrasto] tem uma relação de carinho, amor, afeto. (Menina 12, 14 anos, observadora)

Graças a Deus nunca teve discussão, não tem problema. Minha mãe e meu pai casaram há muito tempo e corre tudo bem. De boa. Conversam. (Menino 30, 18 anos, observador)

[Quando a família se reúne] Alguém sempre conta uma história engraçada. Meu pai de quando ele trabalha, minha mãe, minha irmã do serviço dela, a minha irmãzinha menor conta o que ela fica fazendo na escola, eu conto as situações aqui da escola também. (Menina 22, 12 anos, observadora)

O clima conjugal positivo se revelou como uma experiência complementar para que as interações familiates fossem percebidas como essenciais para a maneira como os adolescentes se comportavam nas escolas ou mesmo se apropriassem de exemplos para o convívio social amplo. Dentro das narrativas alguns aspectos do clima conjugal serão convergentes com, por exemplo, a disseminação de valores éticos e morais que será explorada na segunda categoria temática dessa tese.

Em termos comparativos, esses aspectos das interações familiares positivas (envolvimento, comunicação e clima conjugal), também, foram observados no conjunto de dados dos estudantes não-envolvidos com o bullying:

A gente conversa bastante. Meu pai procura sempre deixar as coisas bem claras, ele não gosta que eu fique escondendo as coisas dele. Então eu confio 
nele, eu confio nele e conto tudo para ele. (Menina 31, 18 anos, sem envolvimento)

Eu gostaria de mostrar [num filme] que a minha família tem um coração bom, é uma família boa. (Menino 11, 17 anos, sem envolvimento)

Minha mãe gosta de mim, eu também gosto dela. Conversamos bastante. Tudo que acontece eu falo para ela. (Menina 43, 16 anos, sem envolvimento)

Minha relação com aminha mãe e meu padrasto é muito boa. Minha mãe é muito amigável comigo, não temos problemas de família. A relação entre minha mãe e meu padrasto, também, é boa. (Menina 53, 15 anos, sem envolvimento)

A gente [família] convive bem. Não tem nenhum conflito. Conversamos. (Menino 26, 16 anos, sem envolvimento)

No grupo das vítimas, ainda, o apego do tipo seguro ${ }^{13}$ às figuras materna, principalmente, e paterna foi um elemento que se apresentou como determinante para a boa interação do grupo familiar:

A convivência é maior com a minha mãe, principalmente quando eu mais preciso. Na hora da luta [...]. Eu tenho anemia falciforme, quanto eu estou com as crises quem está do meu lado é ela. (Menina 23, 18 anos, vítima)

A parte que eu estou em casa e que eu consigo ter um tempo pra dialogar com minha mãe sabe [é importante]? Eu gosto demais dela, incondicionalmente. (Menino 17, 15 anos, vítima)

Às vezes os filhos que são homens falam mais com os pais. Eu falo mais com a minha mãe. [...] Eu falo sempre com eles [pais] sobre os meus problemas, o que acontece de bom comigo, o que acontece de ruim [...]. Só que é aquela coisa: eu passo com a minha mãe primeiro e depois falo com o meu pai. (Menino 42, 16 anos, vítima)

Meu pai nunca briga comigo, meu pai nunca me tratou mal. Nem gritar comigo ele já gritou. [...] Meu pai é muito apegado a mim e ele, também, mostra muito orgulho de mim. (Menina 13, 13 anos, vítima)

0 apego às figuras parentais é um aspecto que propicia a construção de vínculos com outras pessoas, em outros contextos. Observou-se que, o apego seguro pode fazer com que o adolescente vítima de bullying perceba que pode contar com o apoio e o suporte

\footnotetext{
13 Constructo referente à Teoria do Apego de Bowlby. 0 vínculo do tipo seguro é caracterizado pelo atendimento adequado das necessidades da criança. Estudos demostram que esse tipo de apego permite o desenvolvimento de sentimentos de importância pessoal e segurança, aumentando a capacidade de estabelecimento de boas relações interpessoais, melhorando resultados nas escolas e diminuindo problemas de comportamento ao longo do ciclo vital (RAMIRES; SCHNEIDER, 2010).
} 
de um adulto, além de ser um ponto a ser explorado para o desenvolvimento de competências sociais que contribuam com o enfrentamento das situações de agressão. Esse apego, também, foi avaliado por esses estudantes como algo que oferece sentido para a vida e o existir.

Noutra perspectiva, ambientes familiares precários, em termos de níveis estruturais e funcionais, são percebidos como locus de vulnerabilidade, marcados pelo desamparo em face das experiências negativas. Segundo os adolescentes, a base familiar parece ser o que mais influencia e se relaciona com a maneira como os estudantes são na escola, sendo que as experiências de conflito ou de situações limite (brigas, punições corporais etc.) afetam a experiência escolar dos adolescentes, como evidenciado nos fragmentos a seguir:

Se meu pai e minha mãe brigasse ou separasse isso influenciaria no meu comportamento na escola. (Menino 18, 13 anos, agressor)

Quando você fica bravo em casa sempre vai descontar em alguém [...]. Uma vez a minha mãe tentou me ensinar a tabuada. Isso tem muito tempo. $\mathrm{Na}$ época ela me chamou de 'burro' e eu não consigo esquecer. Às vezes eu fico com raiva da minha mãe por isso, por esta palavra e acabou ficando 'desgostoso' para mim. Eu não consigo aprender. (Menino 55, 16 anos, agressor)

A minha avó está doente. Ela tem Alzheimer. Ela é tipo um teste de paciência [...]. Eu tenho muita paciência com ela, eu nunca brigo com ela, eu adoro ficar com ela. Mas tem dia que a minha mãe grita comigo e a minha avó, às vezes, está emburrada. Então isso já me afeta um pouco. (Menina 13, 13 anos, vítima)

É bem difícil! Quando os pais batem demais não adianta nada. Vai bater aí depois, por exemplo, o filho fica ainda mais revoltado e depois vai querer fazer mais coisas erradas. Agora se os pais sentarem e conversarem, aí os filhos vão pensar, conversar, refletir. (Menina 28, 13 anos, vítima)

Bullying é uma ofensa, um desrespeito. É uma raiva que a pessoa tem e desconta na outra pessoa, atoa. A gente tem que olhar o outro lado. A gente não sabe o que essa pessoa que faz o bullying passa dentro da casa dela, da família dela, passa na vida dela. (Menina 45, 19 anos, vítima)

Se eu estiver brigado com a minha irmã, ou com a minha mãe, eu vou chegar mal na escola, nervoso. Quando os pais se separam... Já aconteceu comigo e você chega meio triste na escola. (Menino 10, 15 anos, observador)

Nesse nível da análise, identificou-se algumas variáveis que fortalecem hipóteses da literatura sobre a influência das interações familiares negativas no envolvimento de 
estudantes em situações de bullying. Por exemplo, no âmbito dos afetos, o clima conjugal negativo e os conflitos intrafamiliares produzem, muitas vezes, contextos domésticos adversos e que podem resultar em desvios de comportamento dos filhos nas escolas.

O meu pai é alcoólatra, daí ele bebe, chega lá em casa e briga, discute com a minha mãe. Tem dia que ele bebe e fica de boa e dorme, mas quando ele bebe e dá para abusar fica meio difícil. (Menino 1, 17 anos, observador)

Antigamente meu pai bebia muito, só que ele bebia pinga. [...] Quando eles discutiam xingavam um ao outro, jogava na cara e inventava coisas, tipo traição, tudo inventado, mas é normal em uma discussão quando fica nervoso, eu acho. (Menino 44, 15 anos, observador)

A convivência é boa, entre aspas, porque também tem o meu tio que ele mora com a gente, mas ele não se dá muito bem com a minha mãe. Então sempre tem conflito. (Menina 4, 14 anos, agressora)

[Minha mãe]Briga comigo, é muito ruim. Minha mãe não gosta do meu pai, não dá carinho para ele. Ela é homossexual. Ela não fica com meu pai. Eles só moram junto: meu pai dorme em um quarto e a minha mãe em outro. (Menina 28, 13 anos, vítima)

A sensibilidade para aquilo que ocorre na escola é afetada por vivências domésticas como essas. Acredita-se que não sejam, exclusivamente, essas situações que constroem ou sustentam as situações de bullying, mas elas modelam a percepção de mundo e a sensibilidade para o que ocorre de grave com o outro. São trajetórias que tendem a naturalizar a violência e impedem a erupção do desejo de investir em transformações sociais ou na maneira como os estudantes se relacionam.

Nesse debate, considerou-se como importante, também, a comunicação negativa ou inexistente e episódios de punição corporal que foram assinalados nas narrativas dos adolescentes e são aspectos inversamente correlacionadas aos eventos familiares positivos relatados anteriormente:

Eu não sou muito de conversar com os meus pais, porque eu converso com minha mãe, por exemplo, um minuto depois ela fica jogando na minha cara. Então nós brigamos e ela joga tudo na minha cara. (Menina 28, 13 anos, vítima)

Meu padrasto não conversa comigo e eu também não converso com ele. (Menina 7, 16 anos, vítima)

A minha mãe me bate mais do que meu pai. Meu pai só de vez em quando, ele não é muito de me bater. (Menina 28, 13 anos, vítima) 
A gente [mãe e filha] nem conversa, porque a gente quase não se vê. (Menina, 47, 17 anos, observadora)

Assim como a comunicação positiva pode ser um fator protetivo em relação ao bullying, a comunicação negativa ou inexistente entre os membros da família assume uma posição não integradora, que não gera sentimentos de pertencimento e não articula conhecimentos entre as diferentes gerações. Além disso, como observado, a comunicação negativa ou inexistente, culmina no silenciamento das situações de agressão vividas ou testemunhadas, ponto importante em interconexão com a terceira categoria desse estudo.

A baixa participação dos pais na vida dos filhos (nível de envolvimento familiar), medida pela referência a poucas demonstrações de afeto, carência de apoio e estímulo à autonomia, foram outros elementos extraídos das narrativas dos estudantes:

Eu ligo para ele [pai], ele me vê de vez em quando. Para ele é corrido, porque ele tem uma oficina. (Menino 3, 13 anos, agressor)

Meu pai eu vejo uma vez por ano na época de aniversário. A minha mãe eu vejo de quinze em quinze dias. Só vejo ela no horário de almoço. Ela acha que eu vou ver ela para ela me dar as coisas, se eu for ver ela é porque eu quero roupa quero sapato. (Menina, 38, 17 anos, agressora)

O meu pai trabalha a tarde e de vez em quando ele trabalha de manhã. E a minha mãe trabalha de manhã. Mas a minha mãe também tem que ficar com a minha vó. E a minha irmã fica no curso. Aí a gente não tem jeito de ficar juntos. Aí a noite todo mundo vai dormir, minha irmã fica mexendo no celular, meu pai vendo televisão e eu no computador. (Menina 13, 13 anos, vítima)

Eu tenho contato com meu pai só de domingo, e a minha mãe mora em outra cidade, no estado de São Paulo. (Menina 32, 13 anos, vítima)

A minha mãe dava mais valor para minha irmã do que para mim. Mais carinho também. (Menina 2, 12 anos, observadora)

Quando a minha irmã nasceu, a minha mãe só dava atenção e carinho para eles [padrasto e irmã]. (Menina 7, 16 anos, vítima)

Além disso, estudantes vítimas e agressores expressaram sentimentos de desamparo em suas famílias. Esses sentimentos de desamparo na experiência familiar podem impedir o encontro de amparo na vida compartilhada para o desenvolvimento de relações saudáveis. 
Eles [mãe e padrasto] são de boa, só que um deles dá mais atenção para o meu irmão mais novo. Me dão pouca atenção. Às vezes eu me sinto, sei lá, invisível. Mas é normal. (Menina 4, 14 anos, agressora)

Eu me sinto perdida, por causa que não tem aquele amor de mãe, não tem aquele amor de pai, só de avô e avó. É diferente. (Menina, 38, 17 anos, agressora)

Quando eu sofria abuso sexual, a família em que eu morava [tios] não acreditou em mim e continua acreditando nele. Para mim isso é muito ruim (Menina 32, 13 anos, vítima)

Sugere-se que, os problemas de envolvimento familiar se relacionam com o sentimento de desamparo relatado por vítimas e agressores. 0 reconhecimento de que as relações familiares não são positivas revelaram vínculos fragilizados que são reconhecidos, a partir das narrativas, como padrões de insegurança vividos em outras interações sociais. Essas constatações são reforçadas por um outro nível de análise, já esboçado anteriormente e associado às questões objetivas de vida das figuras parentais que, também, interferem nas interações familiares. Nesse sentido, as longas jornadas de trabalho dos pais e responsáveis foram citadas pelos adolescentes como elemento que dificulta a convivência e maior contato intrafamiliar:

A relação com minha mãe é muito boa e tal, mas a gente convive poucas horas no dia, porque ela trabalha de manhã, de tarde e de noite. É muito corrido para ela. (Menino 40, 18 anos, agressor)

É um pouquinho corrido [a relação com os pais], porque meu pai e minha mãe estão sempre trabalhando. (Menino 55, 16 anos, agressor)

É muito difícil a gente se ver porque quando ela está indo para o serviço eu não estou em casa, já sai para escola, e quando eu chego da escola ela não está em casa. Eu saio para o curso ela ainda não chegou e quando eu chego do curso ela já está dormindo. [...] Eu fico dormindo o final de semana inteiro. Então é muito difícil. (Menina, 47, 17 anos, observadora)

Segundo a literatura, ainda, o estado de saúde dos pais é uma variável a ser considerada em estudos sobre a interface entre o contexto familiar e os comportamentos de bullying. Nesse sentido, estudantes do sexo feminino vítimas de bullying referiram que a saúde mental e física das mães interfere nas relações que a díade (mãe/filho) estabelece:

A minha mãe tem problema de estresse. Ela tem até que tomar remédio. Às vezes, ela grita muito comigo e fica me comparando com a minha irmã. (Menina 13, 13 anos, vítima) 
Tem dias que me dá vontade de sumir. Porque a minha mãe tem que tomar um medicamento durante cinco anos, todos os dias, é uma "quimioterapia pingada", e ela fica muito estressada, muito nervosa. (Menina 7, 16 anos, vítima)

Entrementes, 24 participantes acreditavam que o acontece em casa não influencia no que ocorria ou nos seus comportamentos na escola:

Se fosse assim era para eu vender droga, era para eu ser uma drogada, uma revoltada, porque o meu padrasto fuma maconha. Até uns dois anos atrás a minha mãe vendia droga. (Menina 4, 14 anos, agressora)

Em casa a gente pode ter um comportamento e aqui na escola outro. (Menino 3, 13 anos, agressor)

O que acontece na sua área pessoal, na sua casa, é lá. O que acontece comigo, na minha casa, eu não tenho que trazer para a escola. Eu tenho que deixar em casa. Seja coisa boa, seja coisa ruim. (Menino 17, 15 anos, vítima)

Acho que não tem relação, eu chegar aqui e discutir com um professor porque eu ouvi minha mãe contando uma história de que ela discutiu com um professor quando era jovem, não penso que tem alguma coisa a ver. (Menina 46, 14 anos, observadora)

Porque às vezes eu estou revoltada. Estou com raiva. Eu venho para escola, é como se não tivesse acontecido nada. Não interfere. Eu chego, eu brinco com todo mundo, converso com todo mundo. (Menina 47, 17 anos, observadora)

As coisas que acontecem na minha casa, algum problema, eu deixo na minha casa. Eu não trago para a escola, para descontar em alguma pessoa. (Menina 51, 14 anos, observadora)

Na avaliação desse grupo de participantes há um movimento de separação entre o que acontece em um espaço (família) e outro (escola). Essa noção demonstra uma compreensão sobre a necessidade de separar papéis sociais (filhos/estudante) e "desligar-se" das experiências de um contexto para estar em outro. Essa interpretação, também, ignora a essencialidade da família no processo de formação social e no desenvolvimento humano. Em contradição com a constatação dessa categoria temática de que a modelação do desenvolvimento e do comportamento dos estudantes ocorre por meios das figuras parentais, seus responsáveis ou experiências de base familiar. 


\section{Categoria Temática 2: Família como espaço para o desenvolvimento ético e moral}

Identificou-se no conjunto dos dados aspectos do desenvolvimento ético e moral relacionados às agressões praticadas ou sofridas pelos estudantes no contexto escolar. Esses elementos são importantes para essa tese na medida em que se compreende ser a família uma importante disseminadora de valores e sistemas de crenças que provocam comportamentos positivos ou negativos nas crianças e nos adolescentes. Nesse sentido, a transmissão de valores foi avaliada pelos participantes como um processo unidirecional em que eles, enquanto filhos, eram receptores passivos na família de um conjunto de princípios e regras que eram transportados para as vivências na escola:

Meus pais me falam e eu acho que todo mundo é igual a todo mundo, ninguém pode ser diferente de ninguém ou melhor que o outro. (Menino 19, 13 anos, observador)

Eu sou uma pessoa meio nervosa, é do meu 'gênio'. Então eu acho que, como minha irmã é também bem nervosa, acho que eu puxei isso dela. Alguma coisa que me falam que eu não gosto, eu me irrito. Não bato, essas coisas, mas eu fico bem irritada. Acho que isso eu puxei dela. (Menina 14, 11 anos, vítima)

As coisas que a minha mãe fala eu tenho que escutar para interagir melhor aqui na escola. (Menino 40, 18 anos, agressor)

Quando eu entrei na escola eles [pais] sempre falavam para mim: "Não faz isso"; "Não faz aquilo"; "Fica quieta, não faz bagunça". Porque eu era muito 'atentada'. Então eu sempre fiquei mais quieta nas aulas. (Menina 49, 16 anos, observadora)

Eu vejo eles [pais] fazendo algo que eu acho que é um bom exemplo, eu faço a mesma coisa. Tipo, ser legal com algumas pessoas. (Menino 34, 13 anos, observador)

Denota-se dessa compreensão acerca da transmissão de princípios e valores que houve uma percepção majoritária da família como um espaço educativo para a definição do que é "certo ou errado". Nos fragmentos a seguir essa percepção sobre essa função educadora da família é detalhada:

A educação que meus pais me deram é para respeitar o outro, bastante. Não desrespeitar os professores (isso minha mãe fala bastante), nunca xingar professor, você pode até brincar mais desrespeitar jamais. (Menino 29, 18 anos, observador) 
Do jeito que você é em casa você é na escola. Vai ser a mesma coisa. A educação que os seus pais te deram você vai ter na escola. $O$ principal: a educação. (Menino 8, 16 anos, agressor)

[A família influencia] Um pouco. No âmbito da educação, no jeito de tratar o colega. Quando eles me ensinam a respeitar as autoridades tem uma parte, também, de não ficar brigando com os professores, maltratando. (Menina 21, 12 anos, vítima)

O meu pai sempre me ensinou o que é certo e o que é errado. Minha mãe também. (Menino 42, 16 anos, vítima)

O povo diz 'Maria vai com as outras': se meu amigo está fazendo tal coisa, se está chutando ou agredindo uma pessoa, eu também vou fazer. Se você não tem uma estrutura familiar, você não vai ser uma pessoa boa. Estrutura familiar quando os seus pais te dão uma educação boa, quando você tem no seu lar uma boa influência, você tem um espelho. Você pode se espelhar no seu pai, na sua mãe. (Menina 31, 18 anos, sem envolvimento)

A experiência social é organizada e reorganizada a partir das informações que foram recebidas no contexto familiar. Nesse sentido, esse conjunto de dados permitiu inferências sobre o problema do bullying ser associado a falta de preparo no contexto familiar para o convívio social amplo. Considerando que o bullying é um fenômeno marcado pela intolerância e preconceito, percebem-se deficiências no que se refere à difusão e estímulo a tolerância e valorização da diversidade. Para exemplificar a questão, no caso dos agressores, observou-se que o clima familiar positivo e aprendizagens positivas para o convívio social não os impediu de praticar atos de violência contra os colegas. Nos trechos a seguir se percebe esse movimento de contradição:

Você herda costume, você herda valor, você herda defeitos [da família]. [...] Então, eu aprendi com a minha mãe que fala alto: com certeza eu também falo alto. Só que a gente tem que aprender a tirar as coisas, os valores, não os defeitos. (Menino 9, 17 anos, agressor)

Tudo que minha mãe me ensina eu tento passar para os meus colegas aqui na escola. Eu vou chorar... Respeito, por exemplo, se ela me passa muito respeito. (Menino 40, 18 anos, agressor)

Ainda no que se refere aos estudantes que se autodeclararam agressores, verificou-se o uso de mecanismos de desengajamento moral ${ }^{14}$ para justificar as agressões praticadas. Os mecanismos utilizados por esses participantes foram a difusão de

\footnotetext{
${ }^{14}$ Conceito referente a um conjunto de distorções cognitivas e egoístas que são utilizados para justificar a adoção de comportamentos que, normalmente, promoveriam sentimentos de remorso ou culpa (CARAVITA; GINI, 2010).
} 
responsabilidade (diluindo o senso de responsabilidade com outras pessoas, de modo que ninguém se sinta diretamente responsável pelo que acontece), o uso de eufemismos (justificavam a ação como algo não grave, uma brincadeira) e a culpabilização da vítima pelas agressões (considerando que a vítima provocou as agressões).

Agredir, não: nunca briguei na escola. Mas, brincar de humilhar já. Tipo o cidadão não penteia o cabelo, você fica falando aquele 'trem' repetidamente, o dia inteiro, até ele ficar doido da cabeça. Uma coisa, sempre falando aquilo, sempre falando aquilo, sempre falando aquilo. Você entra na mente dela e ela fica doida, chora. Eu Já fiz isso: a pessoa chorar; mas na época eu achava graça. Todo mundo ria. (Menino 9, 17 anos, agressor)

É gente que fica zombando, tem umas brincadeiras que para você é brincadeira e para a pessoa não é brincadeira. Apelido bobo, jeito de falar da pessoa, o jeito de olhar, você não conhece a pessoa, o jeito de julgar a pessoa sem conhecer. Eu já fiz isso. (Menina 38, 17 anos, agressora)

Tinha uma menina ali na outra sala que não conversava com ninguém. Todo mundo ficava implicando. Todo mundo queria conversar com ela $e$ ficava cochichando perto dela, puxando conversa: "Você já namorou?"; "você tem namorado?". Ela não gostava. Eu fui pela cabeça dos outros. Foi tipo "Maria vai com as outras". (Menina 38, 17 anos, agressora)

Eu excluí porque ele era irritante. [...] Ele chegava, passava corretivo na mesa. (Menino 18, 13 anos, agressor)

[Exemplo de bullying na escola] Tem um colega que tem a cabeça grande e os meninos ficam zoando ele. (Menino 18, 13 anos, agressor)

Os estudantes identificados como agressores, ainda, manifestaram sentimentos de hedonismo, buscavam atingir objetivos próprios quando avaliam as agressões e intencionavam causar sofrimento às vítimas, como pode ser conferido nos trechos a seguir:

Eu pensava assim, como se diz: 'você está na chuva é para se molhar; eu vou fazer isso, porque vai acontecer isso comigo; eu vou falar dele senão ele vai falar de mim'. (Menino 9, 17 anos, agressor)

Que nem agora, a menina nem estava mexendo com a gente, a gente foi implicar com ela, ela começou a falar, a gente foi e bateu nela. [...] Por implicância, a gente às vezes ficava implicando. No caso da [nome da colega], foi 'atoa' mesmo, nós que implicamos com ela. Ela quis revidar e a gente bateu nela. (Menina 4, 14 anos, agressora)

Tem um companheiro aqui da escola e que a gente não queria ele no time de futebol. Ele insistia porque ele estava passando por uma fase difícil da vida dele. A gente foi e excluiu ele do time. Não somente eu, mas os outros amigos também excluíram. Eu acho que sim [foi bullying]. [...] Foi bom fazer 
isso não só para mim, mas para todos que estavam comigo. (Menino 40, 18 anos, agressor)

Teve uma hora que eu não gostei. Fiquei com dó, mas deu um alívio ver ela chorando. Não sei porque, mas foi bom e ruim. Porque foi bom ver ela chorando, porque ela implicou. (Menina 4, 14 anos, agressora)

Além disso, eles também personificavam a experiência de bullying considerando que ela é errada quando se refere a uma agressão cuja justificativa seja uma característica da vítima que se assemelha a um membro de suas famílias, trata-se de um amigo ou se contrapõem a valores morais aprendidos em casa:

A [nome da colega] é bem gordinha. Ela torceu o pé. O povo fica falando que era a gordura dela, que ela não podia jogar bola. Os meninos ficam batendo nela, dando 'safanão'. Eu não gosto. [...] Por causa que na minha família tem muito gordinho e eu não gosto que falem dos gordinhos da minha família. Eu me senti como se fosse um parente meu, porque a gente já foi amiga também. (Menina 38, 17 anos, agressora)

Tinha um moleque que chegou a agredir uma menina. Uma vez eu entrei na frente e ele falou que era para eu sair da frente senão ele ia me bater. Eu falei que não iria sair porque ele não ia bater na menina [...]. Eu não acho certo e aprendi que não é certo bater, muito menos em uma mulher. Não importa qual. (Menino 3, 13 anos, agressor)

Esse é um indício de reflexão ética e moral positiva, mas foi pouco referido pelos agressores. Em geral, as narrativas desses estudantes sobre as situações de bullying demonstraram pouca empatia e senso de auto-responsabilidade diante do outro. Dessa forma, a agressão praticada é explicada a partir das responsabilidades do outro (vítima) sobre os atos.

Esse movimento de justificação e culpabilização foi, também, incorporado pelas vítimas do sexo feminino que quando pensam e refletem sobre si mesmas na dinâmica do bullying, apresentam um comportamento análogo de internalização da culpa pelas agressões. Fato que indica pouca compreensão sobre o próprio papel e o papel desempenhado pelos outros estudantes nas situações de bullying.

Eu também sou muito magra! Eles me chamavam de vareta, de Olívia Palito. [...] Eu tinha até parado de jogar na quadra porque eles me chamavam de magrela e falavam que quem era magra não podia jogar. Eles me ofendiam, eles acabavam comigo. Falavam que eu era horrível, que eu não podia. Então eu parei. Agora, esse ano, estou tentando voltar, mas eu tenho medo. Eu ainda tenho medo. E assim, eu não tenho muitos amigos. (Menina 13, 13 anos, vítima) 
Eu já sofri muito bullying. Por causa que eu não tinha 'cabelão liso'. Até hoje eu não tenho, eu não sou branca. As meninas não conversavam muito comigo. As meninas me excluíam de tudo. Aí era muito ruim, era muito triste isso. (Menina 23, 18 anos, vítima)

Eu já sofri bullying verbalmente. O ano todo! Sempre! Acho que eles [agressores] têm razão também. Geralmente, eles pegam e fazem um apelido, ficam debochando, mas eu já me acostumei. [...] [Eu me sentia] Muito triste, ficava nervosa, envergonhada. Hoje em dia eu já falo: tem razão, tem toda a razão. Eu, basicamente, acredito no que ela [pessoa que agride] está falando. Acho que eu tenho mudado bastante. (Menina 45, 19 anos, vítima)

Assim sendo, percebeu-se que aspectos do desenvolvimento ético e moral se relacionam às vivências familiares, aos exemplos dos pais e responsáveis e aos modelos de educação voltados para a disseminação de valores e princípios. Nessa categoria, também, registrou-se entre os meninos participantes da pesquisa maiores referências a apatia ou indiferença diante das situações de violência testemunhada. As experiências não compartilhadas sugerem que o bullying atravessa as relações, mas parece que ao voltar para casa os meninos preferem não citar esse tipo de situação que ocorre na escola ("não há o que contar"). Esse aspecto se destaca, principalmente, entre os estudantes que não tem nenhum tipo de envolvimento com o fenômeno (não o percebem).

\section{Categoria Temática 3: Sinergias e enfrentamento de base familiar e escolar}

A terceira categoria do presente estudo se refere a dados obtidos junto às vítimas sobre as relações de apoio citadas ou as estratégias utilizadas para enfrentar o bullying. Nesse sentido, observa-se que alguns adolescentes pediram ajuda para a família e, em alguns casos, para outros adultos na escola. Revelou-se que, em geral, eles possuíam poucas pessoas compondo as conexões de apoio ou suporte, ou seja, com quem podiam contar. A estratégia mais utilizada nesses casos foi contar para essas pessoas as situações de agressão vivenciadas. Pais ou responsáveis foram às escolas e buscaram junto à direção solucionar a questão. Contudo, identificou-se que, alguns pais, inadequadamente, foram até as escolas e confrontaram diretamente os agressores ou não atribuíram importância ao relato dos filhos. Nos fragmentos das narrativas a seguir são apresentadas essas diferentes situações: 
Eu era gordo. Eu consegui emagrecer depois. Eu era gordo e eles faziam muita piada comigo. A minha mãe até ia na escola. [...] Teve uma festa junina e eu fiquei sem parceiro. O professor me levou nas salas para arrumar uma parceira. Ninguém queria dançar comigo. (Menino 42, 16 anos, vítima)

A minha mãe me obrigou a vir para a escola porque eu não queria mais estudar, por causa disso. Ela me orientou que não era para eu parar de estudar por causa disso [agressões sofridas]. Depois ela sempre vem me buscar. (Menino 35, 13 anos, vítima)

Depois eu falei com a professora, contei para a minha mãe e ela foi lá e falou com essa aluna [agressora]. (Menina 14, 11 anos, vítima)

Denota-se nesses trechos os esforços das famílias e, em alguns casos de outras pessoas vinculadas ao contexto escolar, em ajudar os estudantes no enfrentamento do processo de vitimização. Contudo, alguns adolescentes não procuraram ajuda ou adotaram estratégias equivocadas de enfretamento como a criação de situações escapistas (fingir adoecimento para sair da escola ou choro, por exemplo). Poucas foram as referências a confronto direto das vítimas com os agressores.

Eu achava que se eu contasse para minha mãe, ela ia na escola e o que ia acontecer? Os outros iam falar que eu era o 'bebezinho' da mamãe, essas coisas. (Menina 23, 18 anos, vítima)

O dia em que o professor de ciências tinha faltado foi o pior dia que eu já tive. Eu lembro direitinho. Eles se reuniram no fundo da sala, ficaram falando de mim, acabavam comigo. Eles me chamavam de horrorosa, de 'cabeção', de nerd, falavam que eu era quatro olhos, que um menino nunca ia olhar para mim, gostar de mim, de tanto que eu era feia, que eu era um monstro, que eu não merecia ter nascido. Aí nesse dia eu fingi que estava passando mal e então eu fui para casa porque eu estava fingindo e eu não aguentei. (Menina 13, 13 anos, vítima)

Acho que essa situação foi a que mais marcou a minha vida. [...] Eu cheguei na escola, um menino chegou e falou assim: 'você acha que você é bonita? você nunca vai ser bonita, você é a menina mais feia desta escola'. Aí eu comecei a chorar e a professora: 'quê que foi [nome da aluna]?; E eu respondi que não era nada. Ele [agressor] falava que se eu contasse para alguém ele ia me bater. [...] Eu sentava bem lá no fundo da sala, bem no cantinho, e ficava lá, quietinha, chorando. (Menina 7, 16 anos, vítima)

Os participantes vitimizados, também, mencionaram que os pais, muitas vezes, os estimulam a ignorar as agressões. Aspecto indicativo de que as figuras parentais reforçam a ideia de que o silêncio, o resignar-se e as estratégias de escapismo, são as melhores respostas para as agressões ou ainda desconhecem a gravidade da situação. 
Minha mãe falava: 'não, você não esquenta. Entra por um ouvido e sai pelo outro; tenta não brigar e se concentra nos seus estudos'. (Menina 45, 19 anos, vítima)

Meu pai falou para eu não falar nada para ela, não falar mal da menina. (Menina 21, 12 anos, vítima)

Minha mãe não gosta que eu brigue na escola. (Menina 27, 12 anos, vítima)

Minha mãe falou que não é para eu caçar briga. Que é para eu ficar mais quieto no meu canto, não conversar com eles [agressores]. Eu estou fazendo. Eu fico mais quieto no meu canto. (Menino 35, 13 anos, vítima)

Quando indagados sobre presenciarem outros estudantes sendo vitimizados, nesse grupo de vítimas, observou-se que muitos dos participantes preferem não adotar comportamentos de defesa para que não sejam duplamente vitimizados.

Eu fiquei calada para não entrar na briga dos outros. Eu já vi várias pessoas chamando a minha amiga de gorda, de baleia. (Menina 6, 13 anos, vítima)

Eu fico olhando e ela fica triste. Eu falo com ela depois, porque na hora se eu for defender ela, vai fazer mal pra mim também. (Menina 32, 13 anos, vítima)

Eu saí de perto dele [vítima sendo agredida]. Eu ia apanhar junto? Eu saí de perto dele e fui para outro lugar. (Menino 35, 13 anos, vítima)

Nota-se que as vítimas fazem referência à própria experiência para (não) compreender a situação de outras vítimas e, mesmo que de forma implícita, reforçam o processo de vitimização (internalização de culpa). Entrementes, alguns dos participantes tentaram ou ajudaram outras vítimas, principalmente quando se tratava de um amigo ou colega próximo. Nesses casos, as estratégias de ajuda mais utilizadas foram aconselhamento ("falo que não é nada daquilo que os outros estão falando"; "falo para esperar dentro da escola ou ligar para os pais"), relato para autoridade escolar ("eu contei para a diretora"; "eu contei para o professor") ou inclusão da vítima em atividades ("se eles têm o grupo deles nós também podemos ter o nosso"; "eu chamei para ficar comigo ou conversar"). As meninas vítimas, que testemunharam situações de bullying, mais que os meninos, manifestaram maior intenção de ajudar ou ajudaram outras vítimas. 
Que a palavra parede não seja símbolo de obstáculos à liberdade nem de desejos reprimidos nem de proibições na infância etc. (essas coisas que acham os reveladores de arcanos mentais)

Não.

Parede que me seduz é de tijolo, adobe preposto ao abdômen de uma casa. Eu tenho um gosto rasteiro de ir por reentrâncias baixar em rachaduras de paredes por frinchas, por gretas - com lascívia de hera.

Sobre o tijolo ser um lábio cego.

Tal um verme que iluminasse.

Manoel de Barros (2010, p. 261-262) 


\section{DISCUSSÃO}

Esse estudo utilizou a triangulação de métodos para analisar e compreender a relação entre a qualidade das interações familiares de adolescentes e o envolvimento em práticas de bullying escolar ou vitimização. Os dados quantitativos coletados junto a 2.354 estudantes de 11 escolas públicas de Uberaba/MG revelaram uma taxa de prevalência de 10,3\% de estudantes agressores, 10,1\% de vítimas e 5,4\% de vítimas-agressoras na amostra. No conjunto de dados qualitativos, coletado por meio de 55 entrevistas semiestruturadas, 29,0\% dos estudantes se autodeclararam vítimas e 15,0\% agressores. Os meninos praticaram mais bullying comparados com as meninas. Os estudantes mais jovens, frequentando as primeiras séries do Ensino Fundamental e o primeiro ano do Enisno Médio apresentaram maior vulnerabilidade para a vitimização.

Essa descrição do diagnóstico da ocorrência de bullying e vitimização entre os estudantes investigados demonstrou que a realidade investigada apresenta alta prevalência de bullying como relatado por outros estudos de diferentes contextos. Nos Estados Unidos, por exemplo, país com forte tradição na pesquisa sobre o fenômeno, a 2009 Massachusetts Youth Health Survey revelou que 8,4\% de uma amostra de 2.948 estudantes do ensino médio havia praticado algum tipo de agressão contra os colegas (CENTERS FOR DISEASE CONTROL AND PREVENTION, 2011). Na América Latina o fenômeno, também, tem sido alvo de investigações, nos diferentes países, e segundo a literatura científica há um incremento de suas formas de manifestação que assumem aspectos mais severos, reflexos das desigualdades sociais (FLEMING; JACOBSEN, 2010).

Diante do cenário desvelado pelos índices de ocorrência do fenômeno, observase que o bullying tem sido aceito como a norma para as relações sociais e as maneiras de resolver conflitos entre crianças e adolescentes em idade escolar (DELPRATO; AKYEAMPONG; DUNNE, 2017). Essa interpretação é confirmada quando, aparentemente, professores, autoridades escolares e estudantes consideram o bullying como naturalizado ou normatizado, sendo impossível de ser combatido (OLIVEIRA et al., 2016c; SILVA et al., 2014a; SILVA et al., 2013a). Esses aspectos foram identificados nas entrevistas desse estudo quando os participantes explicavam o bullying como um evento negativo, porém assumiam comportamentos de apatia, ignorando as situações de vitimização 
testemunhadas ou justificando por meio de mecanismos de desengajamento moral as agressões praticadas.

0 aumento das taxas de prevalência, também, é explicado, em alguma medida, pela disseminação do termo "bullying" entre os estudantes e não favoreceu, ainda, a construção de estratégias eficazes de enfrentamento da questão. No Brasil, a legislação (BRASIL, 2015) e as iniciativas setoriais antibullying (BRASIL, 2009; FALEIROS; FALEIROS; 2008) não provocaram a diminuição da prevalência, como apontado pela presente pesquisa e por outros estudos de nível nacional (MALTA et al., 2014; OLIVEIRA et al., 2015b) e/ou regional (RECH et al., 2013; SOUZA, 2013). 0 acesso à informação pode ser traduzido em um quadro de maior ocorrência, revelando uma maior conscientização sobre o limiar tênue existente entre as "brincadeiras" e as situações de violência.

Esses dados de caracterização da ocorrência de bullying entre os participantes permitiram mapear a problemática e lançam as bases para a construção do exame das interconexões entre o fenômeno e outras variáveis. Nesse sentido, considerando os objetivos e o modelo teórico adotado pelo estudo, os demais dados da pesquisa foram sintetizados nas estruturas individual, microssistema, mesossistema, exossistema e macrossistema, como apresentado na Figura 4.

Figura 5 - Modelo bioecológico para a interface bullying e família no estudo. Uberaba, 2014.

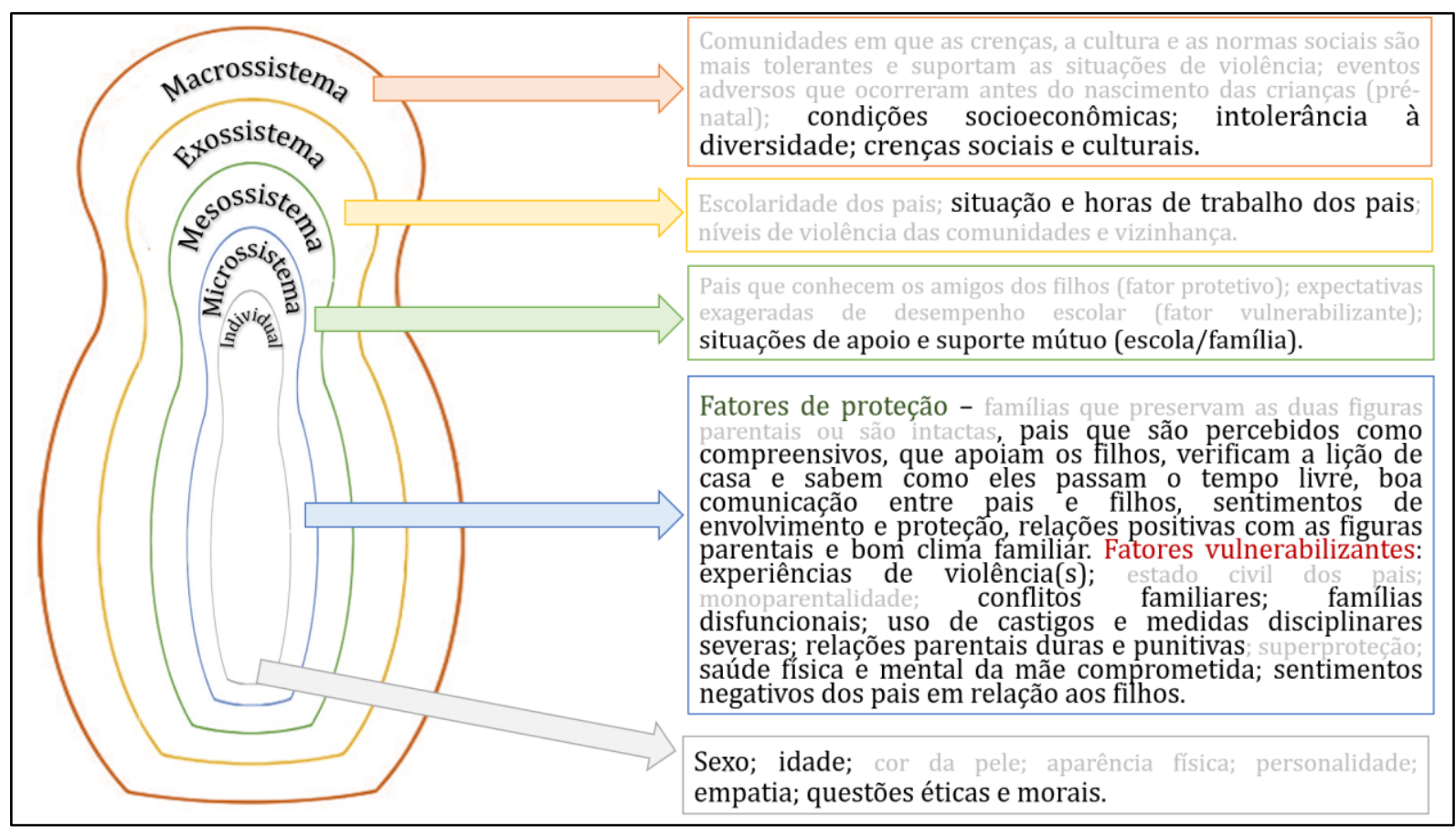

Fonte: Elaborado pelo autor. 
As descobertas do estudo estão em destaque na figura e revelaram, assim, que os meninos eram mais agressores e vítimas-agressoras. Dados que são sustentados por outros estudos científicos sobre bullying. Recentemente, um grande inquérito epidemiológico envolvendo 79 países identificou que, aproximadamente, $30 \%$ dos estudantes apresentaram relatos de vitimização por bullying nas escolas, sendo que $10,7 \%$ dos meninos relataram ter praticado quatro ou mais episódios de agressões físicas, ante 2,7\% das meninas (ELGAR et al., 2015). No estudo de Rech e colaboradores (2013), meninos do Rio Grande do Sul (Brasil) apresentaram mais do que o dobro de chances de serem agressores em relação às meninas.

$\mathrm{Na}$ análise dos dados qualitativos, observou-se que as meninas relataram mais sentimentos positivos em relação às vítimas, bem como maior disponibilidade para serem empáticas, oferecerem apoio e suporte aos estudantes vitimizados, enquanto os meninos eram mais indiferentes às agressões praticadas ou observadas. Esses achados, também, convergem a outras investigações que verificaram no sexo feminino maior potencialidade para romper com o ciclo de violência nas escolas (HONG; ESPELAGE, 2012; THORNBERG et al., 2017).

No que se refere à idade, os estudantes mais jovens e das primeiras séries do ensino fundamental, por sua vez, estavam mais vulneráveis para se tornarem vítimas de bullying. A literatura científica indica que atitudes negativas, como o bullying, diminuem à medida a idade aumenta (OLWEUS, 2013; 2011; 1993; OLWEUS; LIMBER, 2010;) e os estudantes mais velhos, também, são mais propensos a apoiar as vítimas do que os estudantes mais jovens (BRIGHI et al., 2012; CARAVITA; GINI; POZZOLI, 2012; CARLYLE; STEINMAN, 2007; JANSEN et al., 2011), como observado nas narrativas dos estudantes desse estudo. Os primeiros anos da adolescência, que coincidem com os primeiros anos do ensino fundamental, compõem um período crítico em que os indivíduos começam a explorar novos papéis sociais e a perseguir status dentro do grupo de pares, o que pode motivar comportamentos agressivos (CARAVITA et al., 2014; CARAVITA; GINI; POZZOLI, 2012; HUTCHINSON, 2012; LEE, 2011; SIJTSEMA et al., 2014).

Essas diferenças entre meninos e meninas, revelou-se na avaliação individual em termos éticos e morais das situações de bullying e vitimização, que resultam em movimentos de empatia ou indiferença. Assim como a questão da idade suscita um debate sobre como a infância e, especificamente, a adolescência são compreendidas socialmente. 
Essas perspectivas serão melhor exploradas a seguir, pois ela possui interação com os elementos macrossistêmicos.

Congruente com a Teoria Bioecológica do Desenvolvimento, bem como com nossas hipóteses e estudos anteriores, é no âmbito do microssistema que se concentraram a maior parte das descobertas dessa investigação. Bronfenbrenner (2011) definiu em seu quadro teórico que o microssistema se caracteriza pelo padrão de atividades, papéis sociais e relações interpessoais vividas pela pessoa ou por um grupo de pessoas diretamente em um ambiente. É esse movimento, nessa dimensão da vida, que garante a formação da personalidade e o desenvolvimento em um processo de interação com o outro e com o meio em que se está inserido. Neste sentido, variáveis do microssistema são fatores que promovem ou inibem comportamentos que vulnerabilizam as pessoas em relação ao desenvolvimento saudável (LEE, 2011; MARTINS; SZYMANSKI, 2004;).

Repetidas experiências no microssistema família conduzem crianças e adolescentes a internalizar padrões de comportamentos e atitudes que moldarão a conduta social (ASHIABI; O'NEAL, 2015; BRONFENBRENNER, 2011; PATTON et al., 2013). Segundo o modelo ecológico de desenvolvimento, as estratégias aprendidas e os valores compartilhados no contexto familiar vão ser reproduzidos na interação com os pares na escola (BRUBACHER et al., 2009). Essa compreensão ressalta a importância das experiências no ambiente doméstico para o desenvolvimento individual e social de crianças e adolescentes.

Ressalta-se que, no âmbito desse estudo, o foco recaiu sobre a percepção dos estudantes sobre suas interações familiares (família percebida). Esse aspecto a priori pode ser avaliado como negativo, na medida em que se considera como não apreendida a complexidade real e concreta do cotidiano das famílias. Entrementes, numa análise aprofundada, é o processo de interpretação e manipulação dos indivíduos sobre suas experiências singulares que determinará suas estratégias de inter-relação, bem como o curso de seu desenvolvimento. Dessa forma, percebe-se que a "família vivida/real" é contextual e marcada pela contribuição singular (percepção) de seus membros (BRONFENBRENNER, 2011). Consideração relevante ao se verificar uma percepção positiva da família entre os estudantes que se identificaram como agressores e vítimas nas entrevistas, por exemplo.

$\mathrm{Na}$ análise combinada dos dados, especificamente, verificou-se que os estudantes não-envolvidos em situações de bullying possuíam melhores interações familiares, 
sugerindo um padrão inverso de interações familiares para estudantes identificados como agressores, vítimas e vítimas-agressoras. A análise de variância revelou essa constatação ao identificar diferenças significativas entre os grupos de estudantes (nãoenvolvimento, agressores, vítimas e vítimas-agressoras) no que se refere à qualidade das interações familiares. Estudantes não-envolvidos em situações de bullying apresentaram melhores ambientes familiares com mais envolvimento, regras e monitoria, comunicação positiva, clima conjugal positivo, modelo e sentimentos em relação aos pais ou responsáveis. Agressores, vítimas e vítimas-agressoras apresentaram maior pontuação nas dimensões punição física, comunicação e clima conjugal negativos. Aspectos positivos da qualidade das interações familiares, também, foram observados entre os estudantes que declararam nas entrevistas não possuir envolvimento no fenômeno.

Observou-se que os maiores efeitos da qualidade das interações familiares relacionadas ao bullying se encontravam na análise combinada (geral), sendo poucas diferenças quando se analisava separadamente as figuras paterna e materna ou outra pessoa. Inferiu-se, dessa forma, que o clima familiar se sobrepõe à relação unidirecional com uma pessoa ou outra. Esse dado foi confirmado nas entrevistas, uma vez que relações de conflito com o pai, mãe ou outras pessoas, não diminuíam o sentimento positivo pelas famílias ou o relato de experiências familiares satisfatórias.

Essas análises permaneceram semelhantes quando se particularizou os dados referentes aos meninos e às meninas, com algumas variações, na avaliação de uma dimensão da interação familiar ou outra. Por exemplo, meninos e meninas não-envolvidos em situações de bullying apresentaram melhores pontuações nas dimensões positivas de interação familiar de forma geral, com o pai e a mãe, ao passo que nas dimensões negativas agressores, vítimas e vítimas-agressoras de ambos os sexos se diferenciaram em relação ao grupo dos estudantes não-envolvidos. Destaca-se que não foram encontradas diferenças entre os grupos de estudantes, para ambos os sexos, nas análises sobre a interação familiar com outra pessoa que ocupasse alguma função parental. Nas narrativas dos adolescentes, também, não foram identificadas diferenças entre os sexos.

Esses dados são congruentes com estudos que revelaram serem as famílias de agressores e vítimas menos funcionais do que as famílias de estudantes sem envolvimento com bullying. Por exemplo, um estudo na Colômbia com 304 estudantes identificou que a ausência de vínculos afetivos e famílias disfuncionais estavam mais associadas ao bullying escolar (URIBE; ORCASITA; GOMÉS, 2012). Outra pesquisa com 888 estudantes 
australianos confirmou que agressores e vítimas apresentavam famílias disfuncionais (MURRAY-HARVEY; SLEE, 2010). Essa disfunção familiar está associada às dificuldades na negociação e cooperação com os pais, dificuldades de habilidades sociais, padrões de comunicação inadequados ou inexistentes e falta de demonstrações de carinho e afeto.

Nesse sentido, a compreensão e percepção de contextos familiares que favoreciam as relações, os afetos, a comunicação positiva e o envolvimento, refletiam em sentimentos positivos e respostas de competência e adaptação às diferentes etapas do desenvolvimento individual dos estudantes. 0 clima familiar é, portanto, um elemento básico na etiologia de comportamentos de bullying na escola, aspecto bem explorado nas narrativas dos estudantes. É nesta dimensão da vida que ocorrem aprendizagens de comportamento e manejo social, e a internalização de métodos que podem se traduzir em estratégias de relacionamento que extrapolam o contexto familiar que se converte em produtor de fatores determinantes de proteção ou de vulnerabilidade. Dentro de seus efeitos interacionais, o clima afetivo, a comunicação, as práticas educativas, a supervisão e a maneira como as interações acontecem e são percebidas, são variáveis que influenciam diretamente na conduta social de crianças e adolescentes, podendo exercer efeitos diretos ou indiretos no envolvimento com o bullying.

Percebeu-se que os aspectos qualitativos da família (envolvimento, estilos parentais e clima familiar, por exemplo) se sobressaíram à questão da estrutura familiar, diferente de outros estudos em que viver com uma única figura parental era aspecto preditor para o bullying (KIM et al., 2009) ou associado à perpetração do fenômeno (YANG et al., 2013). Por exemplo, a monoparentalidade ou famílias reconstituídas aumentavam a vulnerabilidade para a vitimização na medida em que nesse tipo de contexto familiar há uma maior exposição a cuidadores adicionais que não oferecem carinho, afeto e supervisão adequada para crianças e adolescentes (FINKELHOR et al., 2009). Essa perspectiva poderá ser examinada em outros estudos no cenário brasileiro.

No que se refere aos aspectos protetivos da família em relação ao não envolvimento dos estudantes em situações de bullying, previu-se estatisticamente que somente a dimensão "regras e monitoria" apresentava esse poder. Contudo, a partir das narrativas dos estudantes, observou-se que envolvimento, comunicação positiva, clima conjugal positivo e apego às figuras parentais podem ser dimensões exploradas quando se pensa a questão da proteção dos estudantes e contra o bullying. Esses dados se 
mostraram importantes quando comparados com experiências domésticas negativas ou precárias.

Os efeitos do monitoramento e o estabelecimento de regras no contexto familiar é semelhante aos resultados encontrados em outros estudos (LOSEL; BENDER, 2014). Esse tipo de comportamento apresentado pelos pais ou responsáveis é interpretado como constituinte do envolvimento positivo entre eles e os filhos, aspecto que recebe grande destaque na literatura e é apontado como fator significativo de proteção. 0 envolvimento também é uma variável caracterizada pela supervisão, estabelecimento de regras, acompanhamento e comunicação positiva (BIBOU-NAKOU et al., 2013; CHAUX; MOLANO; PODLESKY, 2009; GEORGIOU; FANTI, 2010). Além disso, a aceitação dos pais em relação às dificuldades, diferenças e aparência dos filhos diminui as chances de envolvimento em situações agressivas, assim como ocorre com aqueles que possuem famílias democráticas e que estimulam comportamentos de não violência (BIBOU-NAKOU et al., 2013; LEE, 2011; LEE; SONG, 2012; PAPADAKI; GIOVAZOLIAS, 2015).

A comunicação entre pais e filhos, também, é um tema recorrente na literatura e aparece como indicador do clima e da maneira como as relações na dimensão familiar se configuram. Neste sentido, ter boa comunicação com os pais reduziu a probabilidade de vitimização entre 8.342 estudantes do ensino médio da China (WANG et al., 2012). Via de regra, percebe-se que a boa comunicação com os pais reduziu nos estudos a probabilidade de vitimização (GOFIN; AVITZOUR, 2012; LEMSTRA et al., 2012). Contudo, no estudo em tela, narrativas sobre boa comunicação e clima familiar positivo entre os agressores não os impediu de agredirem os colegas. Esse aspecto pode ser explicado pela sobreposição de influências macrossistêmicas sobre as de nível microssistêmicas, aspecto a ser exlorado por outros estudos.

A percepção da funcionalidade familiar foi outro fator potencial e preditivo para o bullying identificado em um recente estudo desenvolvido na Colômbia (HIGUITAGUTIERREZ; CARDONA-ARIAS, 2017). Na medida em que a percepção dessa funcionalidade familiar era negativa, maiores eram as chances dos estudantes se envolverem em situações de bullying (HIGUITA-GUTIERREZ; CARDONA-ARIAS, 2017). A funcionalidade foi avaliada de acordo com a satisfação que os estudantes possuíam em relação a ajuda recebida quando diante de algum problema, comunicação positiva entre os membros do grupo familiar, tomada de decisões conjuntas, satisfação com o tempo que 
passavam juntos e sentimentos de pertencimento ao grupo (HIGUITA-GUTIERREZ; CARDONA-ARIAS, 2017).

0 papel da mãe em relação ao envolvimento dos filhos com o bullying é outro tema de destaque nessa discussão, pois o apego à essa figura foi identificado como uma variável significativa para comportamentos de defesa em relação ao bullying. Bowes e colaboradores (2010), analisando dados nacionais dos Estados Unidos de uma amostra de 8.479 participantes, identificaram que mães acolhedoras têm efeitos na proteção dos estudantes e promovem ambientes domésticos positivos que são essenciais para o desenvolvimento de habilidades sociais positivas e para o bom relacionamento entre pares. Os autores sugerem, a partir da comparação de dados de escolares não vítimas de bullying com aqueles que foram intimidados, que o afeto materno é um dos fatores responsáveis pelo desenvolvimento de um clima familiar importante e favorável para o ajustamento emocional e comportamental de crianças e adolescentes.

Na Grécia, uma investigação com 601 pré-adolescentes sobre os tipos de apego apresentados pelos participantes observou que as experiências com o bullying eram positivamente associadas à percepção de que eram rejeitados pelas figuras parentais e negativamente quando os estudantes percebiam maior calor emocional em suas famílias (KOKKINOS, 2013). Análises de regressão revelaram que o apego inseguro era um preditor significativo para se tornar vítima em situações de bullying (KOKKINOS, 2013). Ao passo que, maior apego com os pais foi associado com maior índice de envolvimento com bullying entre 2.817 jovens sul-coreanos (MOON; MORASH; MCCLUSKEY, 2012).

0 maior controle psicológico, em termos de superproteção, principalmente quando relacionados à figura materna foi identificado entre 831 adolescentes norteamericanos como associado ao aumento das chances de sofrer agressões físicas no contexto escolar (MA; BELLMORE, 2012). Dados semelhantes foram encontrados na Turquia. Num estudo com 2871 alunos, os pesquisadores verificaram que baixos índices de supervisão parental e ligação muito próxima com a mãe eram fatores de risco para ser vítima de bullying (ERGINOZ et al., 2015).

Percebe-se que há, assim, um duplo sentido em relação ao apego com as figuras parentais, pois ele pode representar: 1) internalização de sentimentos e modelos (segurança emocional e expressão de afetos se relacionam com a qualidade da vinculação às primeiras figuras significativas); e 2) potencial para o processo de vitimização por meio da superproteção, do desencorajar o enfrentamento ou pela falta de crenças na 
capacidade dos filhos (dificuldade na tomada de decisão e insegurança emocional). Aspectos que merecem ser explorados por outras pesquisas e com diferentes desenhos metodológicos.

Essa ambiguidade em relação ao apego revela que, embora os aspectos positivos das famílias dos estudantes tenham se sobressaído, foi imperativo identificar que algumas dimensões das interações familiares aumentavam as chances de envolvimento em situações de vitimização e bullying escolar. Propriedades da realidade familiar são incorporadas ao modelo de interações entre pares na escola e concorrem para a ocorrência de problemas de comportamento como o bullying. Ambientes domésticos precários e disfuncionais, que aumentavam a vulnerabilidade individual e eram marcados por comunicação negativa, baixo envolvimento e métodos de disciplina corporais, foram percebidos como influências perturbadoras para o desenvolvimento e para o envolvimento dos estudantes em situações de bullying. Nessa perspectiva, comunicação negativa, clima conjugal negativo e punição física foram as dimensões da interação familiar que permaneceram associadas e seriam preditoras para o bullying ou a vitimização. Esses dados são convergentes aos dados obtidos nas entrevistas com os adolescentes e com a literatura divulgada sobre a temática.

Em geral, os alunos mais propensos a se envolverem em situações de bullying apresentaram relações menos favoráveis com seus pais, menos sentimentos de envolvimento e empatia familiar (BARBOZA et al., 2009; BIBOU-NAKOU et al., 2013; CHAUX; MOLANO; PODLESKY, 2009; KOUWENBERG et al., 2012; LEE, 2011; MOON; MORASH; MCCLUSKEY, 2012; YAMAGATA et al., 2013). Ainda segundo a literatura científica, o bullying é significativamente associado com menor satisfação em relação à família, maior punição física e resistência dos estudantes à autoridade parental (CHAUX; MOLANO; PODLESKY, 2009; GEORGIOU; FANTI, 2010; KNOUS-WESTFALL et al., 2012; TOTURA, 2009).

Nos Estados Unidos, Barboza e colaboradores (2009) evidenciaram em uma amostra de 9.816 adolescentes que aqueles identificados como agressores tinham pais autoritários e que usavam o castigo físico como técnica de disciplina. As famílias das vítimas, em seu turno, por vezes eram caracterizadas por mães protetoras que desencorajavam o desenvolvimento da autonomia e autoconfiança dos filhos, assim como por pais distantes, excessivamente críticos e/ou permissivos. Além disso, as práticas parentais ineficazes foram associadas entre 1.393 estudantes finlandeses a fatores como 
auto percepção e cuidados em saúde, satisfação com a vida e com as relações familiares, o próprio bullying escolar e a vida sexual de adolescentes (LEPISTO; LUUKKAALA; PAAVILAINEN, 2011).

O clima familiar percebido como negativo é outro fator que pode favorecer o envolvimento dos estudantes em situações de bullying. Neste sentido, um estudo da Espanha com 1.884 estudantes analisou as relações entre a qualidade percebida do clima familiar e a vitimização nas escolas (POVEDANO et al., 2012). Os autores observaram que os conflitos familiares estavam significativamente relacionados à vitimização escolar (POVEDANO et al., 2012). O conflito familiar, também, foi um preditor para o bullying identificado na Austrália por uma pesquisa longitudinal que contou com a participação de 696 estudantes (HEMPHILL et al., 2012).

Foram, também, referidas nas entrevistas, situações limite como uso e abuso de álcool e outras drogas por parte dos pais, aspecto que pode aumentar as chances dos filhos apresentarem problemas interpessoais, pois longitudinalmente se evidencia uma associação direta entre os problemas com álcool dos pais e o comportamento de bullying dos filhos (EIDEN et al., 2010). Essa é uma questão complexa e que se relaciona com outros fatores que são determinantes para o bom convívio familiar ou a construção de ambientes domésticos pouco seguros ou protetivos. Além disso, o alcoolismo parental (materno ou paterno) ou o uso de outras drogas por essas figuras tem sido considerado um problema de saúde pública associado ao uso de álcool precoce na adolescência e ao divórcio dos pais (PIEROBON et al., 2013; TAVARES; BERIA; LIMA, 2004; WANDEKOKEN; VICENTE; SIQUEIRA, 2011). Nota-se que essas são variáveis complexas que precisam ser investigadas pormenorizadamente e em relação específica com o bullying escolar.

A saúde mental e física das mães foi outro tema abordado pelos estudantes nas entrevistas e considerado como um fator que impacta negativamente nas interações familiares. Estudos revelaram que a saúde mental materna está associada ao aumento ou à diminuição da intimidação. Isso pode ocorrer pela qualidade da interação estabelecida entre a díade mãe/filho, que produz interferências no estado psicológico de ambas as partes e na socialização (SHETGIRI et al., 2012; SHETGIRI; LIN; FLORES, 2013). Especificamente, a depressão ou a presença de alguma psicopatologia materna foi significativamente relacionada com comportamentos de bullying escolar (EIDEN et al., 2010; GEORGIOU, 2008). A experiência de estudantes com mães com uma saúde mental comprometida resulta no estabelecimento de relacionamentos primários pouco seguros 
e não permite que se constituam, no contexto social amplo, relações de proteção diante das adversidades ou ainda de tolerância à diversidade.

Entrementes, pesquisas que oferecem discussões e dados sobre a saúde mental dos pais e a associação com o bullying não são conclusivos e possuem limitações em muitas dimensões como no tipo de desenho metodológico adotado ou na composição amostral dos estudos. Infere-se que a relação entre a saúde mental dos pais e o envolvimento e a perpetração do bullying escolar ocorre na perspectiva de análise da qualidade das interações que pode ser comprometida quando de um diagnóstico ou um funcionamento psíquico adoecido. Assim, os resultados dessa tese, nesse ponto, devem ser examinados por outros estudos com foco específico na saúde dos pais e a associação com o bullying.

Essas análises, globalmente, permitem compreender que, na medida em que os relacionamentos na família não são positivos, os estudantes tendem a fazer associações com pares para praticar comportamentos de violência, numa tentativa de aliviar tensões ou responder às frustrações e conflitos relacionados à vida familiar. Neste sentido, uma das explicações possíveis, é de que os estudantes que se envolvem no bullying aprenderam a se engajar na violência como resposta para os conflitos e as tensões sociais. Por meio da família é que adquirimos modelos de comportamento e estes terminam influindo sobre as demais relações sociais (BOWES et al., 2010; CASTRO-MORALES, 2011; MOON; MORASH; MCCLUSKEY, 2012).

Noutra perspectiva, as considerações anteriores sobre o papel dos pais e responsáveis no enfrentamento do bullying colocam a família no centro da questão não apenas enquanto um fator que pode facilitar ou inibir os comportamentos de bullying, mas também como elemento capaz de mudar o fluxo das histórias dos estudantes já envolvidos com o fenômeno. Esse aspecto é relevante sobretudo quando se percebe que os estudantes vitimizados não conseguem romper sozinhos com o ciclo de violência ou encontrar estratégias adequadas de enfrentamento, o que exige a intervenção efetiva dos pais ou responsáveis (BORSA; PETRUCCI; KOLLER et al., 2015).

Assim sendo, os ambientes familiares percebidos como negativos não são facilitadores para a denúncia e o pedido de ajuda quando o estudante está sendo vitimizado. Nas narrativas dos adolescentes se verificou uma avaliação da importância das figuras parentais no suporte e quando esse não ocorre a situação de vitimização é potencializada em termos de sofrimento e recrudescimento da questão. Sumariamente, 
observa-se que as famílias que oferecem suporte aos filhos ajudam os que são intimidados a romperem com o ciclo de violência e abusos, fortalecendo-os e auxiliando-os a desenvolverem mecanismos de enfrentamento para lidar com o bullying e a vitimização (BIBOU-NAKOU et al., 2013; PATTON et al., 2013). Dessa forma, embora essas condições possuam características diferentes, elas conservam em si potencial para problematizar e planejar programas de intervenção baseados no fortalecimento dos vínculos familiares.

Estudos sobre influências do nível mesossistema (interação família e escola) sobre as situações de vitimização verificaram que, não apenas a intervenção dos pais é importante para romper com as agressões, como também, maior envolvimento dos pais e responsáveis com a escola dos filhos, como participação em reuniões e colegiados, influencia no comportamento dos estudantes (SHETGIRI; LIN; FLORES, 2013). É importante, também, notar que os estudantes estão mais dispostos a procurar a ajuda dos pais quando o clima familiar é positivo e as relações são marcadas pelo favorecimento do diálogo, como explorado em outros pontos desse estudo. Interações familiares baseadas no conflito e na falta de afeto e carinho, dificilmente, oportunizarão pedidos de ajuda.

Noutra direção, as dinâmicas das relações interpessoais capazes de "tornar os seres humanos mais humanos" são baseadas nas relações de ajuda recebidas ou no suporte que se oferece às vítimas. É, também, dentro desse debate que se pode problematizar as potencialidades de ressignificação do processo de vitimização e do bullying entre os estudantes por meio da empatia e reconhecimento do outro enquanto ser humano. Como se observou nesse estudo, os próprios estudantes possuem potencial para empreender ações antibullying ou de suporte e ajuda às vítimas. Além disso, entendese que o comportamento de defesa das vítimas é positivo, melhora o clima escolar e deve ser deliberadamente incentivado por meio de atitudes, projetos e investimentos pessoais e grupais na área da educação e, também, de forma intersetorial, em parceria com outras áreas como a saúde (OBERMANN, 2011; SALMIVALLI, 2014; THORNBERG et al., 2017).

No âmbito do exossistema, nas entrevistas com os adolescentes, agressores e vítimas reclamaram do pouco tempo que ficavam os pais por causa das longas jornadas de trabalho. Estudos (CHRISTIE-MIZELL et al., 2011; LEMSTRA et al., 2011; MA; BELLMORE, 2012) indicam um aumento na propensão à vitimização e à prática do bullying quando a figura paterna possui uma ocupação profissional extensiva ou realiza muitas horas extras no trabalho. Christie-Mizel e colaboradores (2011) indicaram uma interação entre as horas de trabalho do pai e as percepções de pré-adolescentes do tempo 
gasto com eles. A situação de emprego, que garante o sustento familiar e a satisfação das necessidades econômicas do grupo, é avaliada como negativa na medida em que representa uma redução no tempo dos pais para acompanhar, supervisionar e se envolver emocionalmente com os filhos (BRONFFENBRENNER, 2011; CHRISTIE-MIZELL et al., 2011; LEMSTRA et al., 2011; MA; BELLMORE, 2012)).

Embora os locais de trabalho dos pais ou responsáveis não incluam em sua composição os filhos, eles envolvem outros significantes que impactam na vida das crianças e adolescentes. As condições de trabalho são importantes no sistema econômico da sociedade ocidental e representa uma área de grande estresse para os adultos, sobretudo quando eles precisam manter suas famílias, cuidar e acompanhar o crescimento dos filhos (BRONFFENBRENNER, 2011). Esse estresse é provocado pelas incertezas econômicas ou mesmo pela necessidade de manter longas jornadas de trabalho, pois sua diminuição pode representar privações e rupturas nos padrões de vida e na subsistência familiar (CHRISTIE-MIZELL et al., 2011; LEMSTRA et al., 2011; MA; BELLMORE, 2012).

Nota-se que as famílias são atravessadas e reproduzem similaridades dos modelos de relacionamento e valores presentes na sociedade. Isso ocorre por ser um nível de análise que perpassa as demais estruturas, sendo possível identificar macro traços nos âmbitos individual, micro, meso e exossistêmico. Esses aspectos constituintes do ambiente social e cultural, atravessam os demais níveis (que são teóricos e interconectados), para realçar ou inibir processos que fazem "o homem se tornar um homem histórico-cultural” (BRONFENNER, 2011; MARTINS; SZYMANSKI, 2004; ZILLMER et al., 2011). Nesse campo são, então, incluídas as questões macrossistêmicas como as condições socioeconômicas, a intolerância à diversidade, e as crenças sociais e culturais, como explorado em diferentes pontos dessa discussão, e mesmo as variáveis que pertencem à dimensão individual.

As duas variáveis sexo e idade, por exemplo, não se referem exclusivamente à pessoa e incluem a organização social e cultural, bem como suas determinações na maneira como as pessoas se comportam ou se relacionam. Dessa forma, a maior vulnerabilidade do sexo masculino para o envolvimento em situações de bullying e maior empatia entre as meninas são aspectos que podem ser explicados por meio das expectativas macrossistêmicas das culturas e sociedades que, como a brasileira, estimulam a agressividade entre os homens e a sensibilidade entre as mulheres, portanto 
as meninas seriam mais propensas a interpretar, relatar e denunciar comportamentos problemáticos (BRONFENBRENNER, 2011). Dentro do contexto do bullying, ainda, pesquisadores da temática sugerem que, mesmo o sexo masculino sendo mais associado à perpetuação do fenômeno, conclusões sobre as diferenças relacionadas ao sexo dos estudantes devem ser cuidadosas, pois ele pode não ser, necessariamente, um preditor significativo para o comportamento de bullying (MORENO JIMÉNEZ et al., 2005; HERNANDEZ, 2009; SILVA et al., 2013b).

Da mesma forma, os estudos também sugerem que a medida que os adolescentes vão crescendo as agressões vão se tornando mais sutis e de difícil identificação (ocorrência de violência verbal ou psicológica, por exemplo) (GLOVER et al., 2000; SILVA et al., 2014a; SILVA et al., 2013a; SILVA et al., 2013b). Assim sendo, interpreta-se que a ocorrência de práticas de agressão na escola (bullying) entre os meninos e os mais jovens é melhor explicado a partir da manifestação das crenças sociais e culturais nas escolas. 0 bullying é assim transformado numa estratégia deliberada, utilizada para dominar ou estabelecer relações de poder via os princípios de masculinidade, popularidade e competição (MORENO JIMÉNEZ et al., 2005; HERNANDEZ, 2009; SILVA et al., 2013b). Ao mesmo tempo em que é interpretado como uma externalização da agressividade e comportamentos violentos que não podem ser controlados na infância ou início da adolescência (MORENO JIMÉNEZ et al., 2005; HERNANDEZ, 2009; SILVA et al., 2013b).

Nesse campo do macrossistema, também, podem ser incluídas as questões de moralidade, de ética e da família como espaço formador das pessoas. Elas são expressas no âmbito individual, mas possuem uma interconexão com valores e crenças disseminados social e culturalmente. Esses valores e crenças são compartilhados no espaço doméstico, interpretados e transportados para o universo escolar. Nesse sentido, os estudantes indicaram que a família os auxiliavam na compreensão das regras e normas sociais, induzindo comportamentos positivos ou inibindo condutas desviantes.

No curso de desenvolvimento, os comportamentos das figuras parentais (pais, mães ou responsáveis) podem ser internalizados pelas crianças e adolescentes que os adaptam internamente e os aplicam nas relações com os colegas na escola (BRONFENBRENNER, 2011). Esse processo tende a romper com o bullying e a vitimização na medida em que são valorizados os princípios de justiça e tolerância à diversidade, o que parece não ocorrer quando os objetivos dos estudantes são individuais ou há uma disseminação de valores relacionados à falta de respeito, exclusão ou silenciamento das 
diferenças (CARAVITA et al., 2014; CARAVITA; GINI; POZZOLI, 2012; CARAVITA; GINI, 2010; OLIVEIRA et al., 2016c; THORNBERG et al., 2017).

Essas influências mais distais incorporam os microssistemas e os modelos de relacionamento, pois incluem as tradições familiares, a formação religiosa e os entendimentos e ações dos pais a respeito dos filhos, disciplina e socialização. Como se observou nesse estudo, essas diferentes variáveis vão influenciar profundamente na apreciação dos estudantes sobre o certo, o errado e a noção de justiça. Tal perspectiva, também, se refere à dificuldade em reconhecer os sentimentos dos outros ou ao uso de mecanismos de desengajamento moral para justificar ou explicar o bullying (CARAVITA et al., 2014; HYMEL; BONANNO, 2014; SIJTSEMA et al., 2014; THORNBERG et al., 2012; TOGNETTA et al., 2015).

Revelou-se, a partir dessa compreensão, tentativas singulares de interpretar processos sociais e culturais, uma vez que o bullying foi sendo percebido como construído coletivamente e partilhado pelos grupos de estudantes em cada escola. 0 movimento de ajuda e identificação do sofrimento das vítimas, em alguma escala, pode ampliar o debate sobre a importância de estratégias antibullying que disseminem valores como a tolerância e o respeito às diferenças, por exemplo.

Por outro lado, alguns estudantes parecem ter se "acostumado" com as agressões constantes na vida escolar, que viram parte da rotina. Esse processo de naturalização e banalização do bullying torna os estudantes insensíveis ao sofrimento do outro. Dois aspectos que ajudam a explicar esse movimento é a percepção de que há impunidade quando se pratica o bullying ou de que não existem respostas efetivas para inibir sua ocorrência (AZZI, 2011; GASSER; KELLER, 2009; ROBSON; WITENBERG, 2013; THORNBERG et al., 2017). Contudo, é importante despertá-los para consciência de que a violência na escola não é um fenômeno natural ou banal (CARAVITA et al., 2014; GINI; POZZOLI; HYMEL, 2014; HARDY et al., 2011; TOGNETA et al., 2015).

Por fim, observa-se que a triangulação metodológica adotada no presente estudo foi relevante para captar os sentidos e os significados atribuídos pelos adolescentes às diferentes interações familiares na construção de práticas de bullying e vitimização. As influências temporais e potenciais das experiências familiares incluíram desde situações que protegem àquelas que são potencialmente perigosas para que os estudantes pratiquem ou sofram bullying na escola. 
Percebeu-se que embora fatores individuais sejam mais facilmente associados com o bullying, os estilos e práticas parentais, ou seja, a maneira como os pais educam os filhos, os tipos de supervisão exercidos, como estabelecem a comunicação com os filhos e o afeto percebido, são agentes essenciais no processo de desenvolvimento psicossocial dos adolescentes no que se refere ao bullying e à vitimização. Estudantes com padrões seguros de vinculação no ambiente doméstico são mais propensos a serem socialmente competentes e contribuírem para a construção de uma sociedade de não violência. Dessa forma, esse estudo compreende a força, as fraquezas e as estratégias de interação familiar que podem concorrer para a ocorrência, a manutenção ou a inibição do bullying escolar.

\subsection{Implicações para a área da saúde}

O bullying é entendido como grave problema de saúde pública e esse estudo foi desenvolvido no âmbito de um programa de pós-graduação da área. Nesse sentido, é imperativo expor as principais contribuições para a área da saúde. Essa perspectiva, também, atende aos princípios da Teoria Bioecológica (BRONFENBRENNER, 2011; 1996), que enfatiza a necessidade de comunidades e serviços públicos trabalharem no apoio aos esforços das famílias em criar crianças e adolescentes saudáveis. Iniciativas de aplicação das políticas públicas e programas sociais, baseadas nesse modelo, tem potencial para diminuir o "caos contemporâneo" (condições econômicas, sociais, violências etc.) que atinge as pessoas, as famílias e seus modos de se relacionar.

Parte-se, também, do reconhecimento de que na família, muitas vezes, os pais não são eficazes no cuidado com os filhos não por negligência, mas por que as questões ecológicas se sobrepõem e não permitem maior carinho, proximidade e envolvimento (BRONFENBRENNER, 2011). Os contextos sociais nos quais pais e filhos estão inseridos são de uma complexidade tal que não há tempo, lugar ou referência para que sejam promovidas outras formas de interação com crianças e adolescentes, pois as exigências da sociedade são diversas (BRONFENBRENNER, 2011). Essa é uma realidade que traz consigo implicações importantes no que diz respeito a construir políticas e programas sociais que fortaleçam vínculos e não atendam lógicas baseadas na assistência ao adoecimento ou à vulnerabilidade individual. 
Para diminuir o bullying, especificamente, deve-se considerar a dinâmica familiar, pois entre seus determinantes estão as práticas adotadas pelas pessoas que compõem as famílias dos estudantes, bem como suas concepções e crenças. Por exemplo, em um estudo nos Estados Unidos que utilizou um inquérito nacional de saúde como fonte de dados, pesquisadores concluíram que estudantes com boa comunicação e incentivo acadêmico dos pais tinham menores probabilidades de envolvimento com o bullying (SHETGIRI et al., 2012). Diferentemente, uma investigação com estudantes canadenses revelou que aqueles com sentimento de que os pais esperavam muito deles academicamente ou que os pais não confiavam neles eram mais propensos a serem fisicamente maltratados pelos colegas (LEMSTRA et al., 2011).

Assim sendo, oferece-se insights a partir dos aspectos empíricos explorados nesse estudo. A intersetorialidade é a alternativa que viabilizará a proposição de estratégias que criam espaços de cuidado e promoção de saúde e auxiliam na ressignificação da produção da vida e do cuidado (BUSS; PELLEGRINI FILHO, 2007; PEREIRA; SILVA; NUNES, 2009; SILVA et al., 2016). Subjaz a temática do cuidado integral à saúde dos adolescentes como uma possibilidade advinda, inicialmente, da compreensão de que há uma interface entre modelos de interação familiar e a ocorrência, manutenção ou reorientação de comportamentos agressivos na escola (OLIVEIRA et. al., 2017; OLIVEIRA et al., 2016; OLIVEIRA et al., 2013; SENTENAC et al., 2011; VLACHOU et al., 2011; ZOTTIS et al, 2014).

Nesse sentido, percebe-se que o mote das intervenções deve objetivar, primeiramente, melhorar os encontros e as relações familiares para que o desenvolvimento saudável seja favorecido e o comportamento de bullying inibido. Tratase de uma abordagem no nível do mesossistema do quadro bioecológico, pois haverá uma interação entre os microssistemas "equipe de saúde voltada para o cuidado dos adolescentes" e "família". Relações entre os microssistemas, nesta perspectiva, tornam-se produtivas, construtivas e colaborativas na maximização das potencialidades do desenvolvimento saudável (HONG et al., 2014; HONG et al., 2013).

Para tanto, equipes de saúde da Estratégia Saúde da Família (ESF) podem trabalhar com as famílias adscritas às suas áreas de abrangência o fortalecimento de vínculos familiares, estimulando o estabelecimento de regras e monitoria no ambiente doméstico, padrões de comunicação e clima familiar positivo que são aspectos protetivos em relação ao bullying e podem ser trabalhados em grupos nas unidades de saúde ou nas 
visitas domiciliares. Os pais e as famílias devem, ainda, ser encorajados a participarem da vida escolar dos filhos, conferindo tarefas, compreendendo as características do processo ensino-aprendizagem que cada estudante vivencia e supervisionando as relações entre pares. Existem argumentos de que a conscientização dos pais e a compreensão da maneira como as crianças e os adolescentes interagem com seus colegas, professores e comunidade escolar, são elementos fundamentais não só na mitigação do bullying e dos conflitos mais violentos entre escolares, mas também são essenciais no processo de socialização.

As equipes de saúde podem, na perspectiva preventiva, auxiliar e orientar pais e responsáveis na identificação de sintomas e queixas relacionadas à vitimização. Esse tipo de ação emerge do conhecimento prévio das equipes sobre as estruturas familiares e seus modos de funcionar e interagir, para que as necessidades dos adolescentes sejam percebidas. Além disso, os profissionais da área devem possuir conhecimento suficiente para fazer análises da questão. Ao identificar casos de vitimização, podem ser propostas ações de inclusão da vítima em grupos nas unidades, bem como acompanhamento familiar e divulgação para os pais sobre a gravidade do problema e medidas possíveis a serem adotadas.

Com os adolescentes, ainda, as equipes necessitam estar atentas à saúde e à satisfação deles com suas experiências familiares (SILVA et al., 2014b; SILVA, 2013). Para tanto, a escuta sensível sobre as relações familiares, as práticas de disciplinas parentais e a maneira como os conflitos são resolvidos podem ajudar no reconhecimento de situações que tornam as interações familiares negativas e podem culminar no envolvimento dos adolescentes com o bullying (SILVA et al., 2014b; SILVA, 2013).

Nos microssistemas escolas, para realizar intervenções antibullying eficazes, primeiramente, as equipes de saúde devem reconhecer os fatores que estão associados ao bullying. Aspecto que também é válido para a promoção da detecção precoce da ocorrência do fenômeno e a criação de oportunidades para falar de experiências de diferentes tipos de bullying (grupos, estratégias de educação em saúde, por exemplo). Os estudantes podem discutir o tema do bullying, mas muitas vezes eles não sabem como lidar com as agressões que vivenciam ou testemunham, o que provoca um processo de naturalização e banalização do fenômeno no contexto escolar.

As equipes de saúde podem, também, abordar temáticas relacionadas aos valores éticos e morais, rompendo com as lógicas de atenção à saúde do escolar voltadas para 
questõs biológicas ou focalizadas no adoecimento. A escola é um espaço significativo para a formação e nela se possui as melhores ferramentas de construção e desenvolvimento moral e ético dos estudantes (SANTOS; TREVISOL, 2012). 0 desenvolvimento moral dos adolescentes é resultante de um processo contínuo e dependende da atuação dos adultos que, por meio da convivência e a orientação para o manejo adequado de situações problemáticas, oportuniza a construção de relações baseadas na tolerência, no respeito à diversidade e na aplicação desses valores em outros contextos sociais (TOGNETTA et al., 2015). Os estudantes que testemunham o bullying, por exemplo, são componentes essenciais na prevenção e intervenção, e um caminho possível é desenvolver junto a esse tipo de estudante a consciência moral e ética sobre a gravidade do problema (THORNBERG et al., 2017).

No entanto, como observado ao longo desse estudo, deve-se considerar que cada estudante sofre as influências do seu contexto doméstico nesse processo formativo. Muitas vezes, a escola também não está preparada para receber essas demandas e pode ser auxiliada de forma intersetorial. Esse tipo de intervenção tende, ainda, a permitir o fortalecimento da identidade moral dos estudantes que consideram o bullying como errado, mas mesmo assim o toleram ou praticam.

Em termos de produção científica, esse estudo contribui com as áreas da saúde e educação na medida em que oferece uma discussão ampliada sobre um fenômeno social que impacta significativamente na saúde de adolescentes em idade escolar. Os resultados da pesquisa podem ser utilizados em programas de formação profissional, proporcionando melhor compreensão sobre a adolescência, bullying e vitimização. Muitas vezes, justifica-se o não desenvolvimento de ações com queixas de falta de conhecimento sobre determinados temas. Portanto, equipes de saúde que trabalham na atenção à saúde do escolar com adolescentes precisam de mais conhecimento sobre o bullying. Dessa forma, o material decorrente dessa pesquisa poderá orientar grupos de estudos nas unidades de saúde, em que pese a questão da adolescência e suas complexidades, e ao ser divugado poderá ampliar o conhecimento sobre o bullying e outras variáveis, de nível contextual, que podem contribuir com sua ocorrência, manutenção ou inibição. 


\subsection{Pontos fortes e limitações}

Os pontos fortes do estudo incluem: 1) a estimativa dos efeitos de variáveis de interação familiar associadas ao bullying escolar; 2) o tamanho da amostra de base populacional, com boa distribuição entre meninos e meninas, o que permitiu analisar em profundidade as temáticas estudadas, e minimizou o viés de amostragem; 3) o poder estatístico e a alta taxa de resposta global que permitiu determinar as associações entre as diferentes variáveis analisadas em subgrupos (clusters) de estudantes; 4) o uso de instrumentos validados e com confiabilidade demonstrada por meio de análise fatorial para utilização no estudo; 5) e a triangulação de métodos que permitiu o desenho de tendências temporais de prevalência e trajetórias de bullying dos estudantes. Finalmente, 6) esse estudo é um dos primeiros a examinar de forma mista as contribuições das variáveis de interação familiar para o envolvimento de adolescentes em situações de bullying, sendo essa sua maior potência.

Embora reconhecendo esses pontos, os resultados desse estudo devem ser considerados à luz de suas principais limitações. Primeiramente, não foram coletados dados sociodemográficos dos participantes (cor da pele, orientação sexual, renda familiar etc.), o que poderia ter oportunizado um apronfundamento de algumas análises e interpretações. Conseguir uma melhor compreensão do contexto sociodemográfico dos estudantes envolvidos em situação de bullying contribui com o planejamento contextual de programas e políticas interventivas.

Em segundo lugar, os instrumentos e a técnica utilizados na coleta de dados se basearam em relatos retrospectivos de comportamentos de bullying e vitimização. Como resultado dessa perspectiva, os adolescentes podem ter oferecido respostas comprometidas por irregularidades mnêmicas (viés de memória). 0 uso de outras estratégias como a nomeação por pares de vítimas e agressores pode diminuir esse tipo de viés em estudos futuros. Além disso, o estudo se baseou exclusivamente nos relatos individuais dos adolescentes e a coleta de dados com outros informantes (pais, professores, por exemplo) seria vantajoso para a discussão. Também, o instrumento de caracterização dos estudantes (Escala de Agressão e Vitimização entre Pares) não permitiu a identificação de estudantes que observaram ou testemunharam situações de bullying na 
escola. Os observadores de situações de bullying somam, aproximadamente, $85 \%$ dos estudantes segundo a literatura e é um grupo importante para pensar a problemática.

A terceira limitação da pesquisa se refere ao desenho metodológico adotado que impede interpretações relacionadas à causa e efeito. Para esse tipo de definição são necessários estudos longitudinais. Contudo, salienta-se que as associações significativas encontradas no estudo e a coerência entre seus resultados e outros estudos transversais e prospectivos de diferentes contextos oferecem base sólida para as interpretações realizadas.

Em quarto lugar, a coleta de dados quantitativos, previamente às entrevistas qualitativas, pode ter sensibilizado, em alguma medida, os estudantes em relação ao tema em estudo e ao pesquisador principal que conduziu ambas etapas de coleta. Também, pode ter sido favorecido o fenômeno conhecido como "desejabilidade social", que se refere a uma inclinação do participante em oferecer respostas consideradas como socialmente aceitáveis e a negar a associação com opiniões ou comportamentos considerados como desviantes. Essa tendência foi controlada em cada entrevista por meio do uso de diferentes perguntas para se referir ao mesmo aspecto abordado ("Fale-me como é sua relação com seus pais?" "Com sua família?" "Como é estar ou viver na sua casa?").

Salienta-se, ainda, que o estudo confirmou diferenças de prevalência entre os sexos, descritas anteriormente em estudos sobre bullying e vitimização. Nesse caso, os meninos estavam mais envolvidos que as meninas nessas situações. Contudo, na análise sobre a relação do fenômeno com as dimensões de interação, poucas diferenças entre os sexos foram observadas. Não se descarta a possibilidade desse pequeno efeito estatístico, em comparação com os demais resultados estatisticamente significativos do estudo, ser consequência do grande tamanho amostral. Para ampliar a compreensão sobre esse aspecto, estudos futuros podem explorar, especificamente, as diferenças entre os sexos e as dimensões de interação familiar. 
Certas palavras tem ardimentos; outras não. A palavra jacaré fere a voz. É como descer arranhado pelas escarpas de um serrote. É nome com verdasco de lodo no couro. Além disso é agríope (que tem olho medonho). Já a palavra garça tem para nós um sombreamento de silêncios...

E o azul seleciona ela!

Manoel de Barros (2010, p. 277) 


\section{CONSIDERAÇÕES FINAIS}

Essa pesquisa é uma das primeiras a examinar de forma mista as contribuições das variáveis de interação familiar para o envolvimento de adolescentes em situações de bullying. Ela avança na compreensão sobre o fenômeno e aspectos familiares que são preditores ou protetivos em relação a ele. Confirmando que a tese apresentada na introdução desse trabalho pode ser defendida: a qualidade das interações familiares exerce influência no envolvimento de adolescentes em situações de bullying escolar enquanto agressores, vítimas ou vítimas-agressoras. 0 ambiente familiar, que contribuí com o processo de individuação ${ }^{15}$ dos estudantes, é manifesto na maneira como eles se vinculam com os colegas (vinculação por bullying, por exemplo). Oferecendo-se, dessa forma, algumas reflexões que adentram um horizonte considerado invisível, sobre outros fatores associados a ocorrência do bullying. Como uma "terceira margem do rio", usando a metáfora do autor mineiro Guimarães Rosa (ROSA, 2005): uma perspectiva que não existe, aparentemente, e exige sensibilidade para ser abordada e reconhecida.

Nesse sentido, as duas principais conclusões dessa tese são: 1) identificação da dimensão "regras e monitorias" da interação familiar como fator protetivo para o bullying e a vitimização; e 2) verificação do valor preditivo de aspectos negativos das interações familiares (punição física, comunicação e clima conjugal negativos) para o envolvimento dos estudantes em situações de bullying como agressores, vítimas ou vítimas-agressoras. Esses resultados foram suportados pelos dados qualitativos que revelaram serem as experiências familiares positivas dos adolescentes pontos fortes a serem explorados na discussão sobre fatores de proteção. Inversamente, ambientes familiares precários ou marcados pelo desamparo em face das experiências negativas, foram verificados como vulnerabilizantes em relação ao bullying e à vitimização.

Explicita-se que o paradigma bioecológico foi um quadro teórico capaz de avançar nas análises realizadas a partir dos dados empiricos coletados. Nesse sentido, o referencial permitiu identificar diferentes níveis de fatores que influenciam no envolvimento dos estudantes em situações de bullying na escola. Esses níveis incluíram características individuais, dos microssistema, mesossistema, exossistema e

\footnotetext{
15 Processo do desenvolvimento psicológico mediante o qual o homem se torna único que de fato, inteiro,
} indivisível e distinto de outras pessoas (condição ontológica) (VERGUEIRO, 2008). 
macrossistema. Especificamente, no nível individual foram identificados os elementos sexo, idade, empatia e questões ético-morais (em interface com o nível macro).

No microsssitema se sobressaíram informações sobre pais e responsáveis que são percebidos como compreensivos, que apoiam os filhos, verificam a lição de casa e sabem como eles passam o tempo livre, boa comunicação entre pais e filhos, sentimentos de envolvimento e proteção, relações positivas com as figuras parentais e bom clima familiar (fatores protetivos). Ainda nessa estrutura teórica, elementos que podem aumentar a vulnerabilidade dos estudantes para o envolvimento com o bullying foram identificados, como: experiências de violência(s); conflitos familiares; famílias disfuncionais; uso de castigos e medidas disciplinares severas; relações parentais duras e punitivas; superproteção; saúde física e mental da mãe comprometida; sentimentos negativos dos pais em relação aos filhos.

No mesossistema, em que um microssistema está interconectado a outro microssistema, observou-se que essa relação ocorreu nos relatos de suporte ou ajuda oferecida às vítimas, colocando em interação família e escola. 0 exossistema foi expresso nas entrevistas por meio de queixas acerca da situação e horas de trabalho dos pais e responsáveis, que diminuíam o tempo dedicado aos filhos (indicando aspectos socioeconômicos das famílias). No campo do macrossistema, que atravessa os demais níveis bioecológicos, revelaram-se as condições socioeconômicas (associadas às horas de trabalho dos pais); intolerância à diversidade (relacionada à empatia); crenças sociais e culturais (em relação com as questões do desenvolvimento ético e moral). Desvelou-se, assim, que o desenvolvimento humano e os fenômenos sociais são resultado da interação entre fatores individuais e contextuais, sejam eles proximais e distais à pessoa em desenvolvimento, e que têm de ser considerados na abordagem de situações complexas como o bullying e a vitimização.

Metodologicamente, conforme se verificou na revisão de literatura prévia ao estudo, existem poucos estudos de abordagem qualitativa ou que conjuguem métodos quali e quantitativos na abordagem da interface bullying e família. Isto aponta para lacunas na produção científica no que se refere à profundidade sobre a dinâmica do bullying no contexto escolar e suas relações com outras dimensões da vida dos estudantes. 0 estudo contribui nessa perspectiva com a literatura, demonstrando ainda que esse tipo de delineamento possui maior potencial para gerar compreensões enriquecidas do problema sob investigação, do que o uso isolado de métodos qualitativos ou quantitativos. 
Da mesma forma, programas e projetos de intervenção se beneficiam deste tipo de abordagem que congrega diferentes informações, interpretações e significados. Como o estudo que contribuiu com uma abordagem processual e contextual do fenômeno, ao mesmo tempo em que aspectos etiológicos ou os sentimentos relacionados ao bullying foram explorados.

De forma propositiva, pesquisas futuras podem utilizar os modelos testados nessa investigação e que forneceram informações adequadas para formular hipóteses sobre o efeito das horas de trabalho, do uso de álcool e outras drogas e da saúde mental dos pais e responsáveis na ocorrência do bullying e da vitimização, por exemplo. Outras investigações podem explorar dimensões não contempladas por esse trabalho como o convívio comunitário, realidades socioeconômicas das famílias e a perspectiva dos pais e responsáveis sobre o envolvimento dos filhos em situações de bullying. Outro importante aspecto a ser considerado por pesquisas futuras se refere aos fatores de proteção, pois é preciso esclarecer como a vivência ou a percepção positiva sobre as interações familiares não inibem a prática do bullying ou o processo de vitimização.

No campo interventivo, destaca-se que as ações antibullying podem ser melhoradas ao considerar as variáveis familiares em seu planejamento. Essa premissa é válida para diferentes áreas. Profissionais da saúde, educação e assistência social, de forma intersetorial e na proteção e atenção básica às necessidades de pessoas e comunidades, precisam ampliar o foco na abordagem do tema, indo além do ambiente escolar e abraçando preocupações sobre família, os pais e os responsáveis e cuidadores, além de congregar diferentes saberes na definição das ações. Porque o objetivo final dessas ações será garantir o direito dos adolescentes se sentirem seguros em casa, na escola e na comunidade, bem como manterem índices satisfatórios de qualidade de vida e saúde.

As equipes de saúde que trabalham com escolares, por seu turno, devem estar preparadas para ouvir e intervir em todo tipo de história de violência nas escolas. Para tanto, elas precisam de mais conhecimento sobre o bullying e variáveis que podem determinar sua ocorrência. Por outro lado, a família pode ser incluída nas ações antibullying, inclusive para romper com a lógica de que o fenômeno circunscrito ao âmbito escolar não possui relações com o que ocorre no contexto familiar. Sensibilizações em reuniões com pais e responsáveis pode ser um caminho a ser trilhado inicialmente, assim como o acompanhamento domiciliar. 
Essas ações devem ser baseadas nas interpretações de que adotar estilos e maneiras positivas de convívio familiar é a melhor estratégia para pais e responsáveis auxiliarem os adolescentes envolvidos em situações de bullying ou mesmo prevenir a violência escolar. É, também, na família que valores éticos e a perspectiva dos direitos humanos são cultivados primeiramente. Pais e responsáveis, também, são modelos influentes na vida de seus filhos, e, portanto, devem estar atentos aos próprios comportamentos e aos comportamentos dos adolescentes para diagnosticar a questão e, junto às escolas, intervir de forma adequada para diminuir e eliminar o bullying. Eles também devem ser esclarecidos sobre os melhores caminhos a serem adotados, diferenciando-os das estratégias ineficazes (confronto direto com os agressores, por exemplo), para não colocar os estudantes em maior condição de vulnerabilidade.

Por fim, destaca-se que o bullying, assim como outros fenômenos sociais e as maneiras de se relacionar das pessoas, é resultado da interação de múltiplos fatores, como as características individuais de personalidade e os aspectos dos contextos em que os estudantes se desenvolvem. Esse fenômeno é, também, uma expressão das muitas questões sociais amplas que se manifestam de diferentes formas na capilaridade dos territórios escolares. Afora isso, demonstra-se a importância da família no processo de desenvolvimento saudável do adolescente, mas também no desenvolvimento adoecido, como pode ser entendido quando do envolvimento em situações de violência entre pares. Reforçando perspectivas que consideram a família como lugar determinante para o desenvolvimento humano e para a construção de padrões na maneira de se relacionar e existir no mundo.

Entrementes, diante dos resultados e análises apresentados, adverte-se que 1) não foi pretensão dessa pesquisa responsabilizar ou culpabilizar as famílias, exclusivamente, pelo bullying escolar, e 2) o bullying é uma temática complexa, que exige outras pesquisas e reflexões, principalmente no Brasil, onde os estudos sobre o fenômeno ainda são baseados no diagnóstico da questão ou em aspectos individuais de vítimas e agressores. 
Usado por uma fivela, o homem tinha sido escolhido, desde criança, para ser ninguém e nem nunca. De forma que quando pensou em fazer alguma coisa por ele, viu-se que o caso era irremediável e escuro.

Ou uma vespa na espátula. Esse homem pois que apreciava as árvores de sons amarelos - ele se merejava sobre a carne dos muros e era ignorante como as águas. Nunca sabia direito qual o período necessário para um sapato ser árvore. Muito menos era capaz de dizer qual a quantidade de chuvas que uma pessoa necessita para que o lodo apareça em suas paredes. De modo que se fechou esse homem: na pedra: como ostra: frase por frase, ferida por ferida, musgo por musgo: moda um rio que secasse: até de nenhuma ave ou peixe. Até de nunca ou durante.

E de ninguém anterior. Moda nada.

Manoel de Barros (2010, p. 171-172) 


\section{REFERÊNCIAS}

ABDIRAHMAN, H.; FLEMING, L.C.; JACOBSEN, K.H. Parental involvement and bullying among middle-school students in North Africa. Eastern Mediterranean Health Journal. Emirados Árabe, v. 19, n. 3, p. 227-33, 2013.

ABDIRAHMAN, H.A. et al. Bullying, mental health, and parental involvement among adolescents in the Caribbean. West Indian Medical Journal. Mona, v. 61, n. 5, p. 504-08, 2012.

ALMEIDA, A.; CORREIA, I.; MARINHO, S. Moral Disengagement, Normative Beliefs of Peer Group, and Attitudes Regarding Roles in Bullying. Journal of School Violence. Filadélfia, v. 9, n. 1, p. 23-36, 2009.

ALVES, R. Um segredo... que nunca revelei. Revista Educação. São Paulo, v. 172, 2011.

ANDRADE, L.O.M.; BUENO, I.C.H. C.; BEZERRA, R.C. Atenção primária à saúde e estratégia saúde da família. In: CAMPOS, G.W.S. et al. (Orgs.). Tratado de saúde coletiva. São Paulo: Hucitec; Rio de Janeiro: Fiocruz, 2006. p. 783-836.

ASHIABI, G.S.; O'NEAL, K.K. Child social development in context: an examination of some propositions in Bronfenbrenner's Bioecological Theory. Sage Open. Thousand Oaks, v. 5, n. 2, 2015.

AZZI, R.G. Desengajamento moral na perspectiva da teoria social cognitiva. Psicologia: Ciência e Profissão. Brasília, v. 31, n. 2, p. 208-19, 2011.

BANDEIRA, C.D.M.; HUTZ, C.S. Bullying: prevalência, implicações e diferenças entre os gêneros. Psicologia escolar e educacional. Uberlândia, v. 16, n. 1, p. 35-44, 2012.

BARBOZA, G.E. et al. Individual characteristics and the multiple contexts of adolescent bullying: an ecological perspective. Journal of Youth and Adolescence. Indiana, v. 38, n. 1, p. 101-21, 2009.

BARDIN, L. Análise de conteúdo. São Paulo: Edições 70, 2011. 280p.

BARROS, M. Poesia completa. São Paulo: Leya, 2010. 493p.

BAYRAKTAR, F. Bullying Among adolescents in North Cyprus and Turkey: testing a multifactor model. Journal of Interpersonal Violence. Thousand Oaks, v. 27, n. 6, p. 1040-65, 2012.

BIBOU-NAKOU, I. et al. Bullying/victimization from a family perspective: a qualitative study of secondary school students' views. European Journal of Psychology of Education. Belgrade, v. 28, n. 1, p. 53-71, 2013. 
BOCK, A.M.B. A adolescência como construção social: estudo sobre livros destinados a pais e educadores. Psicologia Escolar e Educacional. Uberlândia, v. 11, n.1, p. 63-76, 2007.

BOEL-STUDT, S.; RENNER, L.M. Child and family-level correlates of direct and indirect peer victimization among children ages 6-9. Child Abuse \& Neglect. Manitoba, v. 38, n. 6, p. 1051-60, 2014.

BOEL-STUDT, S.; RENNER, L.M. Individual and familial risk and protective correlates of physical and psychological peer victimization. Child Abuse \& Neglect. Manitoba, v. 37, n. 12, p. 1163-74, 2013.

BOLFARINE, H.; BUSSAB, W. Elementos de amostragem. São Paulo: Egard Blucher, 2005. 290p.

BORSA, J.C.; PETRUCCI, G.W.; KOLLER, S. H. A participação dos pais nas pesquisas sobre o bullying escolar. Psicologia Escolar e Educacional. Uberlândia, v. 19, n. 1, p. 41-48, 2015.

BOWES, L. et al. Families promote emotional and behavioural resilience to bullying: evidence of an environmental effect. Journal of Child Psychology and Psychiatry. Londres, v. 51, n. 7, p. 809-17, 2010.

BOWES, L. et al. School, neighborhood, and family factors are associated with children's bullying involvement: a nationally representative longitudinal study. Journal of the American Academy of Child and Adolescent Psychiatry. Nova Iorque, v. 48, n. 5, p. 545-53, 2009.

BRASIL. Lei 13.185 de 06 de novembro de 2015. Institui o Programa de Combate à Intimidação Sistemática (Bullying). Brasília: Presidência da República, 2015.

BRASIL. Pesquisa nacional de saúde do escolar: 2015. Rio de Janeiro: IBGE, 2016. $132 \mathrm{p}$.

Brasil. Saúde na escola. Cadernos de Atenção Básica n. 24. Brasília: Ministério da Saúde, 2009. 96p.

BREIVIK, K.; OLWEUS, D. An item response theory analysis of the Olweus Bullying Scale. Aggressive Behavior. Malden, v. 41, n. 1, p. 1-13, 2015.

BRIGHI, A. et al. Predictors of victimisation across direct bullying, indirect bullying and cyberbullying. Emotional \& Behavioural Difficulties. Reino Unido, v. 17, n. 3-4, p. 37588, 2012.

BRONFENBRENNER, U. A ecologia do desenvolvimento humano: tornando os seres humanos mais humanos. Porto Alegre: 2011.310p.

BRONFENBRENNER, U. A ecologia do desenvolvimento humano: experimentos naturais e planejados. Porto Alegre: Artes Médicas, 1996. 267p. 
BRUBACHER, M.R. et al. Procedural justice in resolving family disputes: implications for childhood bullying. Psychology Public Policy and Law. Londres, v. 15, n. 3, p. 149-67, 2009.

BUSS, P.M.; PELLEGRINI FILHO, A. A Saúde e seus Determinantes Sociais. PHYSIS: Revista Saúde Coletiva. Rio de Janeiro, v. 17, n.1, p. 77-93, 2007.

CARAVITA, S.C.S. et al. Peer influences on moral disengagement in late childhood and early adolescence. Journal of Youth and Adolescence. Indiana, v. 43, n. 2, p. 193-207, 2014.

CARAVITA, S.C.S.; GINI, G. L'(im)moralidade de bullying. Milão: Unicopli, 2010. 202p.

CARAVITA, S.C.S.; GINI, G.; POZZOLI, T. Main and moderated effects of moral cognition and status on bullying and defending. Aggressive Behavior. Malden, v. 38, n. 6, p. 45668, 2012.

CARLYLE, K.E.; STEINMAN, K.J. Demographic differences in the prevalence, cooccurrence, and correlates of adolescent bullying at school. Journal of School Health. Malden, v. 77, n. 9, p. 623-29, 2007.

CASTRO-MORALES, J. Acoso escolar. Revista de Neuro-Psiquiatría. Lima, v. 74, n. 2, p. 242-49, 2011.

CENTERS FOR DISEASE CONTROL AND PREVENTION. Bullying among middle school and high school students: Massachusetts, 2009. MMWR Morb Mortal Wkly Rep. Massachusetts, v. 60, p. 465-71, 2011.

CHAUX, E.; MOLANO, A.; PODLESKY, P. Socio-Economic, socio-political and socioemotional variables explaining school bullying: a country-wide multilevel analysis. Aggressive Behavior. Malden, v. 35, n. 6, p. 520-529, 2009.

CHRISTIE-MIZELL, C.A. et al. Bullying behavior, parents' work hours and early adolescents' perceptions of time spent with parents. Youth \& Society. Michigan, v. 43, n. 4, p. 1570-595, 2011.

CHAVEZ, B.L.; YAMAMOTO, J.M. Content analysis and computational linguistics: its quickness, reliability and perspectives. Anales de Psicología. Murcia, v. 30, n. 3, 2014.

COSTA, P. et al. Adolescentes portugueses e o bullying escolar: Estereótipos e diferenças de género. Interacções. Lisboa, v. 9, n. 25, p. 180-201, 2013.

CRAIG, W. et al. A cross-national profile of bullying and victimization among adolescents in 40 countries. International Journal of Public Health. Berna, v. 54, n. 2, p. 216-24, 2009. 
CUERVO, V. et al. Diferencias en la situación socioeconómica, clima y ajuste familiar de estudiantes con reportes de bullying y sin ellos. Psicología desde el Caribe. Caribe, v. 29, n. 3, p. 616-31, 2012.

CUNHA, J.M. Violência interpessoal em escolas do Brasil: características e correlatos. 2009. 105f. Dissertação de Mestrado. Curitiba, Universidade Federal do Paraná, 2009.

CUNHA, J.M.; WEBER, L.N.D.; STEINER NETO, P. Escala de Vitimização e Agressão Entre Pares (EVAP). In: WEBER, L.N.D.; DESSEN, M.A. (Orgs.). Pesquisando a família. Instrumentos para coleta e análise de dados. Curitiba: Juruá, 2011. p.103-114.

DANCEY, C. P.; REIDY, J. Estatística sem matemática para psicologia. Porto Alegre: Penso, 2013. 608p.

DELPRATO, M.; AKYEAMPONG, K.; DUNNE, M. The impact of bullying on students' learning in Latin America: A matching approach for 15 countries. International Journal of Educational Development. Tennessee, v. 52, p. 37-57, 2017.

DUE, P. et al. Socioeconomic Inequality in Exposure to Bullying During Adolescence: A Comparative, Cross-Sectional, Multilevel Study in 35 Countries. American Journal of Public Health. Washington, v. 99, n. 5, p. 907-14, 2009.

DUONG, M.T. et al. Associations between maternal physical discipline and peer victimization among Hong Kong Chinese children: the moderating role of child aggression. Journal of Abnormal Child Psycholog. Vancouver, v. 37, n. 7, p. 957-66, 2009.

EIDEN, R.D. et al. Parent alcohol problems and peer bullying and victimization: child gender and toddler attachment security as moderators. Journal of Clinical Child and Adolescent Psychology. Maryland, v. 39, n. 3, p. 341-50, 2010.

ELGAR, F. J. et al. Structural determinants of youth bullying and fighting in 79 countries. Journal of Adolescent Health. Filadélfia, v. 57, n. 6, p. 643-50, 2015.

ERGINOZ, E. et al. The Role of Parental, School, and Peer Factors in Adolescent Bullying Involvement: Results From the Turkish HBSC 2005/2006 Study. Asia Pacific Journal of Public Health. Kuala Lumpur, v. 27, n. 2, p. 1591-1603, 2015.

FALEIROS, V.P; FALEIROS, E.T.S. Escola que protege: Enfrentando a violência contra crianças e adolescentes. Brasília: Ministério da Educação, 2008. 100p.

FANTE, C. Fenômeno bullying. Como prevenir a violência nas escolas e educar para a paz. Campinas: 2005. 224p.

FELIX, E.M.R.; ALAMILLO, R.D.R.; RUIZ, R.O. Prevalencia y aspectos diferenciales relativos al género del fenómeno bullying en países pobres. Psicothema. Oviedo, v. 23, n. 4, p. 624-29, 2011. 
FERNANDES, C.L.C; CURRA, L.C.D. Ferramentas de abordagem familiar. Porto Alegre: Artmed/Panamericana Editora, 2006. p. 13-29

FIELD, A. Descobrindo a estatística usando o SPSS. Porto Alegre: Artmed, 2009. 688p.

FINKELHOR, D. et al. Pathways to Poly-Victimization. Child Maltreatment. Washington, v. 14, n. 4, p. 316-29, 2009.

FISCHER, R.M. Bullying escolar no Brasil. São Paulo: CEATS-FIA, 2010. 108p.

FLEMING, L.C.; JACOBSEN, K.H. Bullying among middle-school students in low and middle income countries. Health Promotion International. Carlton, v. 25, n. 1, p. 73-84, 2010.

FLICK, U. Qualidade na pesquisa qualitativa. Porto Alegre: Artmed, 2009. 168p.

FOSTER, H.; BROOKS-GUNN, J. Neighborhood, family and individual influences on school physical victimization. Journal of Youth and Adolescence. Indiana, v. 42, n. 10, p. 15961610, 2013.

FREIRE, A.N.; AIRES, J.S. A contribuição da psicologia escolar na prevenção e no enfrentamento do bullying. Psicologia Escolar e Educacional. Uberlândia, v. 16, n. 1, p. 55-60, 2012.

FRIESE, S. ATLAS.ti 7 Windows. Estados Unidos: ATLAS.ti GmbH, 2015.

FU, Q.; LAND, K. C.; LAMB, V. L. Bullying victimization, socioeconomic status and behavioral characteristics of 12th graders in the United States, 1989 to 2009: repetitive trends and persistent risk differentials. Child Indicators Research. Jerusalém, v. 6, n. 1, p. 1-21, 2013.

FUNG, A.L.C. Intervention for aggressive victims of school bullying in Hong Kong: a longitudinal mixed-methods study. Scandinavian Journal of Psychology. Linköping, v. 53, n. 4 , p. 360-67, 2012.

GASSER, L.; KELLER, M. Are the competent the morally good? Perspective taking and moral motivation of children involved in bullying. Social Developmen. Malden, v. 18, p. 798-816, 2009.

GEORGIOU, S.N. Bullying and victimization at school: the role of mothers. British Journal of Educational Psychology. Malden, v. 78, p. 109-25, 2008.

GEORGIOU, S.N.; FANTI, K.A.A transactional model of bullying and victimization. Social Psychology of Education. Canberra, v. 13, n. 3, p. 295-311, 2010.

GINI, G. Bullying in Italian Schools: An Overview of Intervention Programmes. School Psychology International. Connecticut, v. 25, n. 1, p. 106-16, 2004. 
GINI, G.; POZZOLI, T.; HYMEL, S. Moral disengagement among children and youth: A meta-analytic review of links to aggressive behavior. Aggressive Behavior. Malden, v. 40, n. 1, p. 56-68, 2014.

GLOVER, D. et al. Bullying in 25 secondary schools: incidence, impact and intervention. Educational Research. Londres, v. 42, n. 2, p. 141-56, 2000.

GOFIN, R.; AVITZOUR, M. Traditional versus internet bullying in Junior High School students. Maternal and Child Health Journal. Nova York, v. 16, n. 8, 1625-635, 2012.

GOMES, R. et al. Organização, processamento, análise e interpretação de dados: o desafio da triangulação. In: MINAYO, M.C.S. et al. (Orgs). Avaliação por triangulação de métodos. Abordagem de programas sociais. Rio de Janeiro: Fiocruz, 2005. p. 185-222.

HANSEN, T.B. et al. A review of psychological factors related to bullying victimization in schools. Aggression and Violent Behavior. Florida, v. 17, n. 4, p. 383-87, 2012.

HAIR, J. F. et al. Análise multivariada de dados. Porto Alegre: Artmed, 2009. 688p.

HARDY, S.A. et al. Adolescent naturalistic conceptions of moral maturity. Social Development. Malden, v. 20, n. 3, p. 562-86, 2011.

HEALY, K.; SANDERS, M.; IYER, A. Parenting practices, children's peer relationships and being bullied at school. Journal of Child and Family Studies. Augusta, v. 24, n. 127, p. 114, 2013.

HEMPHILL, S.A. et al. Longitudinal predictors of cyber and traditional bullying perpetration in Australian secondary school students. Journal of Adolescent Health. Filadélfia, v. 51, n. 1, p. 59-65, 2012.

HERNANDEZ, T.A socio-ecological perspective on bullying: a New Synthesis. Revista Internacional de Sociologia. Córdoba, v. 67, n. 3, p. 631-54, 2009.

HIGUITA-GUTIERREZ, L.F.; CARDONA-ARIAS, J.A. Variables of the family, school, and social environment context that determine bullying in adolescents in Medellin, Colombia, 2014. Journal of School Violence. Filadélfia, v. 16, n. 1, p. 68-85, 2017.

HONG, J.S.; ESPELAGE, D. L. A review of research on bullying and peer victimization in school: an ecological system analysis. Aggression and Violent Behavior. Florida, v. 17, n. 4, p. 311-22, 2012.

HONG, J.S. et al. Social ecology of bullying and peer victimization of Latino and Asian youth in the United States: a Review of the Literature. Journal of School Violence. Filadélfia, v. 13, n. 3, p. 315-38, 2013.

HONG, J.S. et al. A review of bullying prevention and intervention in South Korean schools: An application of the social-ecological framework. Child Psychiatry and Human Development. Florida, v. 45, n. 4, 433-42, 2014. 
HUTCHINSON, M. Exploring the impact of bullying on young bystanders. Educational Psychology in Practice. Londres, v. 28, n. 4, p. 425-42, 2012.

HYMEL, S.; BONANNO, R.A. Moral disengagement processes in bullying. Theory into Practice. Ohio, v. 53, n. 4, p. 278-85, 2014.

INSTITUTO BRASILEIRO DE GEOGRAFIA E ESTATÍSTICA. Estimativas de população para 1 de julho de 2016. Rio de Janeiro, 2016. Disponível em:

<ftp://ftp.ibge.gov.br/Estimativas_de_Populacao/Estimativas_2016/estimativa_2016_T CU.pdf>. Acesso em: 23 mar. 2016.

JANSEN, D.E. et al. Early risk factors for being a bully, victim, or bully/victim in late elementary and early secondary education. The longitudinal TRAILS study. BMC Public Health. Londres, v. 11, p. 440, 2011.

JANSEN, P.W. et al. Prevalence of bullying and victimization among children in early elementary school: do family and school neighbourhood socioeconomic status matter? BMC Public Health. Londres, v. 12, p. 494, 2012.

KIM, Y.S. et al. Time trends, trajectories, and demographic predictors of bullying: a prospective study in Korean adolescents. Journal of Adolescent Health. Filadélfia, v. 45 , n. 4, p. 360-67, 2009.

KNOUS-WESTFALL, H.M. et al. Parental intimate partner violence, parenting practices, and adolescent peer bullying: a prospective study. Journal of Child and Family Studies. Augusta, v. 21, n. 5, p. 754-66, 2012.

KOKKINOS, C.M. Bullying and victimization in early adolescence: Associations with attachment style and perceived parenting. Journal of School Violence. Filadélfia, v. 12, n. 2, p. 174-92, 2013.

KOUWENBERG, M. et al. Peer victimization experienced by children and adolescents who are deaf or hard of hearing. Plos One. São Francisco, v. 7, n. 12, 2012.

KUBISZEWSKI, V. et al. School-bullying evaluation in French adolescents: validation of the French adaptation of the Olweus Bully/Victim Questionnaire revised (BVQr) (1996). Annales Médico-psychologiques, revue psychiatrique. Paris, v. 172, n. 4, p. 261-67, 2014.

LEE, C.H. An ecological systems approach to bullying behaviors among middle school students in the United States. Journal of Interpersonal Violence. Thousand Oaks, v. 26, n. 8, p. 1664-693, 2011.

LEE, C.H.; SONG, J. Functions of parental involvement and effects of school climate on bullying behaviors among South Korean Middle School students. Journal of Interpersonal Violence. Thousand Oaks, v. 27, n. 12, p. 2437-464, 2012. 
LEMSTRA, M. et al. Prevalence, risk indicators and outcomes of bullying among onreserve first nations youth. Canadian Journal of Public Health, v. 102, n. 6, p. 462-66, 2011.

LEPISTO, S.; LUUKKAALA, T.; PAAVILAINEN, E. Witnessing and experiencing domestic violence: a descriptive study of adolescents. Scandinavian Journal of Caring Sciences. Malden, v. 25, n. 1, p. 70-80, 2011.

LEREYA, S.T.; WOLKE, D. Prenatal family adversity and maternal mental health and vulnerability to peer victimisation at school. Journal of Child Psychology and Psychiatry. Londres, v. 54, n. 6, p. 644-52, 2013.

LIEN, L.; WELANDER-VATN, A. Factors Associated with the Persistence of Bullying Victimization From 10th grade to 13th Grade: A Longitudinal Study. Clin Pract Epidemiol Ment Health, v. 9, p. 243-50, 2013.

LOSEL, F.; BENDER, D. Aggressive, delinquent, and violent outcomes of school bullying: do family and individual factors have a protective function? Journal of School Violence. Filadélfia, v. 13, n. 1, p. 59-79, 2014.

LUMLEY, T. et al. The importance of the normality assumption in large public health data sets. Annual Review of Public Health. Los Angeles, v. 23, p. 151-69, 2002.

MA, T.L.; BELLMORE, A. Peer victimization and parental psychological control in adolescence. Journal of Abnormal Child Psycholog. Vancouver, v. 40, n. 3, p. 413-24, 2012.

MALTA, D.C. et al. Bullying in brazilian school children: analysis of the National Adolescent School-based Health Survey (PeNSE 2012). Revista Brasileira de Epidemiologia. São Paulo, v. 17, n. 1, p. 92-105, 2014.

MALTA, D.C. et al. Bullying nas escolas brasileiras: resultados da Pesquisa Nacional de Saúde do Escolar (PeNSE), 2009. Ciência \& Saúde Coletiva. Rio de Janeiro, v. 15, n. 2, p. 3065-076, 2010.

MARTINS, E.; SZYMANSKI, H. A abordagem ecológica de Urie Bronfenbrenner em estudos com famílias. Estudos e Pesquisas em Psicologia. Rio de Janeiro, v. 4, n. 1, p. 63-77, 2004.

MINAYO, M.C.S. Análise qualitativa: teoria, passos e fidedignidade. Ciência \& Saúde Coletiva. Rio de Janeiro, v. 17, n. 3, p. 621-26, 2012.

MINAYO, M.C.S. Los conceptos estructurantes de la investigación cualitativa. Salud colectiva. Lanús, v. 6, n. 3, p. 251-61, 2010.

MINAYO, M.C.S. 0 desafio do conhecimento. Pesquisa qualitativa em saúde. Rio de Janeiro: Hucitec, 2014. 408. 
MOON, B.; MORASH, M.; MCCLUSKEY, J. D. General Strain Theory and school bullying: an empirical test in South Korea. Crime \& Delinquency. Carbondale, v. 58, n. 6, p. 827-55, 2012.

MORENO JIMÉNEZ, B. et al. Diferencias de género en el acoso psicológico en el trabajo: un estudio en población española. Psicologia em Estudo. Maringá, v. 10, n. 1, p. 3-10, 2005.

MURRAY-HARVEY, R.; SLEE, P.T. School and home relationships and their impact on school bullying. School Psychology International. Connecticut, v. 31, n. 3, p. 271-95, 2010.

MUSTANOJA, S. et al. Is exposure to domestic violence and violent crime associated with bullying behaviour among underage adolescent psychiatric inpatients? Child

Psychiatry \& Human Development. Florida, v. 42, n. 4, p. 495-06, 2011.

NASCIMENTO, G.C. A anamorfose na composição de Las Meninas de Picasso.

Significação. São Paulo, n. 14, n. 1, p. 98-118, 2000.

OBERMANN, M.-L. Moral Disengagement Among Bystanders to School Bullying. Journal of School Violence. Filadélfia, v. 10, n. 3, p. 239-57, 2011.

OLIVEIRA, N.H.D. Recomeçar: família, filhos e desafios. São Paulo: Editora UNESP/Cultura Acadêmica, 2009. 270p.

OLIVEIRA, W.A. et al. Associations between the practice of bullying and individual and contextual variables from the aggressors' perspective. Jornal de Pediatria. Rio de Janeiro, v. 92, n. 1, p. 32-39, 2016a.

OLIVEIRA, W. A. et al. Bullying escolar e laços familiares: dimensões contextuais no estado da arte. In: PEREIRA, M. B. F. L. O.;BARBOSA, A. J. G., et al (Ed.). Estudos sobre o bullying: família, escola e atores. Curitiba: CRV, 2016b. p.29-46.

OLIVEIRA, W.A. et al. Experiences and perceptions of discrimination related to bullying among Brazilian students. Maltrattamento e Abuso all'infanzia. Milão, v. 18, n. 1, p. 29-57, 2016c.

OLIVEIRA, W.A. et al. Interfaces entre família e bullying escolar: uma revisão sistemática. Psico-USF. Itatiba, v. 20, n. 1, p. 121-32, 2015 a.

OLIVEIRA, W.A. et al. O lugar da família na construção de cenários de bullying. In: SILVA, P. T. N.; SOUZA, S. A. R., et al (Ed.). 0 desenvolvimento humano. Perspectivas para o século XXI. Memória, lazer e atuação profissional. São Luiz: EDUFMA, 2013. p.409-18.

OLIVEIRA, W.A. et al. Students' health: an integrative review on family and bullying.

Ciência \& Saúde Coletiva. Rio de Janeiro, v. 22, n. 5, p. 1553-564, 2017. 
OLIVEIRA, W.A. et al. The causes of bullying: results from the National Survey of School Health (PeNSE). Revista Latino-Americana de Enfermagem. Ribeirão Preto, v. 23, n. 2, p. 275-82, 2015b.

OLIVEIRA, W.A. et al. Modos de explicar o bullying: análise dimensional das concepções de adolescentes. Ciência \& Saúde Coletiva. Rio de Janeiro. No prelo.

OLWEUS, D.; LIMBER, S.P. Bullying in school: evaluation and dissemination of the Olweus Bullying Prevention Program. In: (Ed.). American Journal of Orthopsychiatry. Estados Unidos, v. 80, 2010. p.124-34.

OLWEUS, D. Bullying at school. Cambrigde: Blackwell: 1993. 152p.

. Bullying at school and later criminality: findings from three Swedish community samples of males. Criminal Behaviour and Mental Health. Malden, v. 21, n. 2, p. 15156, 2011.

. Familial and temperamental determinants of aggressive behavior in adolescent boys: A causal analysis. US: American Psychological Association. Estados Unidos, v. 16, p. 644-60, 1980.

School bullying: development and some important challenges. Annual Review of Clinical Psychology. Estados Unidos, v. 9, n. 1, p. 751-80, 2013.

PAPADAKI, E.; GIOVAZOLIAS, T. The protective role of father acceptance in the relationship between maternal rejection and bullying: a moderated-mediation model. Journal of Child and Family Studies. Augusta, v. 24, n. 2, p. 330-41, 2015.

PATTON, D. U. et al. A review of research on school bullying among African American youth: An ecological systems analysis. Educational Psychology Review. Berlim, v. 25, n. 2, p. 245-60, 2013.

PEREIRA, B.; SILVA, M.A.I.; NUNES, B. Descrever o bullying na escola: estudo de um agrupamento de escolas no interior de Portugal. Revista Diálogo Educacional. Curitiba, v. 9, n. 28, p. 455-66, 2009.

PERRON, T. Peer victimisation: Strategies to decrease bullying in schools. British Journal of School Nursing. Londres, v. 8, n. 1, p. 25-29, 2013.

PIEROBON, M. et al. Alcohol consumption and violence among Argentine adolescents. Jornal de Pediatria. Rio de Janeiro, v. 89, n. 1, p. 100-07, 2013.

PIGOZI, P.L.; MACHADO, A.L. Bullying na adolescência: visão panorâmica no Brasil. Ciência \& Saúde Coletiva. Rio de Janeiro, v. 20, n. 11, p. 3509-22, 2015.

PINHEIRO, F.M.F.; WILLIAMS, L.C.D.A. Violência intrafamiliar e intimidação entre colegas no ensino fundamental. Cadernos de Pesquisa. São Paulo, v. 39, n. 138, p. 995-1018, 2009. 
POVEDANO, A. et al. Relación del conflicto y la expresividad familiar con la victimización en la escuela: el rol de la autoestima, la sintomatología depresiva y el género de los adolescentes. Fundación Infancia y Aprendizaje. Madrid, p. 421-32, 2012.

PRATTA, E.M.M.; SANTOS, M.A.D. Família e adolescência: a influência do contexto familiar no desenvolvimento psicológico de seus membros. Psicologia em Estudo. Maringá, v. 12, n. 2, p. 247-56, 2007.

R CORE TEAM. R: A language and environment for statistical computing. Vienna: R Foundation for Statistical Computing, 2013.

RAMIRES, V.R.R.; SCHNEIDER, M.S. Revisitando alguns conceitos da teoria do apego: comportamento versus representação? Psicologia: Teoria e Pesquisa. Brasília, v. 26, n. 1, p. 25-33, 2010.

RECH, R. R. et al. Prevalence and characteristics of victims and perpetrators of bullying. Jornal de Pediatria. Rio de Janeiro, v. 89, n. 2, p. 164-70, 2013.

ROBSON, C.; WITENBERG, R.T. The influence of moral disengagement, morally based self-esteem, age, and gender on traditional bullying and cyberbullying. Journal of School Violence. Filadélfia, v. 12, n. 2, p. 211-31, 2013.

ROMANÍ, F.; GUTIÉRREZ, C. Auto-reporte de victimización escolar y factores asociados en escolares peruanos de educación secundaria, año 2007. Revista Peruana de Epidemiología. Lima, v. 14, n. 3, 2010.

ROMANÍ, F.; GUTIÉRREZ, C.; LAMA, M. Auto-reporte de agresividad escolar y factores asociados en escolares peruanos de educación secundaria. Revista Peruana de Epidemiología. Lima, v. 15, n. 2, p. 1-8, 2011.

ROSA, J.G. Primeiras estórias. Rio de Janeiro: Nova Fronteira, 2005. 224p.

SALMIVALLI, C. Participant roles in bullying: how can peer bystanders be utilized in interventions? Theory into Practice. Ohio, v. 53, n. 4, p. 286-92, 2014.

SANTOS, A.C.B.H; TREVISOL, M.T.C. Educação moral na escola: relato de experiências. Nuances: estudos sobre Educação. Presidente Prudente, v. 23, n. 24, p. 122-41, 2012.

SAWYER, J.L. et al. The missing voice: parents' perspectives of bullying. Children and Youth Services Review. Toronto, v. 33, n. 10, p. 1795-1803, 2011.

SENNA, S.R.C.M.; DESSEN, M.A. Contribuições das teorias do desenvolvimento humano para a concepção contemporânea da adolescência. Psicologia: Teoria e Pesquisa. Brasília, v. 28, n. 1, p. 101-08, 2012.

SENTENAC, M. et al. Victims of bullying among students with a disability or chronic illness and their peers: a cross-national study between Ireland and France. Journal of Adolescent Health. Filadélfia, v. 48, n. 5, p. 461-66, 2011. 
SEVDA, A.; SEVIM, S. Effect of high school students' self concept and family relationships on peer bullying. Revista Brasileira de Promoção de Saúde. Fortaleza, v. 25, p. 405-12, 2012.

SHETGIRI, R. Bullying and victimization among children. Advances in pediatrics. Maryland, v. 60, n. 1, p. 33-51, 2013.

SHETGIRI, R. et al. Parental characteristics associated with bullying perpetration in US children aged 10 to 17 years. American Journal of Public Health. Washington, v. 102, n. 12 , p. 2280-286, 2012.

SHETGIRI, R.; LIN, H.; FLORES, G. Trends in risk and protective factors for child bullying perpetration in the United States. Child Psychiatry \& Human Development. Florida, v. 44, n. 1, p. 89-104, 2013.

SIJTSEMA, J.J. et al. Friendship selection and influence in bullying and defending: effects of moral disengagement. Developmental Psychology. Michigan, v. 50, n. 8, p. 2093-104, 2014.

SILVA, J.L. et al. Bullying: conhecimentos, atitudes e crenças de professores. Psico. Porto Alegre, v. 45, n. 2, p. 147-56, 2014a.

SILVA, J.L. et al. Bullying na sala de aula: percepção e intervenção de professores. Arquivos Brasileiros de Psicologia. Rio de Janeiro, v. 65, n. 1, p. 121-37, 2013 a.

SILVA, J.L. et al. The effects of a skill-based intervention for victims of bullying in Brazil. International Journal of Environmental Research and Public Health. Basel, v. 13, n. 11, p. 1042-52, 2016.

SILVA, K.N.; RAMIRES, J.C.L. 0 acesso à saúde pública na cidade de uberaba: caracterização e espacialização. In: VIII ENCONTRO INTERNO E XII SEMINÁRIO DE INICIAÇÃO CIENTÍFICA, 1., 2008, Uberlândia. Anais... Uberlândia: UFU, 2008. p.1-8

SILVA, M.A.I. Bullying entre pares na escola: desafio aos enfermeiros que atuam na atenção básica à saúde. Revista Eletrônica de Enfermagem. Goiânia, v. 15, n. 3, p. 603604, 2013.

SILVA, M.A.I. et al. O olhar de professores sobre o bullying e implicações para a atuação da enfermagem. Revista da Escola de Enfermagem da USP. São Paulo, v. 48, n. 4, p. 723-730, 2014b.

SILVA, M.A.I. et al. The involvement of girls and boys with bullying: an analysis of gender differences. International Journal of Environmental Research and Public Health. Basel, v. 10, n. 12, p. 6820-31, 2013b.

SILVA, M.A.I. et al . Vulnerabilidade na saúde do adolescente: questões contemporâneas. Ciência \& Saúde Coletiva. Rio de Janeiro, v. 19, n. 2, p. 619-627, 2014c. 
SOUZA, J.M. Bullying: uma das faces do preconceito homofóbico entre jovens no contexto escolar. 2013. 165f. Dissertação de Mestrado. Aracaju, Universidade Federal de Sergipe, 2013.

SPSS INC. Statistics for Windows, Version 21.0. Chicago: IBM, 2012.

ZIMERMAN, D. Fundamentos psicanalíticos. Porto Alegre: ArtMed, 1999. 478p.

SZWARCWALD, C.L.; DAMACENA, G.N. Amostras complexas em inquéritos populacionais: planejamento e implicações na análise estatística dos dados. Revista Brasileira de Epidemiologia. São Paulo, v. 11, n. 1, p. 38-45, 2008.

SZYMANSKI, H. Teorias e "teorias” de famílias. In: CARVALHO, M.C.B. (Org.). A família contemporânea em debate. 3. ed. São Paulo: EDU/Cortez, 2000. p. 23-28.

SZYMANSKI, H. Viver em família como experiência de cuidado mútuo: desafios de um mundo em mudança. Serviço Social \& Sociedade. São Paulo, v. 23, n.71, p.9-25, 2002.

TAVARES, B.F.; BERIA, J.U.; LIMA, M.S.D. Fatores associados ao uso de drogas entre adolescentes escolares. Revista de Saúde Pública. São Paulo, v. 38, p. 787-96, 2004.

TEISL, M. et al. Differential expression of social dominance as a function of age and maltreatment experience. Developmental Psychology. Michigan, v. 48, n. 2, p. 575-88, 2012.

THORNBERG, R. et al. Bystander motivation in bullying incidents: To intervene or not to intervene? Western Journal of Emergency Medicine. Califórnia, v. 13, n. 3, p. 247-52, 2012.

Thornberg, R. et al. Classroom relationship qualities and social-cognitive correlates of defending and passive bystanding in school bullying in Sweden: a multilevel analysis. Journal of School Psychology. Illinois, v. 63, p. 49-62, 2017.

THORNBERG, R. Informed Grounded Theory. Scandinavian Journal of Educational Research. Nydalsveien, v. 56, n. 3, p. 243-59, 2011.

THORNBERG, R.; JUNGERT, T. Bystander behavior in bullying situations: basic moral sensitivity, moral disengagement and defender self-efficacy. Journal of Adolescence. Ohio, v. 36, n. 3, p. 475-83, 2013.

THORNBERG, R.; KNUTSEN, S. Teenagers' explanations of bullying. Child \& Youth Care Forum. Ames, v. 40, n. 3, p. 177-92, 2011.

TOGNETTA, L.R.P. et al. Desengajamento moral e bullying: desafios da convivência na escola. In: BANDURA, A. et al. (Orgs.). Desengajamento moral: Teoria e Pesquisa a partir da Teoria Social Cognitiva. Campinas: Mercado de Letras, 2015. p.243-84. 
TORTORELLI, M.F.P.; CARREIRO, L.R.R.; ARAÚJO, M.V.D. Correlações entre a percepção da violência familiar e o relato de violência na escola entre alunos da cidade de São Paulo. Psicologia: Teoria e Prática. São Paulo, v. 12, n. 1, p. 32-42, 2010.

TOTURA, C.M. et al. Bullying and victimization among boys and girls in middle school: the influence of perceived family and school contexts. The Journal of Early

Adolescence. Nova Iorque, v. 29, n. 4, p. 571-609, 2009.

TRIVINOS, A.N.S. Introdução à pesquisa em Ciências Sociais. A pesquisa qualitativa em Educação. Ribeirão Preto: Atlas, 2009. 175p.

URIBE, A.F.; ORCASITA, L.T.; GOMÉS, E.A. Bullying, redes de apoyo social y funcionamiento familiar en adolescentes de una institución educativa de Santander, Colombia. Psychologia. Avances de la disciplina. Bogotá, n. 6, v. 2, pp. 83-99, 2012.

VANDER ZANDEN, J. Manual de Psicología Social. Barcelona: Paidós, 1995. 700p.

VERGUEIRO, P.V. Jung, entrelinhas: reflexões sobre os fundamentos da teoria junguiana com base no estudo do tema individuação em Cartas. Psicologia: Teoria e Prática. São Paulo, v. 10, n. 1, p. 125-43, 2008.

VICENTE, C.M. O direito à convivência familiar e comunitária: uma política de manutenção do vínculo. In: KALOUSTIAN, S.M. (Org.). Família brasileira, a base de tudo. 5. ed. São Paulo: Cortez; Brasília: UNICEF, 2002. p. 47-59.

VLACHOU, M. et al. Bully/victim problems among preschool children: a review of current research evidence. Educational Psychology Review. Rotterdam, v. 23, n. 3, p. 329-58, 2011.

VOLK, A.A. et al. Is adolescent bullying an evolutionary adaptation? Aggressive Behavior. Malden, v. 38, n. 3, p. 222-38, 2012.

VON MAREES, N.; PETERMANN, F. Bullying in German Primary Schools gender differences, age trends and influence of parents' migration and educational backgrounds. School Psychology International. Connecticut, v. 31, n. 2, p. 178-98, 2010.

WANDEKOKEN, K.D.; VICENTE, C.R.; SIQUEIRA, M.M.D. Alcoolismo parental e fatores de risco associados. Revista eletrônica saúde mental álcool e drogas. Ribeirão Preto, v. 7, p. 161-67, 2011.

WANG, $\mathrm{H}$. et al. Adolescent bullying involvement and psychosocial aspects of family and school life: a cross-sectional study from Guangdong Province in China. Plos One. São Francisco, v. 7, n. 7, 2012.

WANG, J.; IANNOTTI, R. J.; NANSEL, T.R. School bullying among adolescents in the United States: physical, verbal, relational, and cyber. Journal of Adolescent Health. Filadélfia, v. 45, n. 4, p. 368-75, 2009. 
WEBER, L.N.D.; DESSEN, M.A. Pesquisando a família. Instrumentos para a coleta e análise de dados. Curitiba: Juruá, 2011. 274p.

WEBER, L.N.D.; SALVADOR, A.P.V.; BRANDENBURG, O.J. Escalas de qualidade na interação familiar. In: WEBER, L.N.D.; DESSEN, M.A. (Orgs.). Pesquisando a família. Instrumentos para coleta e análise de dados. Curitiba: Juruá, 2011. p.61-72.

WORLD HEALTH ORGANIZATION. Core competencies in adolescent health and development for primary care providers: including a tool to assess the adolescente health and development component in pre-service education of health-care providers. Geneva: WHO Press, 2015.

YANG, S. J. et al. Differences in predictors of traditional and cyber-bullying: a 2-year longitudinal study in Korean school children. European Child \& Adolescent

Psychiatry. Nova York, v. 22, n. 5, p. 309-18, 2013.

YAMAGATA, S. et al. Bidirectional influences between maternal parenting and children's peer problems: a longitudinal monozygotic twin difference study. Developmental Science. Malden, v. 16, n. 2, p. 249-59, 2013.

ZAINE, I.; REIS, M.D.J.D.D.; PADOVANI, R.D.C. Comportamentos de bullying e conflito com a lei. Estudos de Psicologia. Campinas, v. 27, n. 3, p. 375-82, 2010.

ZILLMER, J.G.V. et al . Modelo bioecológico de Urie Bronfenbrenner e inserção ecológica: uma metodologia para investigar famílias rurais. Texto \& Contexto Enfermagem.

Florianópolis, v. 20, n. 4, p. 669-74, 2011.

ZOTTIS, G.A. et al. Associations between child disciplinary practices and bullying behavior in adolescents. Jornal de Pediatria. Rio de Janeiro, v. 90, n. 4, p. 408-14, 2014. 
Anexo A

Escala de Vitimização e Agressão entre Pares (EVAP) (versão adaptada) 


\section{ESCALA DE VITIMIZAÇÃO E AGRESSÃO ENTRE PARES (EVAP) (CUNHA; WEBER; STEINER NETO, 2011)}

Idade: Sexo:

Escola №:

O que é bullying? Bullying são comportamentos e atitudes agressivas, intencionais e repetitivas, que ocorrem sem motivação evidente, que causam dor e angústia, tais como: apelidar, bater, ignorar, ameaçar, humilhar, empurrar, amedrontar, xingar, roubar, isolar, maltratar, fofocas, espalhar mensagens que ridicularizam os colegas et..

Não é bullying quando dois colegas, que tenham mais ou menos a mesma força, lutam ou brigam entre si.

Por favor, responda as perguntas a seguir pensando no que aconteceu durante os últimos 6 meses na sua escola ou no caminho de ida ou volta para as aulas.

Nos últimos 6 meses... Sempre pensando em situações de bullying Eu provoquei colegas.

Eu briguei quando algum colega me bateu primeiro ou fez algo que eu não gostei.

Eu dei um empurrão, soquei ou chutei colegas.

Eu ameacei ferir, bater ou fiz outro tipo de ameaças contra colegas.

Eu roubei ou mexi nas coisas dos colegas.

Eu xinguei colegas.

Eu exclui colegas de grupos ou brincadeiras.

Eu coloquei apelido em colegas que eles não gostaram.

Eu incentivei colegas a brigarem.

Eu disse coisas sobre colegas para fazer os outros rirem.

Os colegas me provocaram.

Eu fui empurrado, socado e/ou chutado por colegas.

Colegas ameaçaram me ferir, bater ou fizeram outros tipos de ameaça.

Colegas roubaram, mexeram ou estragaram minhas coisas.

Eu fui xingado por colegas.

Colegas me excluíram de grupos e/ou brincadeiras.

Colegas colocaram apelidos em mim que não gostei.

Colegas disseram coisas sobre mim para fazerem os outros rirem. 
AnexoB

Escala de Qualidade na Interação Familiar (EQIF) (versão adaptada) 


\section{ESCALA DE QUALIDADE NA INTERAÇÃO FAMILIAR (EQIF) (WEBER; SALVADOR; BRANDESNBURG, 2011)}

Caro(a) participante: A sua ajuda é muito importante para a nossa pesquisa sobre a família, mas lembramos que você só participa se quiser. Pedimos que você responda sinceramente, sem deixar nenhuma em branco. Não existem respostas certas ou erradas! Você não precisa escrever o seu nome e ninguém mais, além dos pesquisadores, saberá as suas respostas.

Idade:__ Gênero: ( ) feminino ( ) masculino Com quem você mora?

Responda as seguintes questões sobre o seu pai e sobre a sua mãe. Numere de 1 a 5 , de acordo com a seguinte notação: (1) = Nunca; (2) = Quase nunca; (3) = Às vezes; (4) = Quase sempre; (5) = Sempre.

\begin{tabular}{|c|c|c|c|c|}
\hline $\mathbf{N}$ & PERCEPÇÃO DOS COMPORTAMENTOS DOS PAIS & PAI & MÃE & $\begin{array}{c}\text { Outra } \\
\text { Pessoa }\end{array}$ \\
\hline 1. & Meus pais costumam dizer o quanto eu sou importante para eles. & & & \\
\hline 2. & Meus pais brigam comigo por qualquer coisa. & & & \\
\hline 3. & Meus pais costumam xingar um ao outro. & & & \\
\hline 4. & Eu costumo contar as coisas boas que me acontecem para meu pai/minha mãe. & & & \\
\hline 5. & Meus pais costumam falar alto ou gritar comigo. & & & \\
\hline 6. & Meus pais fazem carinho um no outro. & & & \\
\hline 7. & O que meus pais me ensinam de bom eles também fazem. & & & \\
\hline 8. & Eu penso que meu pai/minha mãe são os melhores pais que eu conheço. & & & \\
\hline 9. & Meus pais ficam felizes quando estão comigo. & & & \\
\hline 10. & Meus pais costumam descontar em mim quando estão com problemas. & & & \\
\hline 11. & Meus pais falam mal um do outro. & & & \\
\hline 12. & Eu costumo contar as coisas ruins que me acontecem para meu pai/minha mãe. & & & \\
\hline 13. & Meus pais costumam me xingar ou falar palavrões para mim. & & & \\
\hline 14. & Meus pais fazem elogios um para o outro. & & & \\
\hline 15. & Meus pais também fazem as obrigações que me ensinam. & & & \\
\hline 16. & Eu me sinto amado pelos meus pais. & & & \\
\hline 17. & Meus pais procuram saber o que aconteceu comigo quando estou triste. & & & \\
\hline 18. & Meus pais sabem onde eu estou quando não estou em casa. & & & \\
\hline 19. & Quando ajudo meus pais, eles me agradecem. & & & \\
\hline 20. & Meus pais costumam me bater quando faço alguma coisa errada. & & & \\
\hline 21. & Meus pais costumam estar brabos um com o outro. & & & \\
\hline 22. & Eu costumo falar sobre meus sentimentos para meu pai/minha mãe. & & & \\
\hline 23. & Meus pais costumam se abraçar. & & & \\
\hline 24. & Eu acho legais as coisas que meus pais fazem. & & & \\
\hline 25. & Meus pais são um bom exemplo para mim. & & & \\
\hline 26. & Meus pais costumam mostrar que se preocupam comigo. & & & \\
\hline 27. & Meus pais demonstram orgulho de mim. & & & \\
\hline 28. & Meus pais sabem o que eu faço com o meu tempo livre. & & & \\
\hline 29. & Meus pais brigam um com o outro. & & & \\
\hline 30. & Meus pais costumam me fazer carinhos quando eu me comporto bem. & & & \\
\hline 31. & Meus pais costumam me bater sem eu ter feito nada de errado. & & & \\
\hline 32. & Meus pais costumam me criticar de forma negativa. & & & \\
\hline 33. & Meus pais falam bem um do outro. & & & \\
\hline 34. & Sinto orgulho de meus pais. & & & \\
\hline 35. & Meus pais costumam me dar beijos, abraços ou outros carinhos. & & & \\
\hline 36. & Meus pais costumam me dar conselhos. & & & \\
\hline 37. & Meus pais costumam me bater por coisas sem importância. & & & \\
\hline 38. & Meus pais têm bom relacionamento entre eles. & & & \\
\hline 39. & Meus pais pedem para eu dizer para onde eu estou indo. & & & \\
\hline 40. & Qual a nota que você dá para seus pais, de um a cinco. & & & \\
\hline
\end{tabular}

Este espaço é para você escrever o que quiser sobre seus pais! 
Anexo C

Autorização para o desenvolvimento da pesquisa (SEE) 


\section{TERMO DE AUTORIZACẼ̃O}

\section{PROJETO DE PESQUISA: "RELAÇÕES ENTRE BULLYNG NA ADOLESCÊNCIA E INTERAÇÕES FAMILIARES: DO SINGULAR AO PLURAL".}

INTERESSADO (A): Wanderlei Abadio de Oliveira - aluno do Programa de Pós-Graduação de Enfermagem em Saúde Pública da Escola de Enfermagem de Ribeirão Preto, da Universidade de São Paulo/USP.

A Subsecretaria de Desenvolvimento da Educação Básica e a Comissão de Ética da Secretaria de Estado de Educação de Minas Gerais/ SEE/MG, após análise do Projeto de Pesquisa, proposto pelo doutorando Wanderlei Abadio de Oliveira/USP, são de parecer favorável à realização da pesquisa intitulada acima, nas escolas estaduais da Superintendência Regional de Ensino de Uberaba.

Ressaltamos que os procedimentos de pesquisa devem obedecer, criteriosamente, às orientações da Resolução 466/12 do Conselho Nacional da Saúde que estabelece as Diretrizes e Normas Regulamentadoras de pesquisa envolvendo seres humanos e que, em nenhuma hipótese, a pesquisa poderá interferir no desenvolvimento das atividades pedagógicas da escola no cumprimento de seu Calendário Escolar.

Ressaltamos ainda, que a participação na pesquisa será voluntária e a id́entidade das pessoas envolvidas deverá ser mantida em sigilo.

As instituições e os participantes não terão ônus com a pesquisa.

Belo Horizonte, 23 de outubro de 2013.

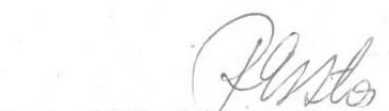

Raquel Elizabete de Souza Santos

Subsecretária de Desenvolvimento da Educação

Cidade Administrativa Presidente Tancredo Neves - Rodovia Prefeito Américo Gianetti, s/n - Bairro Serra Verde Prédio Minas - $11^{\circ}$ andar - Belo Horizonte - Minas Gerais - CEP 31630900 - Telefone 3139153652 
Anexo D

Parecer de aprovação por Comitê de Ética em Pesquisa 

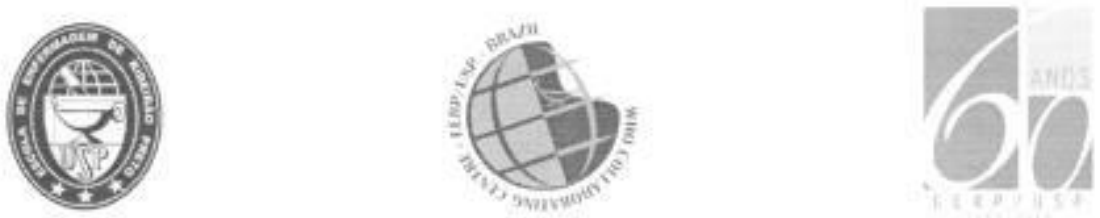

ESCOLA DE ENFERMAGEM DE RIBEIRÃO PRETO DA UNIVERSIDADE DE SÃO PAULO

Centro Colaborador da Organizaçăo Mundial da Saude para o Desenvolvimento da Pesquisa em Enfermagem

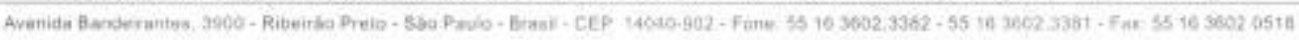
wame eers und br - eeripedu vis Dor

\section{COMITÊ DE ÉTICA EM PESQUISA DA EERPIUSP}

Of.CEP-EERP/USP - 301/2013

Ribeirão Preto, 09 de dezembro de 2013

Prezada Senhora,

Comunicamos que o projeto de pesquisa, abaixo especificado, foi analisado e considerado APROVADO AD REFERENDUM pelo Comitê de Ética em Pesquisa da Escola de Enfermagem de Ribeirăo Preto da Universidade de Săo Paulo, em 09 de dezembro de 2013.

Protocolo: 24555313.6.0000.5393

Projeto: Relaçōes entre bullying na adolescência e interaçōes familiares: do singular ao plural.

Pesquisadores: Marta Angélica lossi Silva

Wanderlei Abadio de Oliveira

Em atendimento à Resolução 466/12, deverá ser encaminhado ao CEP o relatório final da pesquisa e a publicação de seus resultados, para acompanhamento, bem como comunicada qualquer intercorréncia ou a sua interrupçáo.

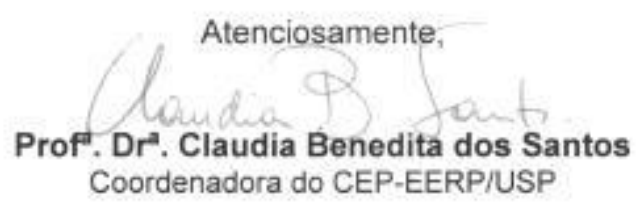

IIma. Sra

Profe. Dra. Marta Angélica lossi Silva

Departamento de Enfermagem Materno-Infantil e Saúde Pública

Escola de Enfermagem de Ribeirāo Preto - USP 
Apêndice A

Roteiro para entrevista semiestruturada 


\section{ROTEIRO PARA ENTREVISTA SEMIESTRUTURADA}

Idade: Sexo:

Escola: ( ) 1( ) 2( ) 3( )4( ) 5( )6 ( ) 7

1. Fale-me como é sua relação com seus pais? Com sua família?

2. Como é estar ou viver na sua casa?

3. Como é estar na escola?

4. Se alguém fosse fazer um filme da sua vida, qual ou quais seriam as partes envolvendo a sua família que não poderiam faltar? 0 que seria importante expor?

5. Quando tem um problema/dúvida a quem você consulta/recorre?

6. Para você o que é bullying?

7. Você já foi ameaçado, humilhado ou agredido na escola? 0 que fizeram com você? Você contou para alguém quando esses fatos aconteceram?

8. Você alguma vez ameaçou, maltratou, humilhou ou agrediu outro colega na escola? 0 que você fez? Você contou para alguém quando esses fatos aconteceram?

9. Você já presenciou alguns dos seus colegas ser ameaçado, maltratado, humilhado ou agredido na escola? 0 que você fez? Você contou para alguém quando esses fatos aconteceram?

10. Você acha que a maneira como as coisas acontecem na sua casa influenciam no que acontece na escola com você? Como? Influencia na maneira de você ser aqui na escola? Você consegue me dar exemplos? 
Apêndice B

Termo de Consentimento Livre e Esclarecido (maiores de 18 anos) 


\section{TERMO DE CONSENTIMENTO LIVRE E ESCLARECIDO DESTINADO AOS ADOLESCENTES MAIORES DE 18 ANOS (a ser impresso em frente e verso)}

Pesquisa: Relações entre bullying na adolescência e interações familiares: do singular ao plural

Prezado(a) Jovem,

Meu nome é Wanderlei Abadio de Oliveira, sou psicólogo e aluno de doutorado na Escola de Enfermagem de Ribeirão Preto/USP (EERP/USP) e sou responsável por esta pesquisa sob orientação da Profa. Dra. Marta Angélica Iossi Silva. Neste sentido, gostaríamos de convidá-lo para participar desta pesquisa, que tem como objetivos conhecer e analisar a relação entre a qualidade das interações familiares de adolescentes e o envolvimento em práticas de bullying.

A pesquisa se dará por meio da aplicação de escalas e questionários na sua escola durante um (1) horário de aula e, caso você seja sorteado, será entrevistado. Essa entrevista será individual, com duração de aproximadamente 20 minutos, realizada também na sua escola por mim, gravada e posteriormente transcrita. Os instrumentos aplicados se referem ao bullying escolar (eu briguei quando algum colega me bateu primeiro ou fez algo que eu não gostei; os colegas me provocaram; colegas me excluíram de grupos e/ou brincadeiras, por exemplo) e à maneira como você percebe e avalia o clima familiar (meus pais costumam dizer o quanto eu sou importante para eles; eu costumo contar as coisas ruins que me acontecem para meu pai/minha mãe; como é sua relação com seus pais, por exemplo). Questionários, escalas e entrevistas somente serão coletadas das pessoas que aceitarem espontaneamente participar da pesquisa. Em todos os momentos se você não souber responder ou se não quiser responder a qualquer pergunta, poderá deixar de participar da pesquisa. As informações serão usadas exclusivamente para esta pesquisa e seus resultados poderão ser divulgados em revistas e encontros científicos, sem que vocês sejam identificados. Os dados e instrumentos utilizados na pesquisa ficarão arquivados com o pesquisador responsável por um período de 5 anos, e após esse tempo serão destruídos.

A aceitação para participar do estudo não trará nenhum risco físico ou gasto financeiro para você, sendo que será mantida em segredo sua identificação, ou seja, você não será identificado por nome, apelido ou qualquer outro meio que possibilite saber quem você é. Você não terá nenhum benefício direto, nesse momento, pela sua participação, mas será uma oportunidade para compartilhar experiências de maneira sigilosa, colaborando para que os resultados da pesquisa possam nos ajudar a compreender e explicar o bullying escolar que prejudica crianças e adolescentes, além de ser um problema de saúde pública. Da mesma forma, participando do estudo, caso haja um desconforto, como por exemplo, ao falar de situações de violência ou da família, você será acolhido pelo pesquisador e poderá interromper a participação imediatamente, continuando ou não mais tarde. Nestes casos, se necessário, você poderá ser encaminhado para atendimentos específicos. Além disso, garante-se o direito à indenização, conforme as leis vigentes no país, caso haja qualquer ou eventual dano decorrente de sua participação na pesquisa.

Destacamos que, embora o presente estudo explore questões relacionadas ao contexto familiar e suas relações com o bullying, os resultados não serão utilizados para responsabilizar ou culpar as famílias, mas se pretende pensar outros fatores que possam explicar o fenômeno da violência e assim consigamos enfrentá-lo de forma adequada e em diversas direções. Sua participação no estudo será importante e contribuirá para a defesa da saúde e do desenvolvimento saudável de nossos adolescentes. Nós, também, vamos aprender muito e o trabalho poderá ajudar na melhora de serviços na área da saúde e educação, principalmente.

Lembramos que a qualquer momento da pesquisa você poderá desistir de sua participação, uma vez que esta participação é voluntária. Esse termo é assinado em duas vias, sendo que uma delas ficará com o pesquisador e outra será entregue a você para conhecimento.

O projeto da pesquisa foi analisado e aprovado pelo Comitê de Ética em Pesquisa com Seres Humanos (CEP) da EERP/USP, que tem a finalidade de proteger os participantes de pesquisas, na medida em que respeita as questões éticas necessárias para a sua realização.

Se tiver alguma dúvida, poderá entrar em contato comigo pelo telefone (34) 91972274 ou (16) 981239714 de $2^{\mathrm{a}}$ à 6 a feira das $08 \mathrm{~h} 00 \mathrm{~min}$ às $17 \mathrm{~h} 00 \mathrm{~min}$ ou pelo e-mail wanderleio@usp.br. Além disso, eu estarei disponível pessoalmente na sua escola durante essa semana de coleta de dados das $07 \mathrm{~h} 00 \mathrm{~min}$ às $11 \mathrm{~h} 30 \mathrm{~min}$. Você ainda poderá contatar o CEP no endereço da EERP/USP - Avenida dos Bandeirantes, 3900 - Campus USP - Ribeirão Preto - SP - 14040-902 - Telefone (16) 3602-3386 - de 2 $\underline{\underline{a}}$ à $6^{\underline{a}}$ feira das 08 h00min às $17 \mathrm{~h} 00 \mathrm{~min}$.

Agradecemos a sua colaboração! 


\section{Consentimento da participação da pessoa como sujeito da pesquisa.}

Após ter conhecimento sobre como poderei colaborar com esta pesquisa, concordo em participar nesta pesquisa, não tendo sofrido nenhuma pressão para tanto.

$\mathrm{Eu}$, ciente das informações constantes no verso sobre o estudo e os meus direitos, aceito a participação no estudo acima especificado. Foi-me garantido que posso desistir de participar da pesquisa a qualquer momento, sem quaisquer penalidades ou prejuízos. Também me foi afirmado que não terei nenhum risco físico ou gasto financeiro, sendo que será mantida em segredo minha identificação. A minha assinatura representa o meu consentimento em participar da pesquisa. Este termo é assinado em duas vias, uma cópia ficará comigo e a outra com o responsável pela pesquisa, e tive a oportunidade de discuti-lo com o mesmo.

Uberaba, de de 2014.

Assinatura do adolescente maior de 18 anos

Pesquisador responsável - Wanderlei Abadio de Oliveira № USP 7472581 - CRP: 113347/06 
Apêndice C

Termo de Consentimento Livre e Esclarecido (responsáveis) 


\section{TERMO DE CONSENTIMENTO LIVRE E ESCLARECIDO \\ Destinado aos adolescentes menores de 18 anos e seus pais ou responsáveis (a ser impresso em frente e verso)}

Pesquisa: Relações entre bullying na adolescência e interações familiares: do singular ao plural

Prezado(a) Senhor(a),

Meu nome é Wanderlei Abadio de Oliveira, sou psicólogo e aluno de doutorado na Escola de Enfermagem de Ribeirão Preto/USP (EERP/USP) e sou responsável por esta pesquisa sob orientação da Profa. Dra. Marta Angélica Iossi Silva. Neste sentido, gostaríamos de convidar o adolescente sob sua responsabilidade para participar desta pesquisa, que tem como objetivos conhecer e analisar a relação entre a qualidade das interações familiares de adolescentes e o envolvimento em práticas de bullying.

A pesquisa se dará por meio da aplicação de escalas e questionários na escola do adolescente durante um (1) horário de aula e, caso ele seja sorteado, será entrevistado. Essa entrevista será individual, com duração de aproximadamente 20 minutos, realizada também na escola por mim, gravada e posteriormente transcrita. Os instrumentos aplicados se referem ao bullying escolar (eu briguei quando algum colega me bateu primeiro ou fez algo que eu não gostei; os colegas me provocaram; colegas me excluíram de grupos e/ou brincadeiras, por exemplo) e à maneira como os adolescentes percebem e avaliam o clima familiar (meus pais costumam dizer o quanto eu sou importante para eles; eu costumo contar as coisas ruins que me acontecem para meu pai/minha mãe; como é sua relação com seus pais, por exemplo). Questionários, escalas e entrevistas somente serão coletadas das pessoas que aceitarem espontaneamente participar da pesquisa. Em todos os momentos se o adolescente sob sua responsabilidade não souber responder ou se não quiser responder a qualquer pergunta, poderá deixar de participar da pesquisa. As informações serão usadas exclusivamente para esta pesquisa e seus resultados poderão ser divulgados em revistas e encontros científicos, sem que vocês sejam identificados. Os dados e instrumentos utilizados na pesquisa ficarão arquivados com o pesquisador responsável por um período de 5 anos, e após esse tempo serão destruídos.

Você e o adolescente sob sua responsabilidade não serão prejudicados em nada e poderão pedir explicações a qualquer momento. A aceitação para participar do estudo não trará nenhum risco físico ou gasto financeiro para vocês, sendo que serão mantidas em segredo suas identificações, ou seja, vocês não serão identificados por nome, apelido ou qualquer outro meio que possibilite saber quem são. Vocês não terão nenhum benefício direto, nesse momento, pela sua participação, mas será uma oportunidade para compartilhar experiências de maneira sigilosa, colaborando para que os resultados da pesquisa possam nos ajudar a compreender e explicar o bullying escolar que prejudica crianças e adolescentes, além de ser um problema de saúde pública. Da mesma forma, participando do estudo, caso haja um desconforto, como por exemplo, ao falar de situações de violência ou da família, o adolescente sob sua responsabilidade será acolhido pelo pesquisador e poderá interromper a participação imediatamente, continuando ou não mais tarde. Nestes casos, se necessário, o adolescente poderá ser encaminhado para atendimentos específicos. Além disso, garante-se o direito à indenização, conforme as leis vigentes no país, caso haja qualquer ou eventual dano decorrente da participação do adolescente na pesquisa.

Destacamos que, embora o presente estudo explore questões relacionadas ao contexto familiar e suas relações com o bullying, os resultados não serão utilizados para responsabilizar ou culpar as famílias, mas se pretende pensar outros fatores que possam explicar o fenômeno da violência e assim consigamos enfrentá-lo de forma adequada e em diversas direções. A autorização para que o adolescente participe desta pesquisa será importante e contribuirá para a defesa da saúde e do desenvolvimento saudável de nossos adolescentes. Nós, também, vamos aprender muito e o trabalho poderá ajudar na melhora de serviços na área da saúde e educação, principalmente.

Lembramos que a qualquer momento da pesquisa você ou o adolescente poderão desistir da participação, uma vez que esta participação é voluntária. Esse termo é assinado em duas vias, sendo que uma delas ficará com o pesquisador e outra será entregue a você e ao adolescente para conhecimento.

0 projeto da pesquisa foi analisado e aprovado pelo Comitê de Ética em Pesquisa com Seres Humanos (CEP) da EERP/USP, que tem a finalidade de proteger os participantes de pesquisas, na medida em que respeita as questões éticas necessárias para a sua realização.

Se tiver alguma dúvida, poderá entrar em contato comigo pelo telefone (34) 91972274 ou (16) 981239714 de $2^{\text {a }}$ à 6 a feira das 08 h00min às $17 \mathrm{~h} 00 \mathrm{~min}$ ou pelo e-mail wanderleio@usp.br. Além disso, eu estarei disponível pessoalmente na escola do adolescente durante essa semana de coleta de dados das 07h00min às $11 \mathrm{~h} 30 \mathrm{~min}$. Vocês ainda poderão contatar o CEP no endereço da EERP/USP - Avenida dos 
Bandeirantes, 3900 - Campus USP - Ribeirão Preto - SP - 14040-902 - Telefone (16) 3602-3386 - de $2^{\underline{a}}$ à $6^{\underline{a}}$ feira das $08 \mathrm{~h} 00 \mathrm{~min}$ às $17 \mathrm{~h} 00 \mathrm{~min}$.

Agradecemos a sua colaboração!

\section{Consentimento da participação da pessoa como sujeito da pesquisa.}

Após ter conhecimento sobre como poderei colaborar com esta pesquisa, concordo com a participação de meu filho (a) nesta pesquisa, não tendo sofrido nenhuma pressão para tanto.

$\mathrm{Eu}$, ciente das informações constantes no verso sobre o estudo e os meus direitos, aceito a participação do adolescente sob minha responsabilidade no estudo acima especificado. Foi-me garantido que posso desistir de participar da pesquisa a qualquer momento, sem quaisquer penalidades ou prejuízos. Também me foi afirmado que não terei nenhum risco físico ou gasto financeiro, sendo que será mantida em segredo minha identificação. A minha assinatura representa o meu consentimento em participar do estudo. Este termo é assinado em duas vias, uma cópia ficará comigo e a outra com o responsável pela pesquisa, e tive a oportunidade de discuti-lo com o mesmo.
Uberaba,
de de 2014.

Assinatura do responsável pelo adolescente

Pesquisador responsável - Wanderlei Abadio de Oliveira № USP 7472581 - CRP: 113347/06 
Apêndice D

Termo de Assentimento (menores de 18 anos) 


\title{
TERMO DE ASSENTIMENTO \\ DESTINADO AOS ADOLESCENTES MENORES DE 18 ANOS \\ (a ser impresso em frente e verso)
}

Pesquisa: Relações entre bullying na adolescência e interações familiares: do singular ao plural

\author{
Prezado(a) Jovem,
}

Meu nome é Wanderlei Abadio de Oliveira, sou psicólogo e aluno de doutorado na Escola de Enfermagem de Ribeirão Preto/USP (EERP/USP) e sou responsável por esta pesquisa sob orientação da Profa. Dra. Marta Angélica Iossi Silva. Neste sentido, gostaríamos de convidá-lo para participar desta pesquisa, que tem como objetivos conhecer e analisar a relação entre a qualidade das interações familiares de adolescentes e o envolvimento em práticas de bullying.

A pesquisa se dará por meio da aplicação de escalas e questionários na sua escola durante um (1) horário de aula e, caso você seja sorteado, será entrevistado. Essa entrevista será individual, com duração de aproximadamente 20 minutos, realizada também na sua escola por mim, gravada e posteriormente transcrita. Os instrumentos aplicados se referem ao bullying escolar (eu briguei quando algum colega me bateu primeiro ou fez algo que eu não gostei; os colegas me provocaram; colegas me excluíram de grupos e/ou brincadeiras, por exemplo) e à maneira como você percebe e avalia o clima familiar (meus pais costumam dizer o quanto eu sou importante para eles; eu costumo contar as coisas ruins que me acontecem para meu pai/minha mãe; como é sua relação com seus pais, por exemplo). Questionários, escalas e entrevistas somente serão coletadas das pessoas que aceitarem espontaneamente participar da pesquisa. Em todos os momentos se você não souber responder ou se não quiser responder a qualquer pergunta, poderá deixar de participar da pesquisa. As informações serão usadas exclusivamente para esta pesquisa e seus resultados poderão ser divulgados em revistas e encontros científicos, sem que vocês sejam identificados. Os dados e instrumentos utilizados na pesquisa ficarão arquivados com o pesquisador responsável por um período de 5 anos, e após esse tempo serão destruídos.

Para participar deste estudo, o responsável por você deverá autorizar e assinar um Termo de Consentimento Livre Esclarecido. Você será esclarecido(a) em qualquer aspecto a qualquer momento sobre o que desejar e estará livre para participar ou recusar-se. 0 responsável por você, também, poderá retirar o consentimento ou interromper a sua participação a qualquer momento. A sua participação é voluntária e a recusa em participar não acarretará qualquer penalidade ou modificação na forma em que como você é atendido pela escola. Você não será identificado em nenhuma publicação. Este estudo apresenta risco mínimo, isto é, o mesmo risco existente em atividades rotineiras como conversar, tomar banho, ler etc.. Apesar disso, você tem assegurado o direito a ressarcimento ou indenização no caso de quaisquer danos eventualmente produzidos pela pesquisa. Além disso, participando do estudo, caso haja um desconforto, como por exemplo, ao falar de situações de violência ou da família, você será acolhido pelo pesquisador e poderá interromper a participação imediatamente, continuando ou não mais tarde. Nestes casos, se necessário, você poderá ser encaminhado para atendimentos específicos.

Destacamos que, embora o presente estudo explore questões relacionadas ao contexto familiar e suas relações com o bullying, os resultados não serão utilizados para responsabilizar ou culpar as famílias, mas se pretende pensar outros fatores que possam explicar o fenômeno da violência e assim consigamos enfrentá-lo de forma adequada e em diversas direções. Sua participação no estudo será importante e contribuirá para a defesa da saúde e do desenvolvimento saudável de nossos adolescentes. Nós, também, vamos aprender muito e o trabalho poderá ajudar na melhora de serviços na área da saúde e educação, principalmente.

Lembramos que a qualquer momento da pesquisa você poderá desistir de sua participação, uma vez que esta participação é voluntária. Esse termo de assentimento é assinado em duas vias, sendo que uma delas ficará com o pesquisador e outra será entregue a você para conhecimento.

0 projeto da pesquisa foi analisado e aprovado pelo Comitê de Ética em Pesquisa com Seres Humanos (CEP) da EERP/USP, que tem a finalidade de proteger os participantes de pesquisas, na medida em que respeita as questões éticas necessárias para a sua realização.

Se tiver alguma dúvida, poderá entrar em contato comigo pelo telefone (34) 91972274 ou (16) 981239714 de $2^{\text {a }}$ à 6 a feira das 08 h00min às $17 \mathrm{~h} 00 \mathrm{~min}$ ou pelo e-mail wanderleio@usp.br. Além disso, eu estarei disponível pessoalmente na sua escola durante essa semana de coleta de dados das 07h00min às 11h30min. Você ainda poderá contatar o CEP no endereço da EERP/USP - Avenida dos Bandeirantes, 3900 
- Campus USP - Ribeirão Preto - SP - 14040-902 - Telefone (16) 3602-3386 - de 2 ${ }^{\mathrm{a}}$ à 6 6 $^{\mathrm{a}}$ feira das 08h00min às $17 \mathrm{~h} 00 \mathrm{~min}$.

Agradecemos a sua colaboração!

\section{Assentimento da participação da pessoa como sujeito da pesquisa.}

Após ter conhecimento sobre como poderei colaborar com esta pesquisa, concordo em participar nesta pesquisa, não tendo sofrido nenhuma pressão para tanto.

$\mathrm{Eu}$, , ciente das informações constantes no verso sobre o estudo e os meus direitos, aceito a participação no estudo acima especificado. Foi-me garantido que posso desistir de participar da pesquisa a qualquer momento, sem quaisquer penalidades ou prejuízos. Também me foi afirmado que não terei nenhum risco físico ou gasto financeiro, sendo que será mantida em segredo minha identificação. Tendo o consentimento do meu responsável já assinado, declaro que concordo em participar desse estudo. Recebi uma via deste termo assentimento e me foi dada a oportunidade de ler e esclarecer as minhas dúvidas.

Uberaba, de de 2014 .

Assinatura do adolescente menor de 18 anos

Pesquisador responsável - Wanderlei Abadio de Oliveira № USP 7472581 - CRP: 113347/06 